
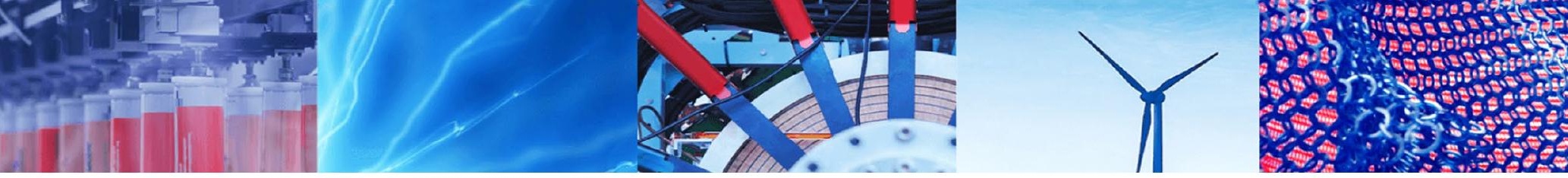

Review

\title{
Role of co-sensitization in dye-sensitized and quantum dot-sensitized solar cells
}

\author{
Soosaimanickam Ananthakumar ${ }^{1}$. Devakumar Balaji ${ }^{1,2} \cdot$ Jeyagopal Ram Kumar ${ }^{1,3} \cdot$ Sridharan Moorthy Babu $^{1}$
}

(c) Springer Nature Switzerland AG 2019

\begin{abstract}
Novel materials for third generation solar cells have emerged as one of the major scientific contribution in alternative energy approaches. In this scenario, semiconductor nanomaterials and organic dye molecules have greatly acknowledged for their vast contribution to the solar energy applications. Research on semiconductor nanomaterials for fabricating future generation solar cells is still fascinating due to their extraordinary structural and optical properties. Moreover, functionalization of organic dye molecules helps to harvest large amount of photons in order to apply them for high efficiency solar cell devices. Various attempts have been made to improve efficiency of quantum dot-sensitized solar cells and dye-sensitized solar cells using semiconductor inorganic nanomaterials and organic/organometallic dye molecules. Out of these, co-sensitization has been looking as most promising approach to improve the efficiency considerably. A record of over $14 \%$ of efficiency has been achieved in recent years through co-sensitization strategy. The energy transfer process during co-sensitization is also a very crucial and interesting. This review deals about materials, methods, various approaches and role of co-sensitization in enhancing the efficiency of dye-sensitized and quantum dot sensitized solar cells. The critical issues existing in the co-sensitization approach are also elaborately discussed.
\end{abstract}

Keywords Third generation solar cells · Co-sensitization · Quantum dots · Dye-sensitized solar cells · Forster resonance energy transfer

\section{Introduction}

Extreme shortage of fossil fuels in recent years has made more demand in search of alternative energy sources for commercial as well as home applications. In this regard, utilization of renewable energy sources in particular, photon harvesting through solar energy has been triggered huge interest since the past few decades. Out of others, solar energy technologies based on silicon has made a major breakthrough in this area. Even though silicon plays indomitable role in solar photovoltaic industry, the tedious process associated with its production and obtaining good quality of silicon has opened a pathway in the alternative materials research. In this view, organometallic, particularly ruthenium based molecular dyes, metal free organic dyes and extremely smaller sized inorganic semiconductor nanoparticles [also termed out as "quantum dots (QDs)"] are playing major role in materials aspects for the construction of future generation photovoltaic devices. The structural, optical and optoelectronics based applications of both topics have studied with huge interest. In the year 1991, Gratzel et al. fabricated a very first dye-sensitized solar cell (DSSC) and after that, the sensitization of $\mathrm{TiO}_{2}$ mesoporous layer by organic and organometallic dyes became keen research interest $[63,184]$. Later, due to the disadvantages exists in dye molecules, QDs are proven as efficient candidates in replacing them for the sensitization and therefore improved stability

$\triangle$ Soosaimanickam Ananthakumar, ananthacgc@gmail.com | ${ }^{1}$ Crystal Growth Centre, Anna University, Chennai 600025 , India. ${ }^{2}$ Department of Physics, Sri Vidhya Mandhir College of Arts and Science, Uthangarai, India. ${ }^{3}$ Department of Physics, Faculty of Physical and Mathematical Sciences, University of Concepcion, Concepción, Chile.

SN Applied Sciences (2019) 1:186| https://doi.org/10.1007/s42452-018-0054-3

Received: 3 July 2018 / Accepted: 9 November 2018 / Published online: 29 January 2019 
together with moderate efficiency has been achieved. From its journey, the efficiency of DSSCs has reached about $13-15 \%$ whereas for the QDs sensitized solar cells (QDSSCs), a recent record of $12.07 \%$ has been achieved [102]. By carefully manipulating the device architecture with suitable bandgap molecules, it has been proven that increase of efficiency is still possible.

For the past few years, apart from new materials, novel methodologies to improve efficiency in these approaches have turned a large interest. Though new materials with excellent absorption properties in the visible region could solve this problem, there are many innovative ways required to overcome the present hurdles associated with the efficiency improvement. One of the idea is extending the absorption spectrum beyond the absorption limit of the absorber. In third generation solar cells, features such as multiple exciton generation (MEG) in QDs, co-sensitization through dyes as well as by QDs, tandem approach, concentrating the solar light are playing important role in improving the efficiency. For DSSCs, an ideal sensitizer need to possess a sufficiently high LUMO energy level for efficient electron injection into the $\mathrm{TiO}_{2}$ and a sufficiently low HOMO energy level for efficient regeneration of the oxidized state $[263,265]$. It is clearly known that through sensitization of a single dye molecule, efficiency enhancement could not be achieved in DSSCs due to the limited absorption of dyes and similar situation can be expected in QDSSCs. When two different dyes absorb in two different spectral regions, for example, one in the visible region and another one is in the near infra-red (NIR) region, the absorption as well as efficiency of the solar cell can be enhanced. Similarly, when semiconducting nanoparticles with different band gaps (like CdS and CdSe) combined together, a large amount of photons can be harvested. In association with this, cosensitization has emerged as the promising approach for such efforts. Through co-sensitization with suitable energy levels of dyes, one could efficiently reduce recombination issues and can extend the absorption spectrum beyond certain limit. Though this method has also been used for other application like photoelectrochemical solar hydrogen production [74, 76], photo-sensors [229], majority of the available literature focus only on solar cells. Through the co-sensitization approach, efficiency of the DSSCs has reached a record of about $14.7 \%$ [110]. Furthermore, the panchromatic absorption by the combination of dye and QDs has successfully demonstrated for the tandem solar cell device to generate hydrogen [64]. Therefore, it is essential to combine the molecular dyes (or) QDs together for the enhanced light absorption. Before carrying out the co-sensitization of dyes (or) QDs, it is imperative to understand the fundamental knowledge of co-sensitization process. Though there are excellent number of review articles dealing about the fundamental principle $[41,66,72,239$, 269], mechanism [127], materials [3, 16, 122, 218, 242] and various aspects of the DSSCs $[18,139]$ and QDSSCs $[2,22$, $105,106,121,225,248,267]$, articles dealing about the specific methods, materials and mechanism involved in co-sensitization process of DSSC as well as QDSSCs are not available in literature. In view of that, this present review article has been devoted to discuss about principle, methods and current status of co-sensitization process in DSSCs and QDSSCs. The detailed conditions for the effective cosensitization in both cases are also discussed elaborately. The energy transfer process from donor to acceptor through Forster resonance energy transfer process (FRET) for improved absorption has also been analysed.

\section{Dye-sensitized solar cells and quantum dot-sensitized solar cells: an introduction}

\subsection{Dye-sensitized solar cells (DSSCs)}

Dye-sensitized solar cells are the inception of modern solar cell concepts such as QDSSCs and perovskite solar cells. The first successful demonstration of a DSSC was achieved during 1991 by Gratzel et al. [184]. A DSSC consists of four important components namely photoanode, redox dye, electrolyte and photocathode. Photo anode of DSSC is consisting of thin layer of a nanocrystalline metal oxide (ex: $\mathrm{TiO}_{2}, \mathrm{ZnO}$ ) deposited on fluorine doped tin oxide (FTO) and photocathode is generally a thin layer of platinum coated FTO. Because of wide band gap of metal oxides (for anatase phase of $\mathrm{TiO}_{2}, \mathrm{E}_{\mathrm{g}}=3.2 \mathrm{eV}$ ), artificial or natural sensitizers are used to sensitize in order to extend the absorption spectra. In this regard, several organic, organometallic and natural dyes are used as the sensitizers and ruthenium complex dyes are the dominating category out of other dyes [56]. The charge transfer process of all these dyes towards photo anode is playing important role in producing highly efficient solar cells and hence before sensitization process, the energy level of the sensitizing dye has to be analysed thoroughly. Size, shape of the $\mathrm{TiO}_{2}$ nanoparticles also important as the case that a $20 \mathrm{~nm}$ size of $\mathrm{TiO}_{2}$ nanoparticle generate about $2.4 \times 10^{17} \mathrm{~cm}^{-3}$ electron concentration during the injection process [67]. Among the ruthenium dyes, the most commonly used sensitizing dye is cis-di(thiocyanato) bis(2,2'-bipyridyl)-4,4'-dicarboxylate) ruthenium (II) (denoted as N3 or N-719 dye depend on the functional group attachment). Factors such as porosity, concentration of $\mathrm{TiCl}_{4}$, viscosity of the electrolyte are affecting the solar cell parameters [268]. Also, like organic solar cells, fabricating DSSCs using transparent conducting oxide (TCO)-free, highly flexible polymeric substrates have been successful which implies that this technology 
can be adopted for large scale fabrication [251]. Different kind of liquid, solid, quasi-solid state electrolytes and different varieties of counter electrode materials were studied and analyzed in order to improve the performance and reduce the cost of fabrication. In terms of efficiency, over $14 \%$ efficiency has been achieved in recent years through co-sensitization process [110]. The basic device configuration and energy level diagram of a typical DSSC is given in Fig. 1 [240].

\subsection{Quantum dot-sensitized solar cells (QDSSCs)}

Quantum dot-sensitized solar cells (QDSSCs) are one of the promising solar cell technology similar to DSSC concept. Because of huge synthetic and characterization developments achieved in semiconductor nanomaterials during recent years, this solar cell concept is still getting expanded with more new novel materials and efficiency improvements. Important properties of QDs such as tunable band gap with respect to size, extremely adoptable solution processing techniques, generating multiple excitons (MEG) under the illumination of high intensity photons, good photostability over organometallic sensitizers have been found as suitable for constructing highly stable, high efficient solar cell devices [111, 112]. The basic construction of a QDSSC mimics the structure of DSSC but having the difference in the sensitizer and electrolyte. Because of corrosive nature of iodide redox electrolyte, poly sulphide mixture $\left(\mathrm{S}^{2-} / \mathrm{S}_{\mathrm{x}}^{2-}\right)$ is used as the electrolyte in QDSSCs. Out of many systems studied, sensitizers such as cadmium chalcogenide nanoparticles (CdS, CdSe, $\mathrm{CdTe}$ ), lead chalcogenide nanoparticles (PbS, PbSe) and their core-shell assembly with different sizes have delivered interesting results and promising stability. For the deposition of QDs on metal oxide surface, methods such as chemical bath deposition (CBD) and successive ionic layer absorption and reaction (SILAR) are used. Attachment of QDs on the metal oxide surface is very important and short chain organic ligand mercapto propionic acid (MPA) is found to be an efficient candidate in the charge transfer process [89]. Surface states, defect sites, recombination process of semiconductor nanoparticles are playing prominent role in the charge transport and influencing on the efficiency. Using surface modification processes, the efficiency of QDSSCs has reached over $8 \%[208,290]$ and recently this has been further enhanced to $12.07 \%$ using nitrogen doped mesoporous carbon as counter electrode [102]. Since hole extraction process is very slower in QDs [113], less efficiency is often observed and to improve this, co-sensitization process is carried out with different band gap of QDs. The schematic diagram of the typical charge transfer from a semiconductor nanoparticle to metal oxide and the size dependent energy levels of nanoparticles are represented in Fig. 2.

\section{Co-sensitization in solar cells: an introduction}

In order to improve the efficiency of DSSCs, the required framing conditions of a dye molecule are (a) a broad absorbing dye sensitizer with suitable energetic positions (b) a strongly bound sensitizer with efficient electron transfer to $\mathrm{TiO}_{2}$ photoelectrode that can admit for additional $\mathrm{TiO}_{2}$ film co-adsorbents [191]. Co-sensitization also termed as "dye-cocktail" method in DSSCs, is a widely followed strategy in DSSCs and QDSSCs. Due to the complexity associated with the dyes owing to the absorption

Potential vs. NHE / V

(a)

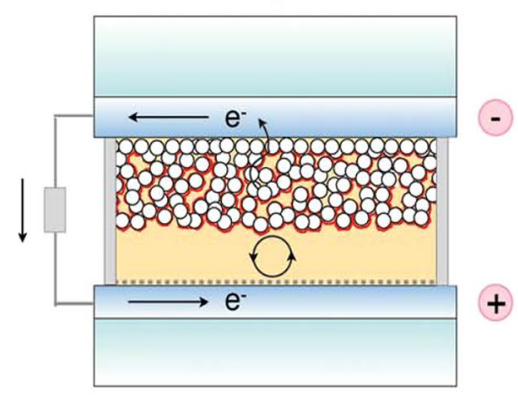

sunlight

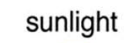

Glass substrate

TCO

Dye-sensitized $\mathrm{TiO}_{2}$

Redox mediator

Platinized TCO

Glass substrate
Th

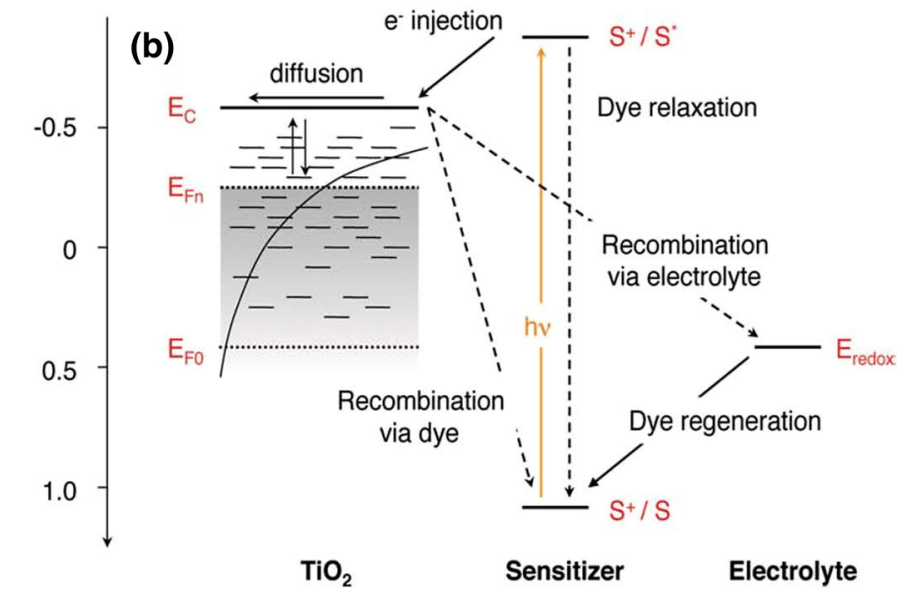

Fig. 1 a Basic structure of a DSSC and b illustration of the typical energy diagram of a DSSC. Reprinted from Ref. [240] with the permission of The Royal Society of Chemistry 

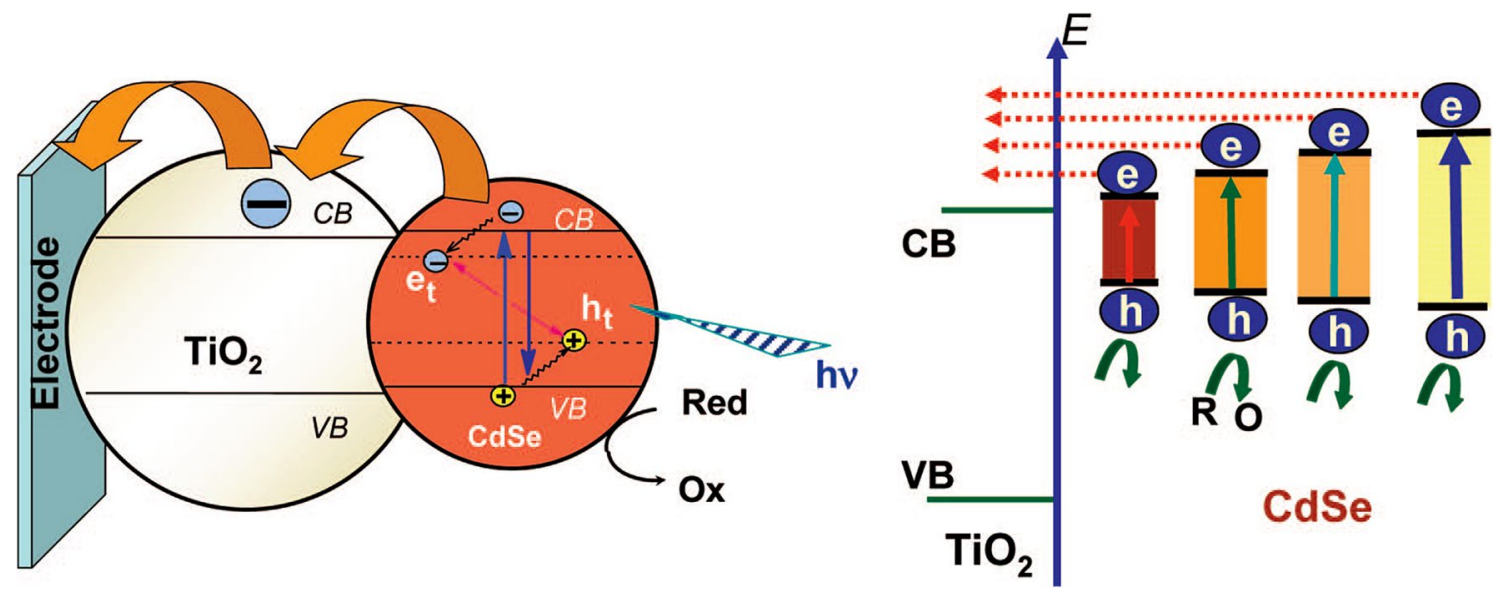

Fig. 2 Charge injection of electrons from QDs to titania and the modulation of energy levels depend on the size of the nanoparticles. Reprinted with permission from Ref. [111] Copyright@2008 American Chemical Society

in visible region alone, co-sensitization is required. Cosensitization allows increase in the absorption edge of the resultant spectrum and also increasing the internal photon conversion efficiency (IPCE) of the resultant solar cell. Cosensitization can effectively be achieved through single solvent system or mixture of two different solvents that are capable to dissolve the dyes. The key criteria for a potential dye co-sensitizer (or) co-adsorbate includes (a) a lowest unoccupied molecular orbital (LUMO) energy level that lies above the semiconductor conduction band, (b) a highest occupied molecular orbital (HOMO) energy level that lie below the electrolyte redox potential, (c) presence of an anchor group to provide the coupling between dye and semiconductor, (d) directed intramolecular charge transfer on photoexcitation from donor to semiconductor through the anchor, (e) good chemical compatibility between dye sensitizers, $(f)$ should have a high molecular extinction coefficient, (g) should reduce the charge recombination and (h) should be suitable for the competitive adsorption without aggregation on the photoanode (metal oxide) surface $[12,94]$. The schematic diagram of a charge transfer process during co-sensitization is given in Fig. 3 a. In co-sensitization process, different dyes (or) QDs are utilized to absorb the different region of the solar spectrum, which gives a panchromatic absorption spectrum (Fig. 3b). Through this, the increase of light harvesting further enhancing the short-circuit current density, $\mathrm{J}_{\mathrm{sc}}$ of the fabricated solar cell. Also, the two sensitizing dyes form a tightly packed monolayer at the surface that prohibits the back electron transfer ultimately increases the open-circuit
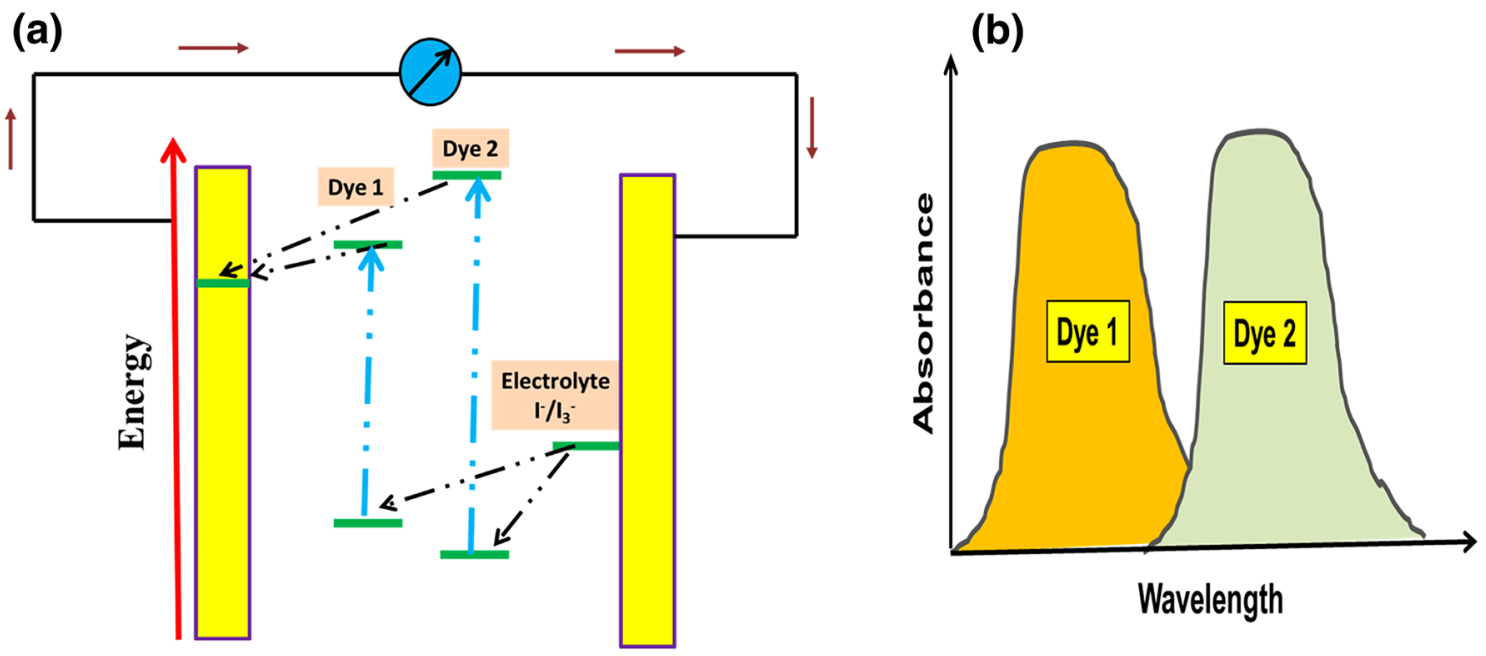

Fig. 3 Schematic diagram of a co-sensitized solar cell using two different dyes, b extending absorption spectra through co-sensitization 
voltage, $\mathrm{V}_{\mathrm{oc}}$ of the device [58]. Moreover, change in the electron life time is commonly observed in co-sensitization strategy which is much beneficial for optoelectronic device applications. Thus, the complementary absorption spectra of two or more dyes with matched energy levels are the most important criteria for the co-sensitization process. In addition to this, other criteria include good understanding of molecular orientation, size and shape of the dyes [202].

\subsection{Methods and methodologies of co-sensitization}

Co-sensitization is generally a two-step process. In the first step, sensitization of mesoporous $\mathrm{TiO}_{2}$ electrode by dye 1 is carried out in suitable solvent system for the fixed time in order to anchor the functional group of the dye (mostly carboxylate end) on the $\mathrm{TiO}_{2}$ surface. This is followed by the sensitization of the dye 2 in the suitable solvent system which is not supposed to affect the dye 1. This deposition process is called sequential deposition and this is a widely followed method in co-sensitization. The schematic diagram of the sequential co-sensitization in DSSCs is given in Fig. 4. It is important to note about the three important properties which are dependent on the anchoring group moieties. These properties include (a) electronic coupling between the dye and metal oxide photoanode, (b) orientation and packing of the adsorbed dye molecules and (c) long-term stability of the device [214, 215]. Besides, the available anchoring site for the dye 2 depends upon the surface area of the $\mathrm{TiO}_{2}$ nanoparticles. Co-sensitization process can also be done simultaneously (i.e., by cocktail method). In this process, both sensitizing dyes are mixed together in the solvent(s) and directly used for the sensitization. In co-sensitization, self-organization of two dyes on $\mathrm{TiO}_{2}$ mesoporous electrode enhances the absorption as well as efficiency. Co-sensitization can be achieved using dipping method, through supercritical fluids, slow dying procedure, ultrafast sensitization etc. In dipping method, mesoporous $\mathrm{TiO}_{2}$ layer deposited on the conducting substrate is immersed (i.e., sensitization) in the first dye for a particular period and the same is followed for the second dye. For a longer sensitization period, the aggregation of dyes on the mesoporous layer is one of the biggest problem exists in the co-sensitization method. This greatly reducing performances of the fabricated solar cells through self-quenching process. Hence, careful observation in sensitizing period, selection of suitable solvent and adopting suitable deposition process are necessary to achieve a successful co-sensitization. Also, type of dyeloading, whether it is through side-by-side adsorption or complementary adsorption also found to be an important factor influencing co-sensitization [237]. Adsorption of dyes takes place through the anchoring group(s) present in the dye and it differs depend on the nature of functional group. For instance, it has been experimentally found that the binding of benzoic acid takes place through bidentate mode whereas for cyanoacrylic acid it's a tridentate mode [254]. These kind of different mode attachment of dyes also influenced by their geometrical parameters $[214,215]$. Each dye has some specific adsorption sites on the surface of the photoelectrode and hence there will be some available sites for the second dye adsorption. Perhaps if it is a sequential deposition, the first adsorbing dye will have more dye-loading than the second adsorbed one. Since each functional group consist of variable binding energy values, the improper dye loading on the surface of the nanoparticles would ultimately result aggregation on the surface of the $\mathrm{TiO}_{2}$ photoanode. The quantity of dye loading can be estimated using desorption of the adsorbed dye with $\mathrm{NaOH}$ solution. The duration of dye-loading may differ from one dye to another dye and this affects internal photon conversion efficiency (IPCE) of the device. A recent report of Zhao et al. who analyzed the effect of dyeadsorption time using a porphyrin dye LP-2 (in ethanol/ tetrahydrofuran (THF)) with N719 (in ethanol) dye [291] dealing this concept clearly. The authors found that the $5 \mathrm{~h}$ sensitization of LP-2 and $21 \mathrm{~h}$ sensitization in N719

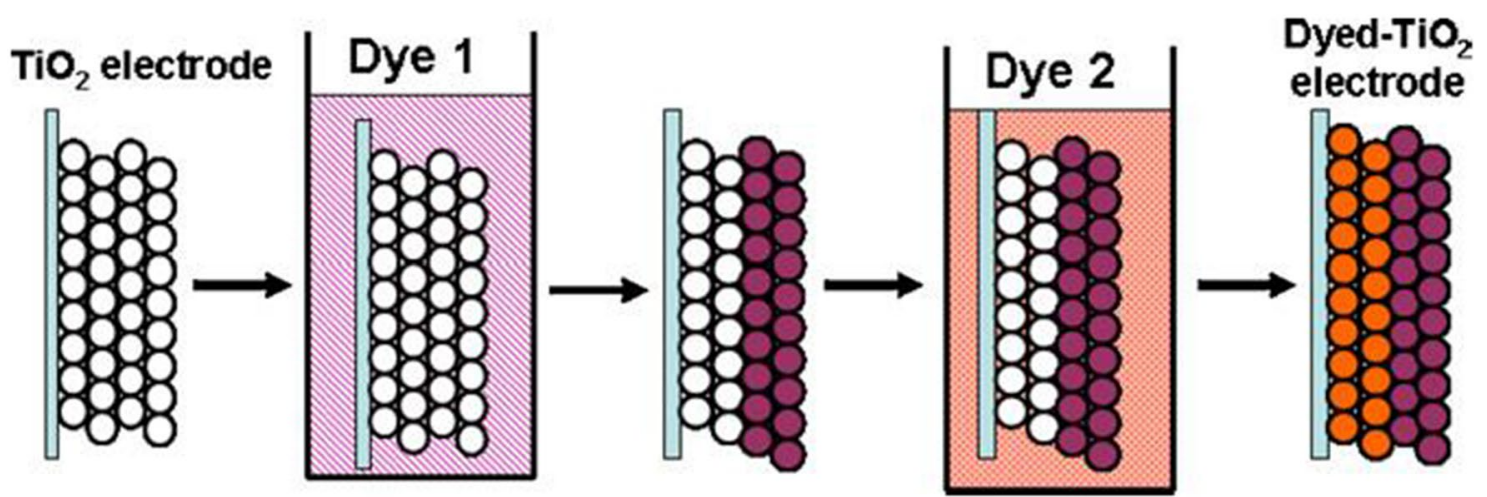

Fig. 4 Schematic diagram of step wise co-sensitization in DSSCs. Reprinted with permission from Ref. [136] Copyright@2011 Elsevier 
resulted highest efficiency of $7.7 \%$. Therefore, it is clear that along with the nature of dyes, careful manipulation of parameters will help to improve the efficiency in co-sensitization process. Co-sensitization through the stepwise absorption (sequential deposition) of two different dyes also a promising approach [181]. It has been experimentally found that compared with the dye-cocktail method, stepwise co-sensitization of organic dyes delivering higher efficiency [52, 290]. During the deposition of two sensitizing dyes on the mesoporous photoanode, the dyes are undergoing a synergetic interaction in the adsorbed state that lead to the reduction of unfavourable interaction of first dye. The sensitization of two different dyes are done through different approaches and each approach has its own merits and demerits. However, this has significant influence on the efficiency of the device. The electrolyte used during co-sensitization is mostly a traditional iodine/ tri-iodide redox couple or an ionic liquid [123].

In case of co-sensitization of QDSSCs, sequential deposition is mostly followed in which the photoanode is immersed in the ionic precursors of aqueous solution of QDs for a fixed time interval for the first layer deposition and then the similar kind of procedure is followed for the deposition of second layer of QDs. This method is commonly called as successive ionic layer adsorption and reaction (SILAR) and this is a widely followed method in fabricating highly efficient QDSSCs. The effectiveness of SILAR process depending on several factors which include the concentration of precursors, immersion time, immersion cycles, $\mathrm{pH}$ of the medium and the experimental conditions. After the immersion of photoanode certain time in the precursors solution, annealing at certain temperature is required to evaporate solvent before depositing another semiconductor QDs layer. This annealing process should not damage the deposited QDs layer and careful regulation is necessary to achieve the uniformity. Another important method used for the co-sensitization of QDs is chemical-bath deposition method (CBD). This is a very simple technique and often used to deposit the cadmium chalcogenides thin film in solution medium. In this method, through the aqueous solution, the required deposition is both chemically generated and deposited in the same bath medium [81]. Simply says, here a solvated metal complex is reacted with the chalcogenide source to form the solid film on the substrate. A chemically stable substrate such as glass is used for the deposition of layers and CBD is affected by many parameters like crystallinity of the layers formed, solvent, $\mathrm{pH}$ of the medium, temperature, thickness of film, post-treatment and time allowed for $\mathrm{CBD}$ etc. The schematic diagram of the co-sensitization of QDs through SILAR and CBD methods is given in Fig. 5. The remarkable achievements in power conversion efficiency through the co-sensitization process through various approaches have been elaborately discussed in the next sessions.

\section{Effect of co-sensitization in efficiency of solar cells}

Co-sensitization process has played a key role in enhancing the efficiency of dye-sensitized and QDs sensitized solar cells. The dye and quantum dot coupled together through electronic interaction also delivered exemplary results through efficient charge transfer (called Forster resonance energy transfer, FRET). These concepts are discussed in detail as below.

\subsection{Co-sensitization by molecular dyes on $\mathrm{TiO}_{2}$ photoelectrode}

Effective sensitization of mesoporous $\mathrm{TiO}_{2}$ electrode by suitable dyes that provide extended absorption spectra is one of the important criteria in fabricating highlyefficient DSSCs. The important sensitizing dyes used in DSSCs are ruthenium based organometallic dyes. These dyes are having excellent photoelectrochemical, photophysical properties for DSSC applications [137]. The chemical structure of commonly used ruthenium dyes for the construction of DSSC is given in Fig. 6 with their commercial names. It is known that the sensitization of organometallic dyes is mostly limited with the visible region (except some limited dyes which covers NIR) [96]. Also, the low molar extinction coefficient of ruthenium based organometallic dyes has also become one of the major issue. In this regard, mixing of two different dyes is found to be enhancing the photocurrent considerably for DSSC applications [68, 128]. To improve the spectral absorption beyond the limit, co-sensitization by another dye is utilized. For this, the energy level (LUMO and HOMO positions) of the second dye should be a favorable one for charge transfer with the first dye. To satisfy this condition, cyanine, squaraine, hemicyanine, phthalocyanine dyes are used since these dyes have comparable energy levels with the ruthenium dye. For instance, a squaraine dye co-sensitized solar cell was able to produce about $6.36 \%$ efficiency which was higher than their individual performance [149]. Using an unsymmetrical squaraine dye which has the extinction coefficient of $319,000 \mathrm{M}^{-1} \mathrm{~cm}^{-1}$ at $662 \mathrm{~nm}$, the efficiency has reached to $6.7 \%$ through co-sensitization with pyrenoimidazole based organic dye [24]. These dyes are hardly exploited for the co-sensitization in DSSCs. The comparable energy level of these dyes facilitates the efficient charge transfer from one to another and hence improved efficiency 

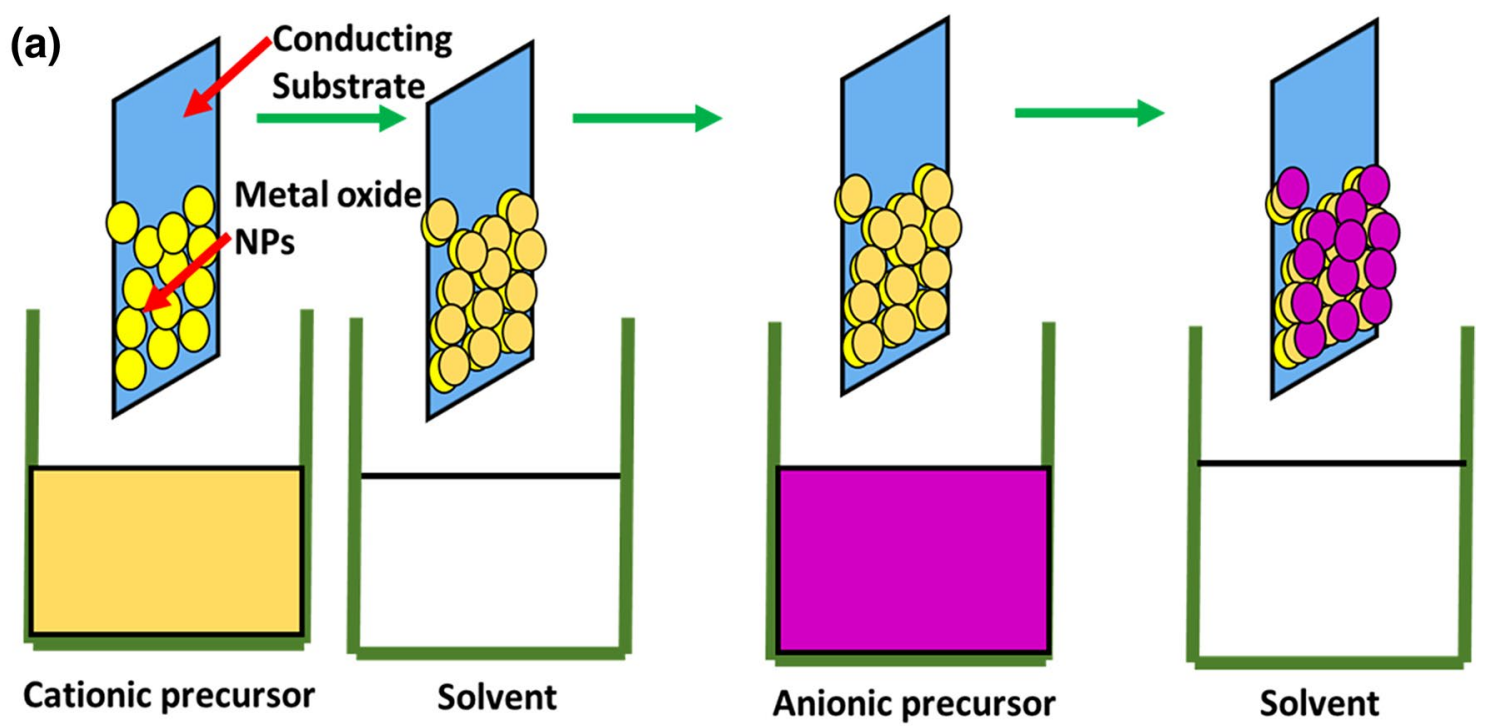

(b)

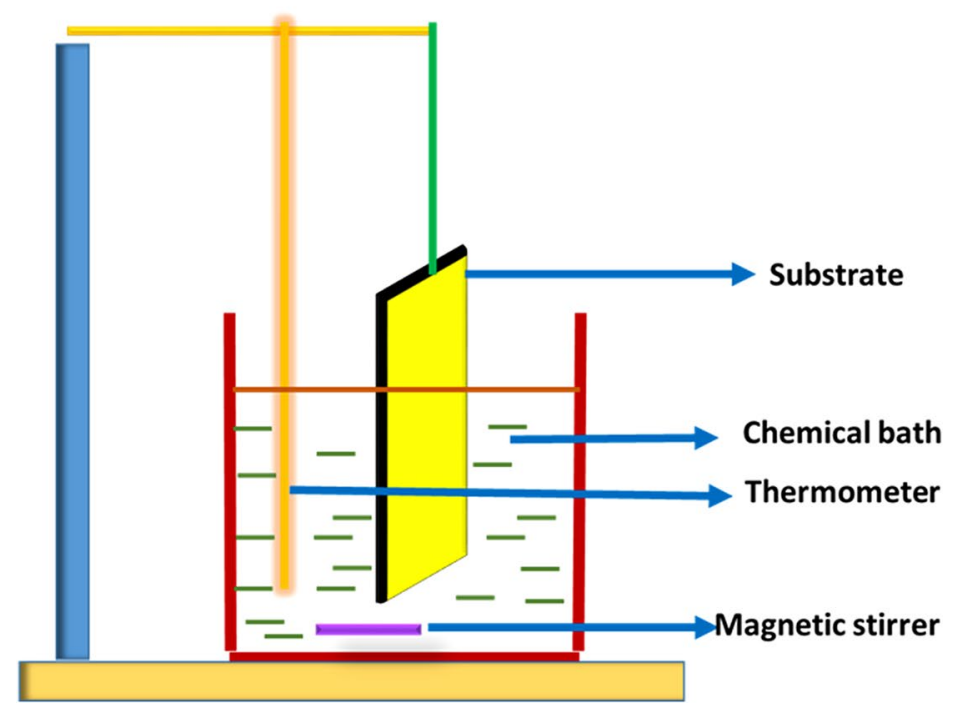

Fig. 5 Schematic diagram of a successive ionic layer absorption and reaction (SILAR) process and $\mathbf{b}$ chemical bath deposition (CBD) process

was achieved. In addition, transport of electrons from the dyes without recombination, position of chromophores in the acceptor molecule, molar extinction co-efficient also critically affect co-sensitization $[12,136]$. For a case, a recent analysis predicting that the extinction co-efficient value of an organic dye T191 after sensitization is higher than its value in solution owing to the formation of new electronic transition [80]. Babu et al. [7-9] have shown that higher efficiency is possible by altering the electron withdrawing (or) donating group in the side chain of the main components. Such efforts could be advanced by incorporating new functional groups and analyzing their effect. Metal-free organic dyes such as coumarin dyes are having specific sensitization effect in the construction of
DSSCs. When a coumarin moiety is attached with a low band-gap chromophore like 3,4-ethylenedioxythiophene (EDOT), benzotiadiazole, the efficiency is significantly improved [220]. There are another class of luminescent dyes which allows the broadening the spectral response of DSSCs without reducing the absorption coefficient of the dye, which function through FRET called "Energy Relay Dyes (ERD)" are also successfully used for the cosensitization process [49, 91, 195, 277].

Other than the above discussed artificial dyes, natural dyes have also proven potential applications for the DSSCs $[126,209]$. In this regard, co-sensitization process using natural dyes has also been effectively studied by several research groups $[86,124,125,129,188]$. But, since the 
N3

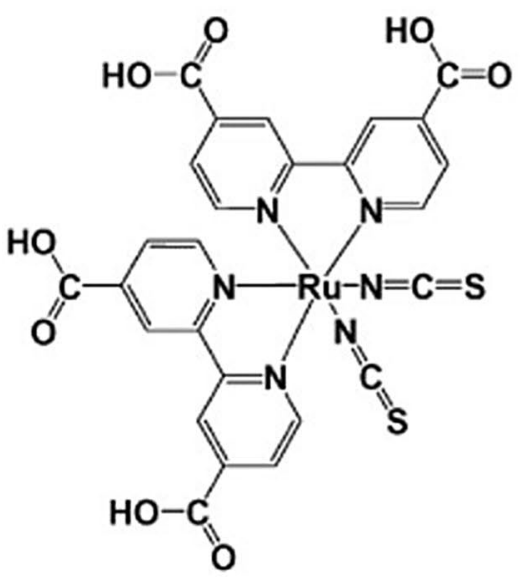

N719

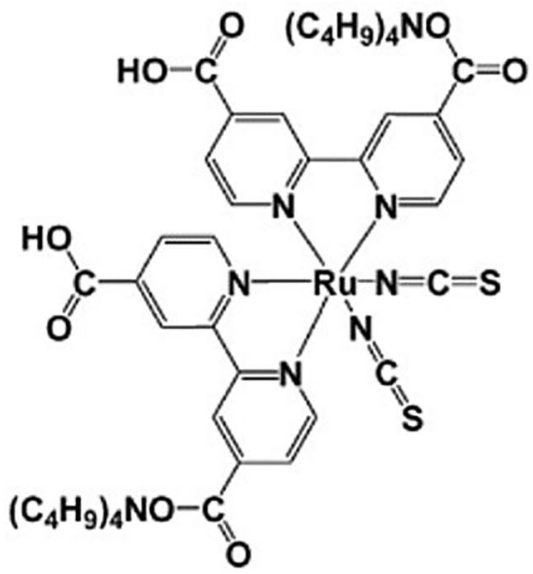

N749

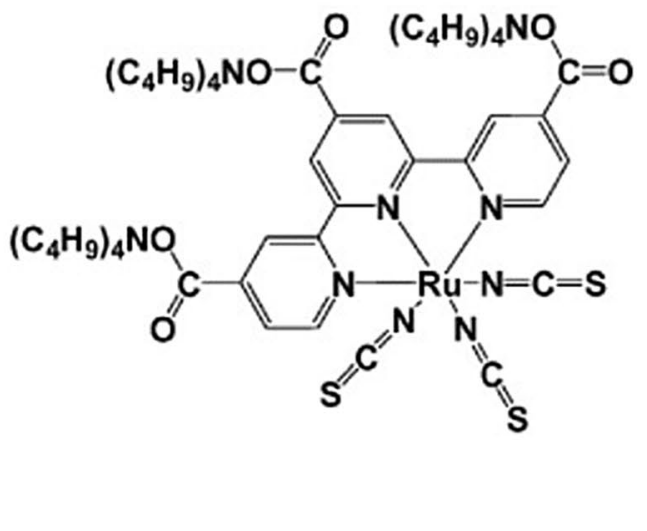

Fig. 6 Chemical structures of important ruthenium complex dyes used in DSSC. Reprinted from Ref. [137] with the permission of The Royal Society of Chemistry

efficiency is very less due to the restriction in the functionalization and adsorption, very limited efforts have been made in this aspect. Typically, in co-sensitization, one dye absorbs the blue region of the spectrum where as another one absorbs in the higher (or) red region of the spectrum. In advance of this co-sensitization method, a modified method of deposition of dyes on $\mathrm{TiO}_{2}$ photoelectrode was also proposed, in which an intermediate metal oxide layer (usually $\mathrm{Al}_{2} \mathrm{O}_{3}$ ) is deposited between the two dyes. This novel method of approach was first attempted by Clifford et al. [39] and this electron cascade formation efficiently enhances device performance when compared with the device without $\mathrm{Al}_{2} \mathrm{O}_{3}$. This step wise co-sensitized process was also called as multilayer co-sensitization [33]. Lee et al. [132] analysed the effect of addition of low molecular weight organic dyestuff triazoloisoquinoline together with N719 monolayer and the authors found that the device performance was improved from 4.49 to $5.15 \%$. Other than this, the low temperature processed step-wise cosensitization to construct plastic dye-sensitized solar cells are also an interesting approach [136]. Attempts were also made to mix the multiple organometallic dyes to improve the efficiency. Yang et al. [263, 265] analysed the efficiency of the tri sensitizers (namely D131, D149 and N3) mixed sensitization on the mesoporous $\mathrm{TiO}_{2}$ layer. The authors found that D149 and N3 mixed ratio could able to provide the highest efficiency of about $9.5 \%$ which was higher than the individual sensitization. A similar kind of effort by Islam et al. [95] who used three organic sensitizers Y1,TP2A and HSQ4 have led to $7.48 \%$ efficiency with the improved IPCE spectrum. Presence of anchoring sites on the surface of the nanoparticles, anchoring group present in the dye, electron donating or withdrawing group present in the dye molecules, solvent etc. are playing important role in co-sensitization. If the concentration of the dye exceeds certain level, it induces aggregation in solution and this differ from one solvent to another solvent [158]. Similarly, if the structure and nature of the side chains attached on a dye is different from other, this affect the sensitization of another dye [80]. An interesting study carried out by Mehmood et al. [168] revealed that the composition of dyes used for co-sensitization play important role in the efficiency of the solar cell. The authors obtained highest efficiency of $9.23 \%$ through co-sensitization of N3 dye with an organic dye, RK-1 with the composition ratio of $0.3 \mathrm{mM}$ of N3 and 0.2 mM of RK-1. Furthermore, lack of anchoring site on the surface of $\mathrm{TiO}_{2}$ nanoparticles is another important parameter which strongly affects the efficiency of the solar cell. Also, the adsorption of first dye may hinder the adsorption of the second one. Honda and his colleagues analysed the effect of adsorption of the mixed dyes N719 and D131 (an organic dye consists of indoline ring) on the mesoporous $\mathrm{TiO}_{2}$ surface and found that the attachment of N719 was hindered by the sulphur atom in D131 [84]. From this analysis, about $7.34 \%$ of efficiency was achieved which was higher than the efficiency obtained using N719 alone. In addition, with carboxylate end, through X-Ray photoelectron analysis (XPS) and NEXAFS analysis, it has been revealed that the thiocyanate $-\mathrm{N}=\mathrm{C}=\mathrm{S}$ - group in N719 plays a predominant role in the adsorption on $\mathrm{TiO}_{2}$ layer. Moreover, the infusion effect of the two dyes strongly affects the final efficiency. Nguyen et al. [181] found that sensitization of ruthenium dye C106 together with D131 dye showed significant enhancement in the 
performance up to $11.1 \%$. Here, because of the smaller size of D131 dye, the specific adsorption on the sites of $\mathrm{TiO}_{2}$ nanoparticles was possible. The schematic diagram of interaction of $\mathrm{C} 106$ and $\mathrm{D} 131$ dyes on the $\mathrm{TiO}_{2}$ nanoparticles surface is given in Fig. $7(a, b)$. While increasing the thiophene units of a co-sensitizer, it is found that the performance gets increased due to the improvement in electron injection [44]. When the $\mathrm{TiO}_{2}$ photoanode layer was treated by acid like formic acid, it was observed that the efficiency of co-sensitized solar cell was significantly improved [216]. Other than anchoring groups, surface coverage of each dye molecules also significantly affecting the co-sensitization process. This depend on the concentration of each dye used for this process [58]. Interestingly, it is found that the adsorption site present in the $\mathrm{TiO}_{2}$ nanoparticles for one dye is different from the another dye and hence adsorption of total dye loading is sum of the individual dye loading [80]. This finding also emphasizing the importance of selection of dyes for effective co-sensitization. The important contributions of different kind of dyes to the co-sensitization in DSSCs are discussed below.

\subsection{Role of organic dyes in co-sensitization}

Organic dyes are more superior one for the co-sensitization process than ruthenium based organo-metallic dyes because of their molar extinction coefficient value $\left(>3 \times 10^{4} \mathrm{M}^{-1} \mathrm{~cm}^{-1}\right)$. Also, their easy synthesis process, environment friendly and cost effective nature, favorable for flexible devices and feasible to large scale production are the main advantages of organic dyes over ruthenium based organometallic dyes [10, 192, 193]. Due to their very narrow absorption spectra, enhancement of light harvesting is possible through co-sensitization with another dye. There are many organic dyes, metal-free organic dyes and their derivatives are showing promising results in enhancing the efficiency of DSSCs through cosensitization process. Through effective dye loading and avoiding the aggregation effect, Singh et al. [231] obtained about $8.37 \%$ of efficiency through the co-sensitization of N719 dye with metal free organic dye TA-St-CA. Here, by altering the order of co-sensitization of dyes, i.e., TA-StCA/N719, the authors were able to achieve $6.12 \%$ which show that sensitization of dyes with efficient charge transfer level is essential to obtain high efficiency. Attachment of functional groups on the main structure of the organic dye influences a lot because of their electron donating or withdrawing tendency. Athanas et al. [6] have observed that a diamino bypyridyl structured ruthenium complex dye produced about $7.09 \%$ efficiency when co-sensitized with a carbazole dye containing a thiophene moiety. In an another case, co-sensitization of metal-free 2,6-anthrazene
Fig. 7 Schematic diagram of step-wise co-sensitization of C106 and D131 dyes on the surface of the $\mathrm{TiO}_{2}$ nanoparticles. Reprinted from Ref. [181] with the permission of The Royal Society of Chemistry

\section{(a) C106 Dye adsorption on $\mathrm{TiO}_{2}$ surface}

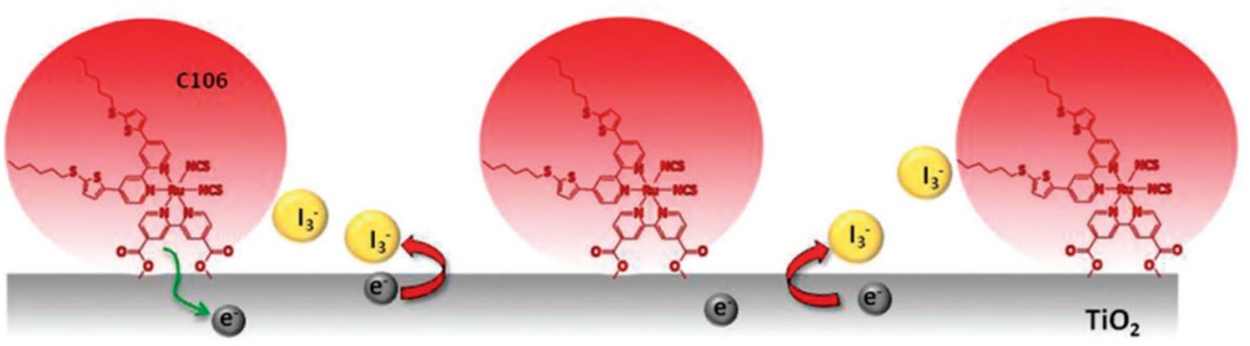

(b) Grafting of D131 dye molecules resulting in co-sensitization

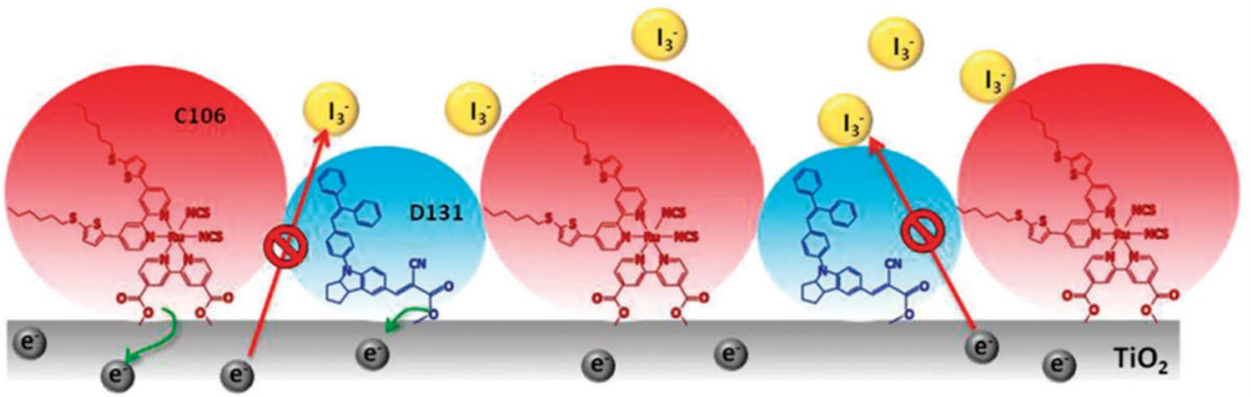


carboxylic acid (Ant3) with a NIR dye SQ2 produced $10.42 \%$ efficiency $\left(V_{o c}=0.72, J_{s c}=5.21 \mathrm{~mA} \mathrm{~cm}^{-2}, F F=0.71\right)$ [150]. Interestingly, a recent investigation showing that incorporation of graphene molecules together with $\mathrm{TiO}_{2}$ nanoparticles improving co-sensitization effect reasonably [169]. Among organic dyes, carbazole dyes are significantly helping to improve the performance of solar cells. Because of their robustness against physical parameters, carbazole dyes can be functionalized at different positions in the structure. Recently, Naik et al. [173] have observed over $8 \%$ efficiency by sensitizing a functionalized ruthenium complex dye (NCSU-10) with a carbazole organic dye and also with carbazole based chromophores. Same research group also used different metal-free carbazole dyes consisting with different units and achieved $8.32 \%$ efficiency by sensitizing with NCSU-10 [175]. Furthermore, the efficiency was exceeded over $9 \%$ with $\mathrm{FF}=62.2 \%$ using carbazole dyes consisting of different electron acceptor/anchoring units [176]. The structure of metal-free carbazole dyes and NCSU-1 used in this process are given in Fig. 8(a). A similar kind of efficiency achievement also accompanied through metal-free organic dyes MR-3 and MR- 4 by simply modifying the anchoring moiety in the $D-\pi-\pi-A$ structure [50] (Fig. 8(b)). These results are claiming that organic dyes are still have promising directions in the development of co-sensitization strategy. In contrast to these findings, Naik et al. found that when the metal-free, un-symmetric A- $\pi-\pi \pi-A$ structured carbazole dyes with cyano acetic acid/2,4-thiazolidinedione/barbituric acid as efficient acceptor/anchoring units were co-sensitized with the NCSU-10, very low efficiency was observed compared with the individual performance of NCSU-10 [177]. This further emphasizing about the importance of designing potential anchoring units attached with the dye molecules. Other than carbazole, boron dipyrromethane (BODIPY) with triphenylamine dye also has shown significant role in co-sensitization. When this dye is co-sensitized by a twostep deposition method with traditional N719 dye, 5.14\% of efficiency was achieved [250]. A recent report by Giannouli et al. [62] who examined the sensitization of more than two organic dyes including xanthene, coumarin etc. revealing that the sequential sensitization of optimum level of dyes could provide highest efficiency over the cocktail type sensitization.

Co-sensitization of organic dyes on the $\mathrm{ZnO}$ photoelectrode is very less studied. Magne et al. [163] have co-sensitized two metal-free indoline dyes on the $8 \mu \mathrm{m}$ thickness $\mathrm{ZnO}$ film photoanode through a one-step cocktail strategy. Using octanoic acid as the co-adsorbent, the authors achieved $4.53 \%$ efficiency under optimized conditions [163]. The different classes of organic dyes and their crucial role in co-sensitization are discussed in the forthcoming sections.

\subsubsection{Role of squaraine dyes in co-sensitization}

Squaraine dyes, due to their effective light harvesting ability at NIR region, widely used for co-sensitization in liquid and solid state dye-sensitized solar cells (SSDSSCs). Squaraine dyes co-sensitized DSSC (VG1-C8 and HSQ4) with an organic dye ( $D-A-\pi-A$ (here, $D=$ donor, $A=$ acceptor) featured organic dye WS-1) using spiro OMeTAD could able to deliver $9.0 \%$ and $8.7 \%$ of efficiency [286]. Using such systems indeed accelerate the intermolecular charge transfer process upon excitation. Attachment of electron withdrawing group on the structure of squaraine performs well in the co-sensitization process. Qin et al. [199] prepared a novel cis-HSQ1 squaraine dye by attaching the dicyanovinyl group and they achieved about $8.14 \%\left(\mathrm{~V}_{\mathrm{oc}}=0.68 \mathrm{~V}_{,} \mathrm{J}_{\mathrm{sc}}=15.76 \mathrm{~mA} \mathrm{~cm}^{-2}, \mathrm{FF}=0.76\right)$ through co-sensitization with N3 dye. Another report of squaraine dyes SPSQI and SPSQ2 which are having near (a)

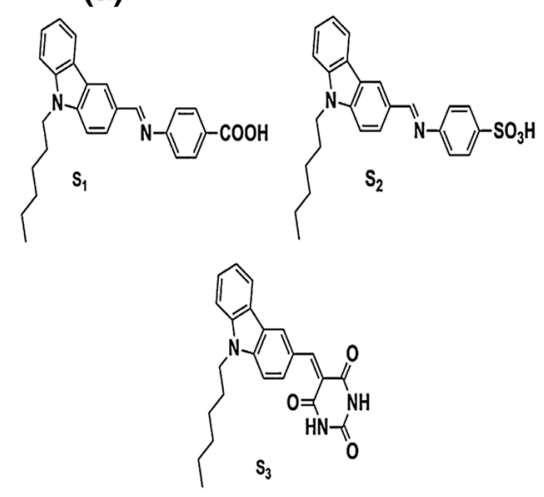

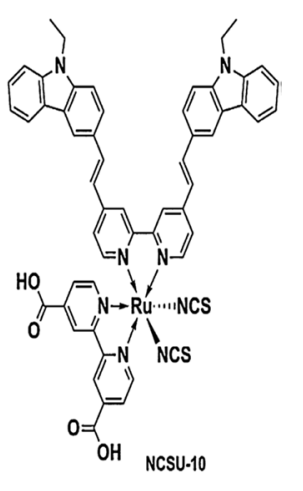

(b)
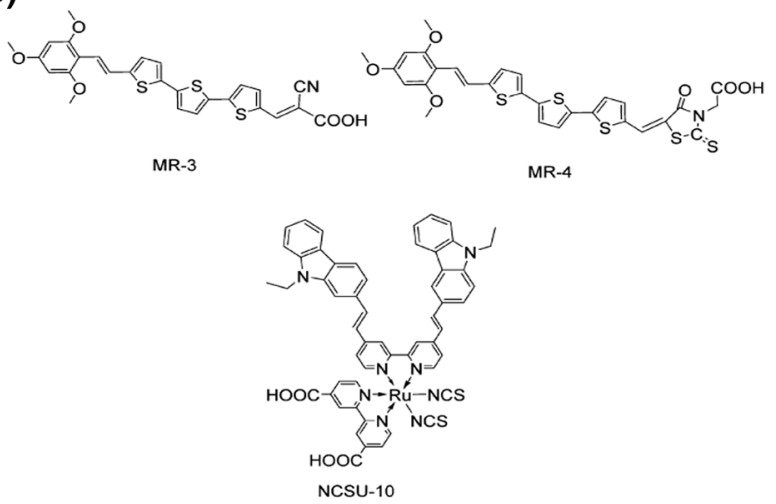

Fig. 8 Chemical structures of a D1-3 dyes and NCSU-10 dye. Reprinted with permission from Ref. [176] Copyright@2018 Elsevier and b MR-3, MR-4 and NCSU-10. Reprinted from Ref. [50] with the permission of The Royal Society of Chemistry 
infra-red absorption (NIR) when sensitized with N3 dye (in the range of 350-800 $\mathrm{nm}$ ) produced highest efficiency of about $8.20 \%$ [202]. Recently, Bisht et al. [15] experimentally observed that when two unsymmetrical squaraine dyes namely, RSQ1 and RSQ2 with benzodithiophene (BDT) as the $\pi$-bridge were used for the sensitization process, about $6.72 \%$ of efficiency was achieved with the RSQ2 dye. Here, BDT effectively played a vital role in reducing the charge recombination process. Theoretical studies show that the improper selection of co-adsorbed dye with squaraine dye result poor performance [210] and hence careful selection of secondary dye for co-sensitization is an imperative process. Co-sensitization of squaraine dye SQ2 with two D- $\pi-A$ type compounds called ' $\mathrm{H}$ ' type of sensitizers has also reached with moderate efficiency [54] and proper tuning of core structure of these kind of compounds would be a good approach to enhance the efficiency further. Squaraine dyes have the extinction coefficient of about $5.7 \times 10^{4} \mathrm{M}^{-1} \mathrm{~cm}^{-1}$ at $634 \mathrm{~nm}$ in dichloromethane [65]. Generally, unsymmetrical squaraine dye co-sensitization is preferred for the DSSC applications compared with the symmetrical one. The absorption spectra of unsymmetrical squaraine dye is well matched with the emission spectrum of an energy relay dye like Eosin and improved efficiency has been achieved through FRET [146]. This unsymmetrical co-sensitization of a squaraine dye has also been carried out on the flexible $\mathrm{TiO}_{2}$ substrate using SQ2 sensitizer with a metal-free organic dye [134]. With the help of Au nanorods@ $\mathrm{SiO}_{2}$ core-shell on the $\mathrm{TiO}_{2}$ layer, further enhancement of efficiency was observed in the co-sensitization of SQ2 dye with LI dye [281]. Here, the localized surface plasmon in Au nanorods contribute more to improve the efficiency. The major problems of squaraine dyes are described as their weak absorption below $500 \mathrm{~nm}$ and their aggregation behavior on the surface of the $\mathrm{TiO}_{2}$ photo anode. Aggregation of SQ2 dye is considered as one of the major problem though it can be used to harvest the excess amount of light by optimizing the degree of aggregation [164]. To suppress this aggregation behavior, dye with suitable functional groups is used to co-sensitize with squaraine dyes. Hua et al. [87] examined on the cosensitization effect of phenothiazene core structured 3D dyes having different functional groups with the organic dye YR6. The authors found that hexylcarbazole dye appended phenothiazene dye could deliver the efficiency close to $10 \%$. When squaraine dyes with cis-configuration is used for the co-sensitization, no aggregation is found on the surface of the primary dye. Islam et al. [94] found this inference through using two cis-configured squaraine dyes namely HSQ3 and HSQ4 and obtained $7.4 \%$ of efficiency by co-sensitization of an oligothienylene dye with the HSQ4 dye. The light harvesting ability of squaraine dyes varies depends on the substitution present on its core. By putting an electron withdrawing group (ethyl cyanoacetate) on the side chain of a squaraine dye, Zhang et al. [286] were able to broaden the IPCE spectra from 300 to $800 \mathrm{~nm}$ through co-sensitization. The chemical structures of some of the squaraine dye used for the co-sensitization process are given in Fig. 9.

Though iodide based redox couple deliver high efficiency in DSSCs, other systems such as cobalt based electrolyte has also shown promising results. Kakiage et al. utilized co-sensitization of alkoxysilyl anchor dye (ADEKA1) with the carboxy anchor organic dye (LEG4) and fabricated a DSSC using cobalt based electrolyte. The authors achieved champion value of $14.7 \%\left(V_{o c}=0.994 \mathrm{~V}\right)$ with $93 \%$ IPCE [110]. The chemical structures of these dyes and the $\mathrm{I}-\mathrm{V}$ curve together with the energy levels is represented in Fig. 10a-d. So far, this is the best reported efficiency in DSSC category through co-sensitization method. When a blue region harvesting dye with diketopyrrolopyrrole moiety is co-sensitized with a red dye in the presence of cobalt redox electrolyte, about $8.7 \%$ efficiency was achieved [77]. Compared with the traditionally used cobalt based bipyridyl electrolyte $\left[\mathrm{Co}(\mathrm{bpy})_{3}\right]^{2+/ 3+}$, hemicage structured cobalt electrolyte $[\mathrm{Co}(\mathrm{ttb})]^{2+/ 3+}$ produced stable solar cells with moderate efficiency through co-sensitization [57]. This has strengthened the hope of commercializing the DSSCs fabricated through co-sensitization. The combined use of organometallic and organic dye, ruthenium dyes based co-sensitization has also been reported [201, 232].

\subsubsection{Role of porphyrin dyes in co-sensitization}

Porphyrins, due to their high photostability and strong band (Soret and Q bands) absorption at 400-500 and $600-700 \mathrm{~nm}$, are one of the efficient candidates used for the co-sensitization process [226]. The main advantage of porphyrins is, their weak absorption in the range of $500-600 \mathrm{~nm}$ could be improved by inserting small organic molecules. Chang et al. [25] found that insertion of the phenothiazine with zinc porphyrin improved the efficiency up to $10.1 \%\left(\mathrm{~V}_{\mathrm{oc}}=0.735 \mathrm{~V}, \mathrm{~J}_{\mathrm{sc}}=19.36 \mathrm{~mA} \mathrm{~cm}^{-2}\right)$ which was higher than the devices sensitized individually by zinc porphyrin $(7.4 \%)$ and phenothiazine (8.2\%). In addition, with improving efficiency as co-adsorbent, phenothiazine also retards back transfer of electrons from conduction band of $\mathrm{TiO}_{2}$. Addition of other donor unit like dithiafulvenyl with phenothiazine unit in the $D-\pi-A$ configuration was found as helpful in improving the efficiency $[159,162]$. Liyanage et al. [157] have achieved about $8.1 \%$ of efficiency by altering the donor and acceptor group in thieno[3,4-b]pyrazine (TPz) based dyes. This variation of the substitution groups makes a drastic change in the energy level position of the dyes and hence facilitates the efficient carrier transfer. The authors also observed that minimal addition of lithium 
(a)

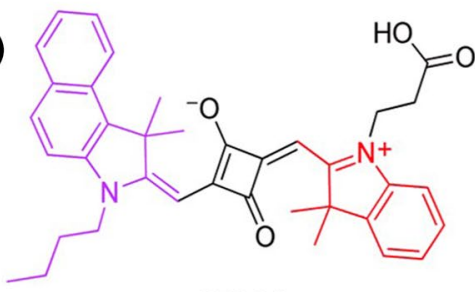

SPSQ1

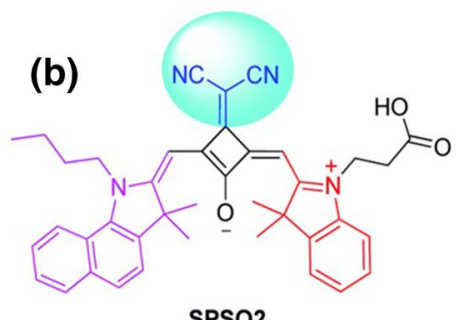

SPSQ2

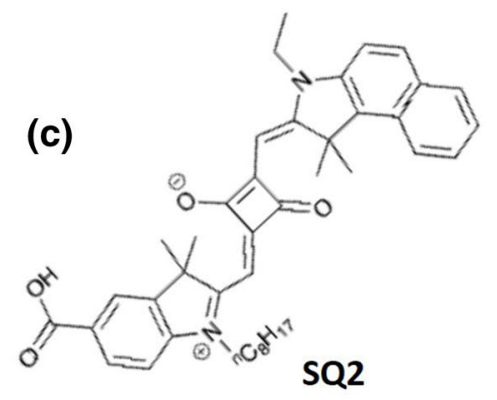

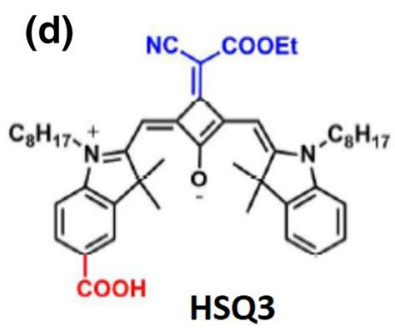

(d)

HSQ3

Fig. 9 Chemical structures of important squaraine dyes used in DSSCs a, b SPSQ1 and SPSQ2. Reprinted from Ref. [202] with the permission of The Royal Society of Chemistry. c SQ2 Reprinted with

salt with the electrolyte could change the overpotential level which helped to improve efficiency. Very recently, through substituting dual donors and dual acceptors in electron-deficient thieno[3,4-b]pyrazine (TPz) $\pi$-bridge, Peddapuram et al. [191] have achieved $10 \%$ efficiency under reduced sun intensity with excellent photostability. Impressively, Xie et al. [258] used traditional iodide redox electrolyte in the co-sensitization process of porphyrin dye XW11 with an organic dye WS-5, $11.5 \%$ of efficiency with $V_{o c}=760 \mathrm{mV}$ was observed which clearly indicating that functionalization of porphyrin dyes will still have a space to improve the efficiency. An interesting study carried out by Lodermeyer et al. [158] revealed about the selective attachment of porphyrin dyes on the $\mathrm{TiO}_{2}$ nanoparticles. In this work, the authors used two layers, namely transparent layer and light scattering layer of $\mathrm{TiO}_{2}$ and used carboxysubstituted tetraphenylbenzoporphyrins dyes H2cTPBP and ZncTPBP by sequential co-sensitization process. It was observed from this study that ZncTPBP attach only on the transparent layer due to its size dependent selective adsorption whereas H2cTPBP attach equally on the both transparent and light scatter layers of $\mathrm{TiO}_{2}$. One of the problem with the porphyrin dyes is formation of aggregation during sensitization process and a recent finding shows that this could be eliminated using optimized immersion time and suitable solvents [206].

In addition to retarding aggregation, a new carbazole moiety containing co-adsorbent HC-A effectively functioning in reducing the recombination and as a dye

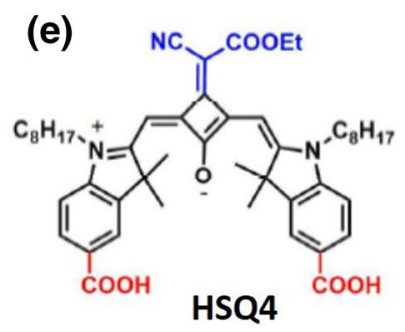

permission from Ref. [281] Copyright@2018 Elsevier. d HSQ3 and e HSQ4. Reprinted with permission from Ref. [94] Copyright@2016 American Chemical Society

while absorbing light [234]. In the sequential sensitization method, when porphyrin dye is sensitized at first, the second dye may replace some amount of the adsorbed dye from the surface of the photoanode. This effect was experimentally observed after sensitization of a porphyrin dye LP-2, about $54.7 \%$ of it was replaced by the co-sensitization of the second dye N719 [291]. In addition to these, combination of co-sensitization of porphyrin-organic dye systems have found to be helpful in improving the efficiency of solar cells $[13,155]$. In specific, organic compounds based on push-pull type $D-\pi-A$ moiety is very helpful to improve the efficiency through co-sensitization and modification of this structure by substituting the functional groups would additionally enhance the performance. There are many attempts of co-sensitization have been made using $D-\pi-A$ compounds with potential anchoring groups to improve the efficiency of DSSCs. Lan et al. [131] analysed the co-sensitization effect of porphyrin contained LD12 dye with donor-acceptor (push-pull) type of CD5 organic dye through a stepwise co-sensitization process. It was observed that the co-sensitized film covered a broad absorption from 350 to $650 \mathrm{~nm}$ and the device showed about $9.0 \%$ efficiency $\left(J_{\mathrm{sc}}=16.74 \mathrm{~mA} \mathrm{~cm}^{-2}\right.$, $\mathrm{V}_{\mathrm{oc}}=0.73 \mathrm{~V}, \mathrm{FF}=0.73$ ) with good stability. The chemical structures of LD 12 and CD5, their absorption co-efficient values, absorptin spectra, I-V curve and IPCE spectra are given in Fig. 11. Moreover, this efficiency was found as higher than the individual device made from CD5 $(\eta=5.7 \%)$ and LD12 ( $\eta=7.5 \%)$. Also, a shift of soret band 


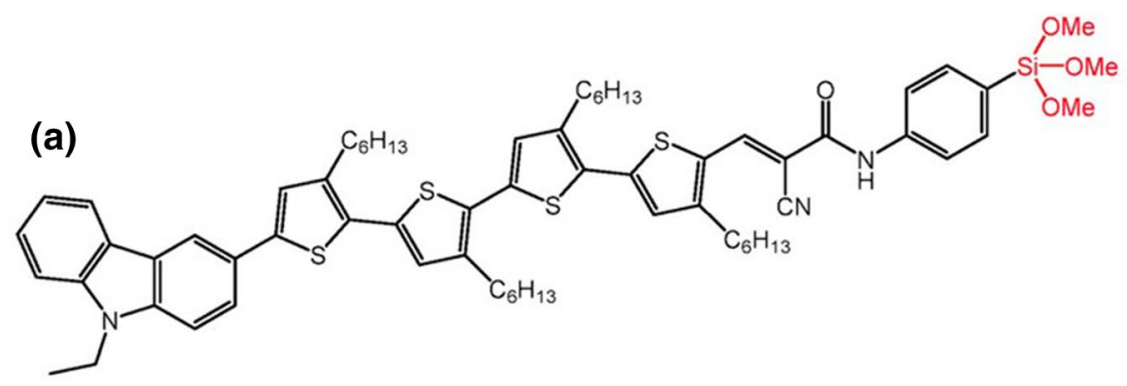

(b)<smiles>CCCCCC1(CCCCC)c2cc(/C=C(\C#N)C(=O)O)sc2-c2sc(-c3ccc(N(c4ccc(-c5ccc(OC)cc5OCC)cc4)c4ccc(-c5ccc(OCC)cc5OCCOCC)cc4)cc3)cc21</smiles>

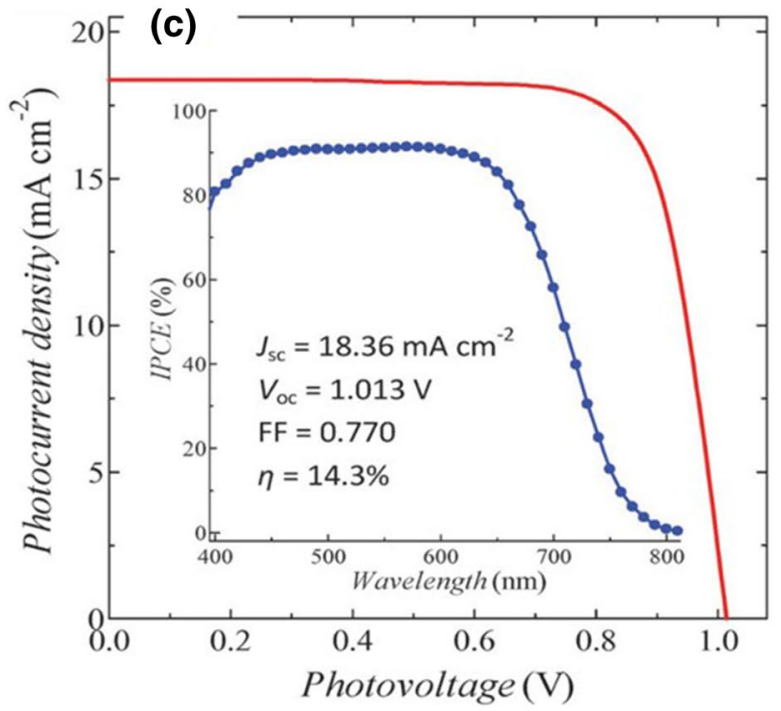

Fig. 10 Chemical structures of a ADEKA-1 and b LEG4 $\mathbf{c}$ I-V curve of the ADEKA-1 co-sensitized with LEG4 device and d Schematic diagram of the charge separation process in the device based on the

in the co-sensitized thin film indicated that the arrangement of porphyrin molecule was adjusted by CD5 dye. Ding et al. [45] used two different porphyrin co-sensitizers (XW11, SM315) together with benzothiadiazole as $\pi$-linker and found that alteration of electron-donating group in SM315 and electron-rich/deficient moieties in $\pi$-linker delivered an impressive efficiency of $13 \%$. The chemical

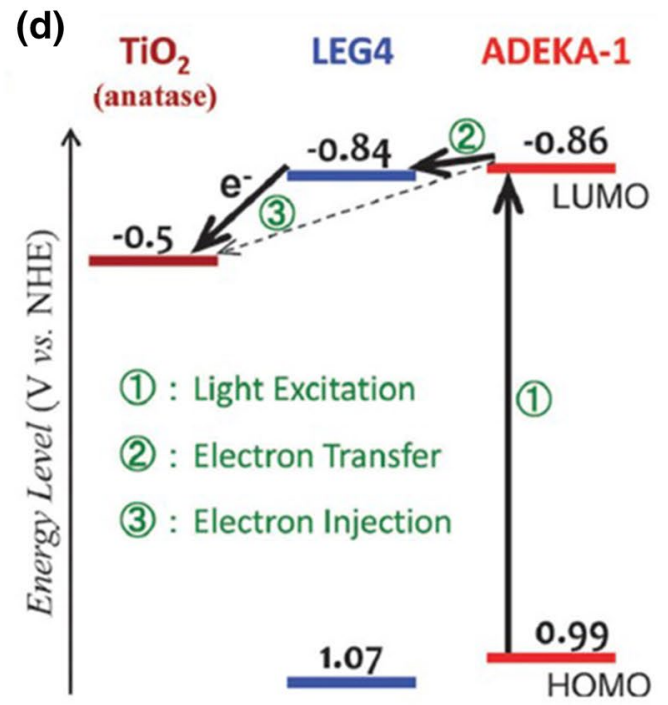

energy levels. Reprinted from Ref. [110] with the permission of The Royal Society of Chemistry

structures of porphyrin dyes and linker used in this process are given in Fig. 12. A similar kind of analysis by Pan et al. [185] in the structure of porphyrin dyes with different electron donors also shown improved efficiency. Prakash et al. [194] synthesized trans- $A_{2} B_{2} Z n$ (II) porphyrin dyes with different donor groups (carbazole, phenothiazine, pyrene and bisthiophene) and by co-sensitizing with N719 


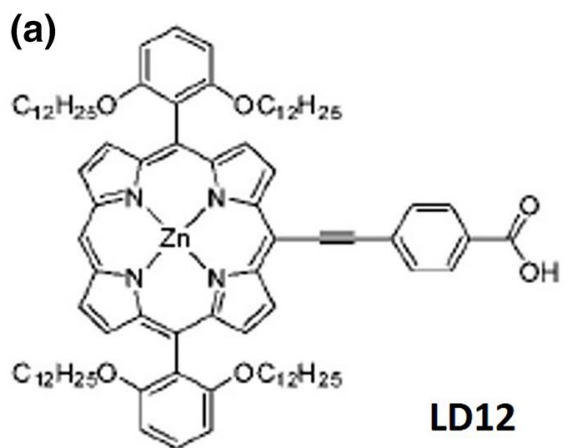<smiles>N#C/C(=C\c1ccc(-c2ccc3c(c2)C(c2ccccc2)(c2ccccc2)c2ccccc2C=C3)s1)C(=O)O</smiles>

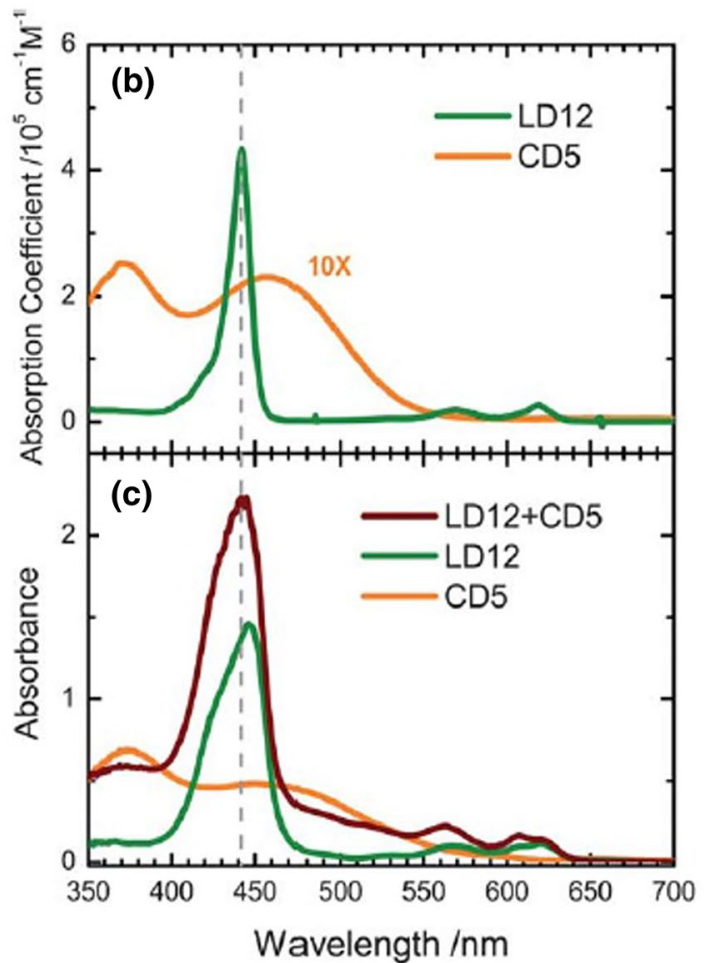

Fig. 11 a Molecular structures of LD12 and CD5 dyes b UV-visible spectra of LD12 \& CD5 dyes in THF, c UV-visible spectra of LD12, $\mathrm{CD} 5$ and $\mathrm{LD} 12+\mathrm{CD} 5$ sensitized $\mathrm{TiO}_{2}$ films and $\mathbf{c}$, d I-V character-

dye, the authors found that phenothiazine group attached porphyrin dye has delivered $8.80 \%$. These results clearly indicating that such kind of molecular structural modulations by different functional groups will ultimately help to achieve new record in the performance of DSSCs. Since the construction of effective photoanode is very important for the co-sensitization of dyes, pore size and porosity are greatly influencing recombination rate, electron transport and trap states. Yella et al. [268] showed that a $20 \mathrm{mM}$ concentrated solution of $\mathrm{TiCl}_{4}$ treatment on the optimized size and porosity of $\mathrm{TiO}_{2}$ photoanode resulted $12.7 \%$ efficiency through co-sensitization of a porphyrin dye SM342 with an organic dye Y123. A diketopyrrolopyrrole coupled zinc porphyrin has shown a broad coverage of spectrum with

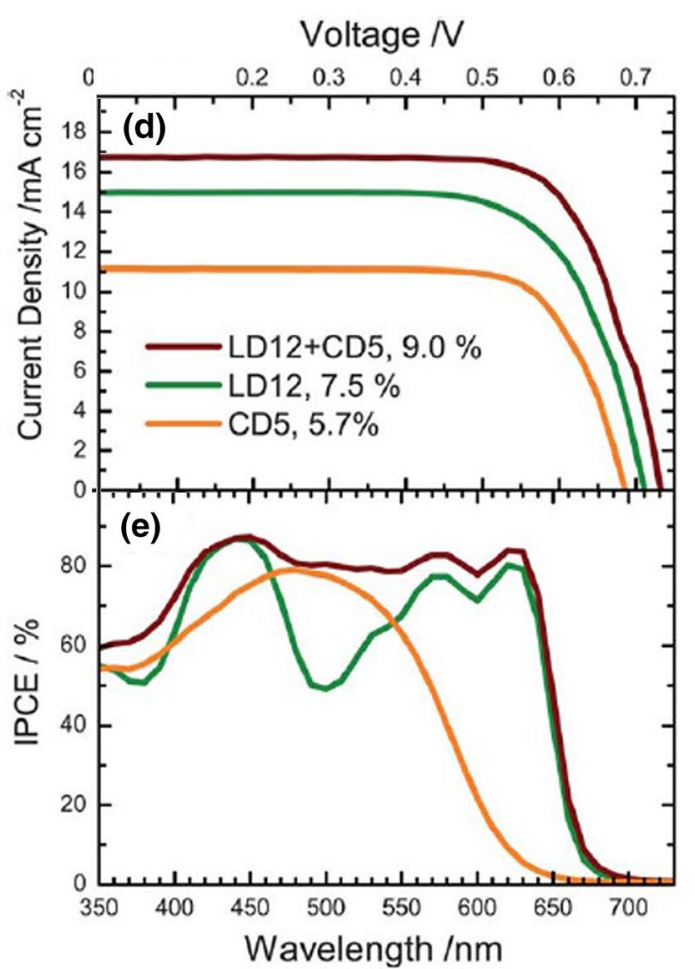

istics and e IPCE analysis of the single and co-sensitized devices. Reprinted from Ref. [131] with the permission of The Royal Society of Chemistry

outstanding efficiency of 7.74\% [55]. Mixing of two porphyrin dyes has also been found as useful to enhance the photoconversion efficiency ( $300 \%$ enhancement) of a solar cell [248]. Sharma and his colleagues analysed the co-sensitization effect of functionalized porphyrin compound $\mathrm{ZnP}$-triazine- $(\mathrm{gly})_{2}$ with the tertiary aryl amine dye-D. In this case, about $7.34 \%$ efficiency was achieved with $\mathrm{J}_{\mathrm{sc}}=14.78 \mathrm{~mA} \mathrm{~cm}^{-2}, \mathrm{~V}_{\mathrm{oc}}=0.70 \mathrm{~V}, \mathrm{FF}=0.71 \%$ which was much higher than the device with porphyrin compound alone $(\eta=4.72 \%)$ [224].

Fan et al. [52] investigated stepwise co-sensitization of novel D- $\pi-A$ Zn (II) porphyrin dye sensitizers FNE57 and FNE59 with the organic dye FNE46. The devices were fabricated with a quasi-solid state electrolyte and the 
Fig. 12 Molecular structures of dye SM315, XW11, cosensitizer WS-5, and newly designed dyes 1-4. Reprinted with permission from Ref. [45] Copyright $\odot 2017$ Elsevier

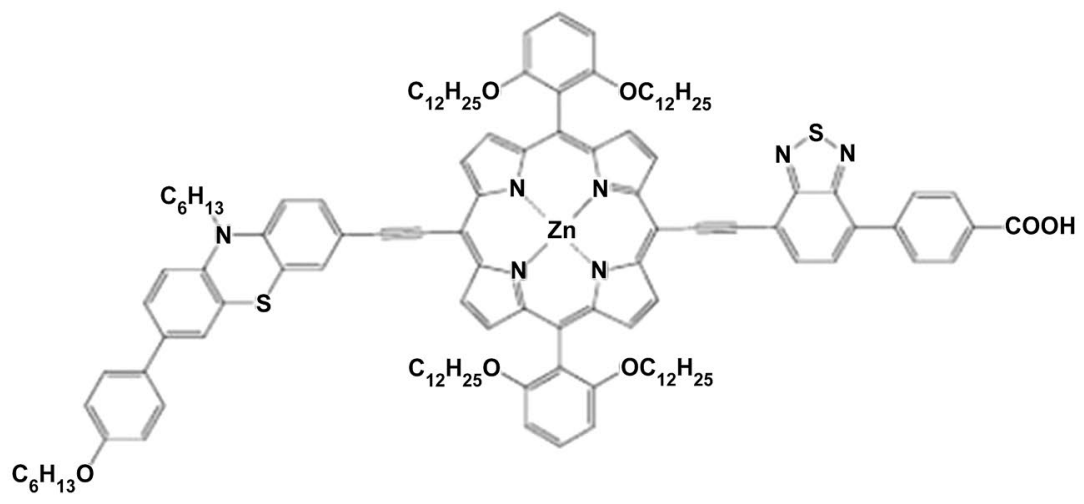

XW11

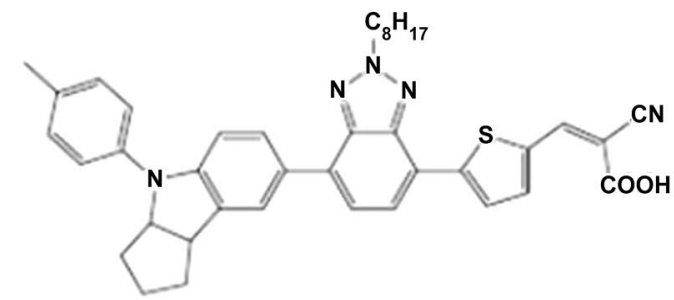

WS-5

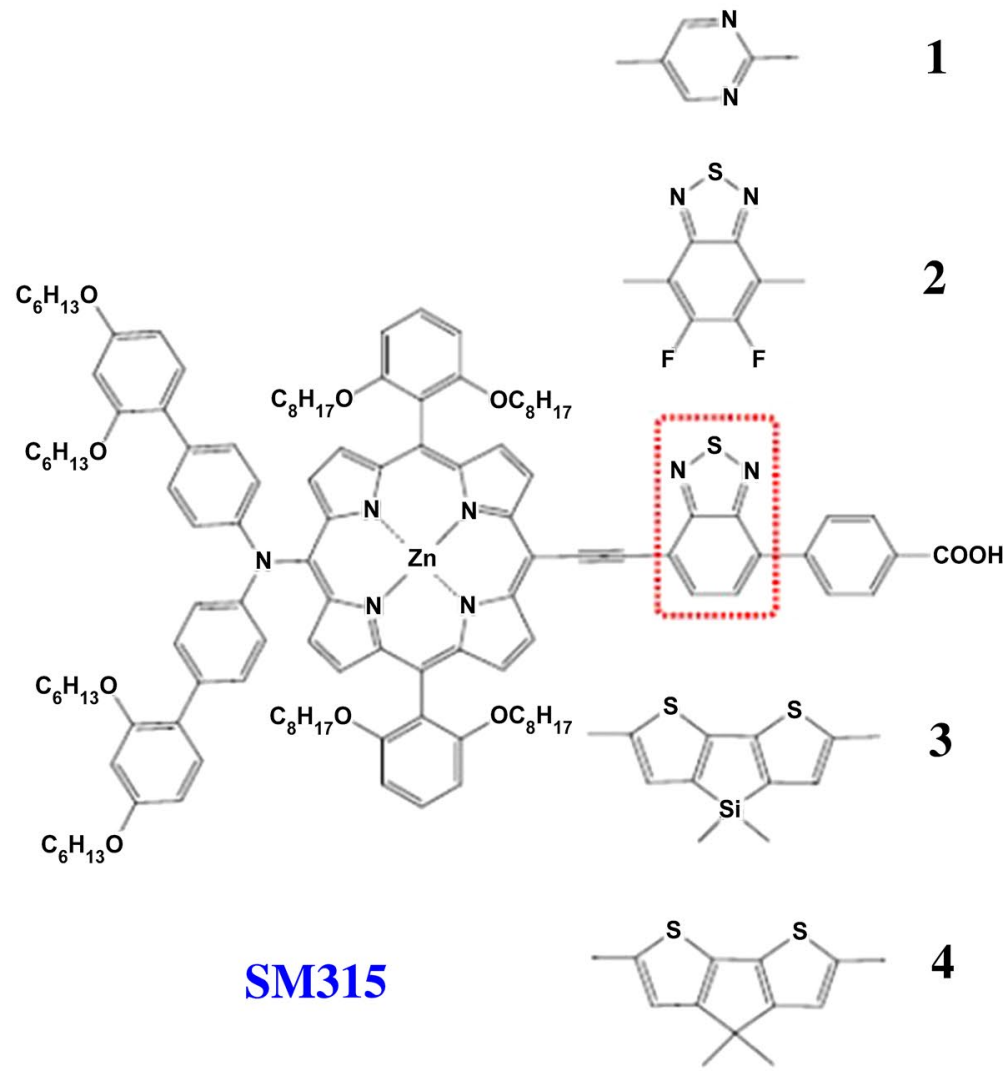




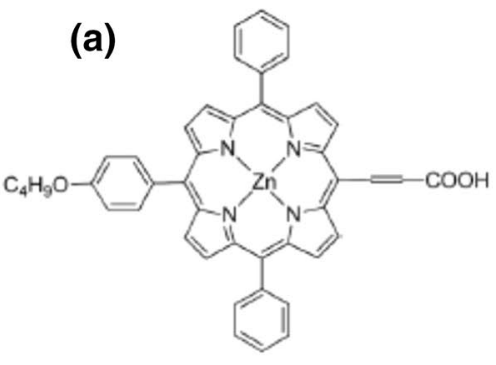

LP-2 (b)

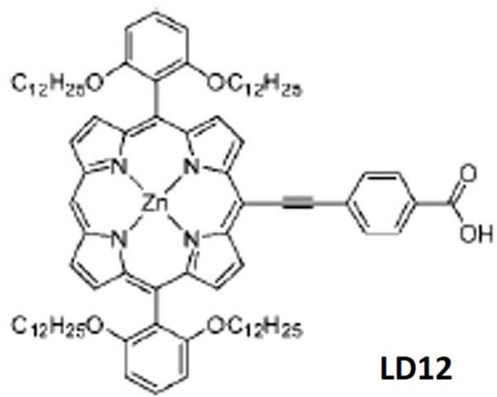

(c)

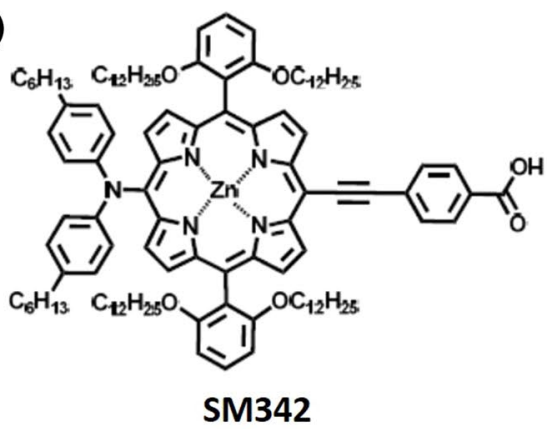

(d)

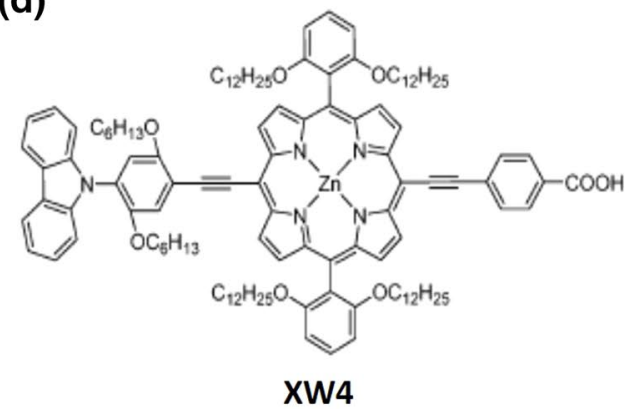

(e)

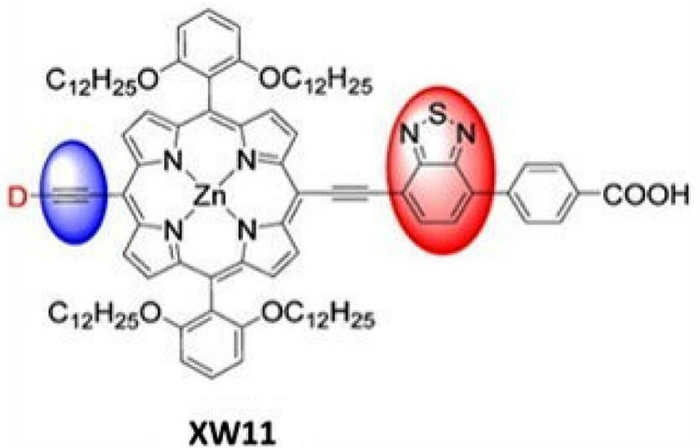

Fig. 13 Molecular structures of some of the porphyrin dyes used for the co-sensitization process $\mathbf{a}, \mathbf{b}$ LP-2 and LD12. Reprinted from Ref. [291] and Ref. [131] with the permission of The Royal Society of Chemistry, c SM342. Reprinted from Ref. [268] with the permis-

efficiency FNE57 + FNE46 sensitized device was found to be $7.88 \%$ and $8.14 \%$ in the case of FNE59+FNE46 sensitized device. Also, the electron lifetime was found in the order of FNE59 + FNE46 > FNE57 + FNE46 which shows that influence of electron life time in addition to the spectral absorption. Other than the $D-\pi-A$ structure, efficiency could be improved using two acceptor (or) two donor groups in the structure i.e., $A-D-\pi-A$ (or) $D-A-\pi-A$ (or) $D-D-\pi-A$. Co-sensitization of $D-A-\pi-A$ benzotriazole organic dye (WS-5) with porphyrin dye XW4 resulted $10.41 \%$ efficiency $\left(V_{o c}=0.77 \mathrm{~V}, J_{s c}=18.78 \mathrm{~mA} \mathrm{~cm}^{-2}\right.$, $\mathrm{FF}=0.72$ ) through $2.5 \mathrm{~h}$ dipping time of WS-5 [155]. As mentioned earlier, addition of other moieties in the porphyrin ring could enhance the efficiency as well. A phorphyrin dye with its free-base analogue (LD14 and H2LD14) which red shift the Q-band, when co-sensitized by an organic dye AN-3 up to $9.72 \%$ of efficiency was obtained [243]. The same group also prepared the LDI porphyrin dye that absorb over $800 \mathrm{~nm}$ by extending the $\pi$-conjugation in the dioctylaminophenyl group and porphyrin core and through co-sensitization with the organic dye AN-4, the efficiency was still enhanced to $10.3 \%$ [244]. A very recent report by Freitag et al. [58] demonstrated the successful co-sensitization of D- $\pi-A$ dye D35 with benzothiadiazole based sensitizer called $X Y 1$. Here, in the presence of sion of The Royal Society of Chemistry, d XW4. Reprinted from Ref. [155] with the permission of The Royal Society of Chemistry, e XW11. Reprinted from Ref. [258] Copyright@2015 American Chemical Society

copper complex electrolyte, the authors achieved about $11.3 \%$ of efficiency under AM 1.5 conditions with impressive maximum open-circuit voltage of $1.1 \mathrm{eV}$. It is thus clear that $D-\pi-A$ with different donor and acceptor molecules are playing significant role in enhancing the sensitization as well as efficiency. If the $\pi$ linkers present in D- $\pi-A$ structure of different compounds, for example, benzene, thiophene, indole, thiophene and furan, the final efficiency of the fabricated devices showed significant variation [7-9, $159,162]$. According to a report by Babu et al. [8,9] who analyzed the barbituric acid as the acceptor with indole moiety in the A- $\pi-D-A$ (acceptor-p bridge-donor-acceptor) configuration, more than $10 \%$ efficiency is possible through co-sensitizing with the ruthenium sensitizer NCSU-10. Here, decrease in $\mathrm{V}_{\text {oc }}$ was observed in co-sensitization due to the enhanced charge recombination process. Based on this result, same research group developed D-D-A type dyes with indole moiety with different electron donating groups and achieved the best efficiency of $10.12 \%$ [9]. Through triarylamine based D-D-ח-A dyes sensitization with D1 dye, Xie et al. [257] achieved about $6.44 \%$ by meticulously optimizing the ratio between the sensitizers. Therefore, it is clear that the role of $\pi$ linkers in the dyes and the ratio of the sensitizing dyes play a vital role in improving the efficiency through co-sensitization. 


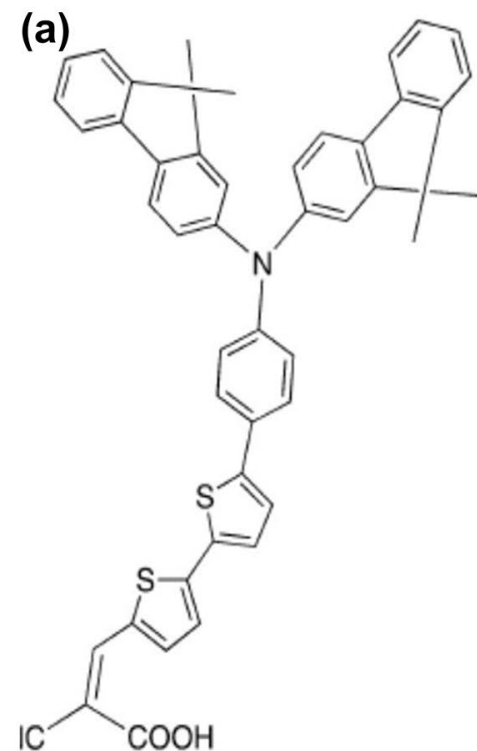

JK2

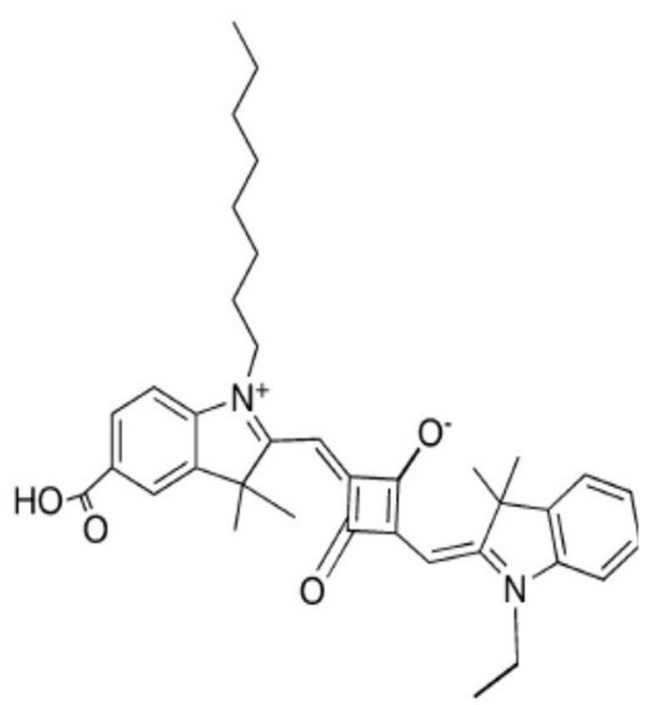

SQ1
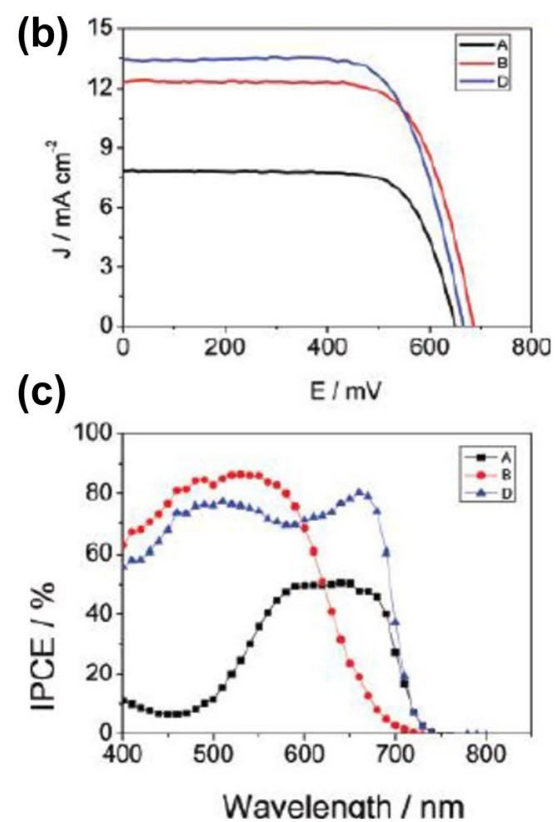

Fig. 14 a Molecular structures of JK2 and SQ1 dyes, b current density-voltage characteristics and c photocurrent action spectra of the ionic liquid electrolyte based DSCs for device A (SQ1, black), device B (JK2, red), and device D (co-sensitization of SQ1 (4 h) and JK2 (1 h) dyes, blue. Reprinted with permission from Ref. [123] Copyright@2007 American chemical society
By modifying the $\pi$ bridge i.e., substituting the benzothiadiazole in the porphyrin dye SM315, Ding et al. [45] have recently achieved $13 \%$ efficiency with $\mathrm{J}_{\mathrm{sc}}=18.1 \mathrm{~mA} \mathrm{~cm}^{-2}$, $V_{o c}=910 \mathrm{mV}$ which is one of the highest performance in this category. The additional carboxylic acid treatment of electrodes can enhance the efficiency of solar cell considerably. Sharma et al. [226] analysed this effect and found that the co-sensitized solar cell efficiency was significantly improved from 6.16 to $7.68 \%$ after the $\mathrm{TiO}_{2}$ photoanode was treated by formic acid. The chemical structures of some of the important porphyrin dyes used for the cosensitization process are given in Fig. 13.

\subsubsection{Role of cyanine dyes in co-sensitization}

Cyanine (absorption extinction co-efficient $\sim 10^{5} \mathrm{M}^{-1} \mathrm{~cm}^{-1}$ ) and its derivatives have been found as suitable for the co-sensitization in dye sensitized solar cells [253]. The mixed dye component of cyanine dyes (pentamethylcyanine and trimethylcyanine derivatives) aggregate easily on the surface of $\mathrm{TiO}_{2}$ nanoparticles layer and this aggregate enhances the efficiency [48, 70]. The reason for this effect is the aggregated cyanine dye molecules act as 'light harvesting antenna' and also transferring electrons from one chromophore to another chromophore of the dye [48]. Apart from the extending the spectrum, the role of co-sensitizer in electron transport is also an accountable. A meager amount of squariliyum cyanine as a co-adsorbate with N3 dye on $\mathrm{TiO}_{2}$ photoanode surface reduces the back electron transfer from $\mathrm{TiO}_{2}$ [296]. Other than the traditional iodide redox couple, co-sensitization process was also being carried out in presence of ionic liquid electrolyte. Kuang et al. [123] fabricated first DSSC based on the solvent free ionic liquid (coded as Z655) through co-sensitization of dyes SQ1 $\left(\varepsilon=158,500 \mathrm{dm}^{3} \mathrm{~mol}^{-1} \mathrm{~cm}^{-1}\right.$ at $\left.636 \mathrm{~nm}\right)$ and JK2 ( $\varepsilon=42,000 \mathrm{dm}^{3} \mathrm{~mol}^{-1} \mathrm{~cm}^{-1}$ at $452 \mathrm{~nm}$ ) (Fig. 14a). Here, it was found that co-sensitization promotes the light absorption and through IPCE, over $40 \%$ efficiency was observed in the region of 400-700 nm (Fig. 14b, c). Also, the co-sensitized device efficiency was found as $6.41 \%$ which was higher than the individual dye performance. Transparent conducting oxide (TCO) free substrate like stainless steel mesh was also utilized as the substrate for the deposition of $\mathrm{TiO}_{2}$ nanoparticles for the effective co-sensitization [166, 167].

\subsubsection{Role of phthalocyanine dyes in co-sensitization}

Phthalocyanine dyes are a kind of large $\pi$-aromatic molecules which are having high molar extinction co-efficient (about $\varepsilon>100,000 \mathrm{M}^{-1} \mathrm{~cm}^{-1}$ ) comparable with the organic dyes. They are transparent over large portion of the visible spectrum which admits them to use as "photovoltaic windows" [92]. Moreover, both phthalocyanines and porphyrins are having the potential of harvesting photons in 

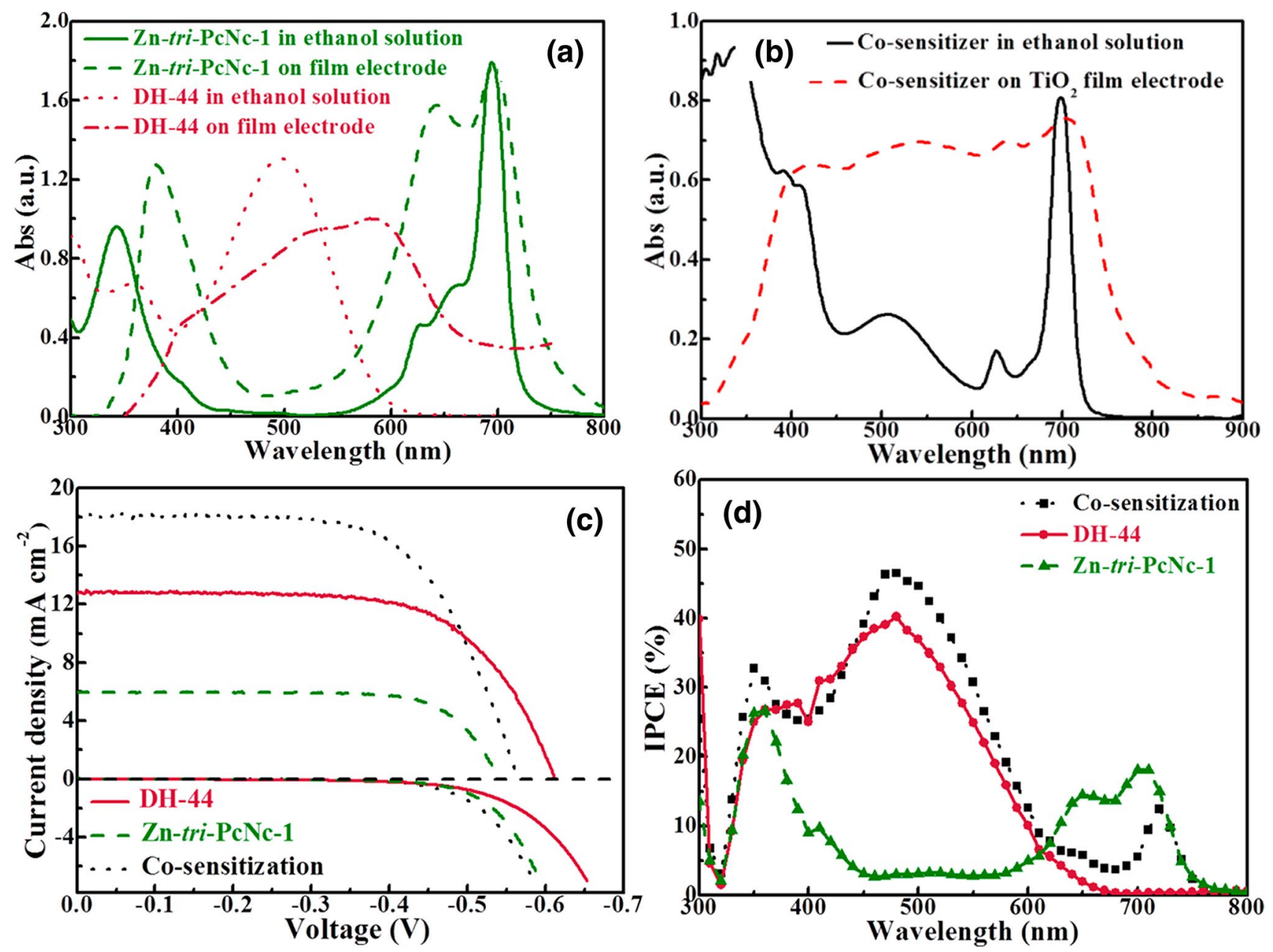

Fig. 15 Chemical structures of a Zn-tri-PcNc-1, b DH-44, c I-V curve of the single sensitized and co-sensitized devices, $\mathbf{d}$ IPCE spectra of the fabricated devices. Reprinted with permission from Ref. [271] Copyright $\odot 2014$ American Chemical Society

NIR region. Deposition of phthalocyanine on the $\mathrm{TiO}_{2}$ photoelectrode after dye adsorption has shown enhancement in efficiency $[263,265]$. Besides, substitution of electron donating methoxy groups around the $\mathrm{ZnPcPcS} 6$ dye moiety has been found to improve the photo response. A dyecocktail approach of ZnPc Pc515 with red and orange dyes namely D102 $\left(\lambda_{\max }=491 \mathrm{~nm}\right)$ and D131 $\left(\lambda_{\max }=425 \mathrm{~nm}\right)$ gave the improved efficiency of $6.2 \%$ and $5.6 \%$ from $5.3 \%$ [120]. As an advantage, by functionalizing the phthalocyanine, the aggregate behavior could be eliminated. For example, carboxy-zinc phthalocyanine dye anchored on the $\mathrm{TiO}_{2}$ nanoparticles surface suppresses the aggregation and about $80 \%$ of IPCE at $690 \mathrm{~nm}$ was observed [38]. Besides, aggregation also minimized by the sensitization of a long chain co-sensitizer in a suitable solvent [134]. Aggregation effect of dyes could also be minimized by the addition of additives like chenodeoxycholic acid (CDCA), cholic acid and octanoic acid through which improved performance is possible $[15,47,150,163,174-177,185]$. In contrast of these findings, Gräf et al. [65] found that the $\mathrm{H}$ and $\mathrm{J}$ aggregates bathochromically shift J bands (tilted orientation) and hypsochromically shift $\mathrm{H}$ bands (parallel orientation) of the aggregates of the squaraine dye with significant contribution to photocurrent. Through the cosensitization of zinc phthalocyanine derivative dye with triarylamino-bithiophene-cyano acrylate based organic dye (DH-44), about $6.61 \%$ efficiency was successfully achieved [271]. The chemical structures of DH-44 and $\mathrm{Zn}$ phthalocyanine dye and their IV, IPCE curves are given in Fig. 15(a-d). In order to enhance the efficiency, increasing effective electron collection length $\left(L_{\text {eff }}\right)$ of the dye during co-sensitization process has also been found as an effective way to minimize the recombination process [99]. Modern approach such as developing $D-\pi-A$ sensitizer dyes to absorb lewis acid sites and bronsted acid sites on the $\mathrm{TiO}_{2}$ nanoparticles surface has also been found as fruitful method to improve performance [183]. 
Fig. 16 Schematic diagram of FRET process (a) and its mechanism (b) (a)

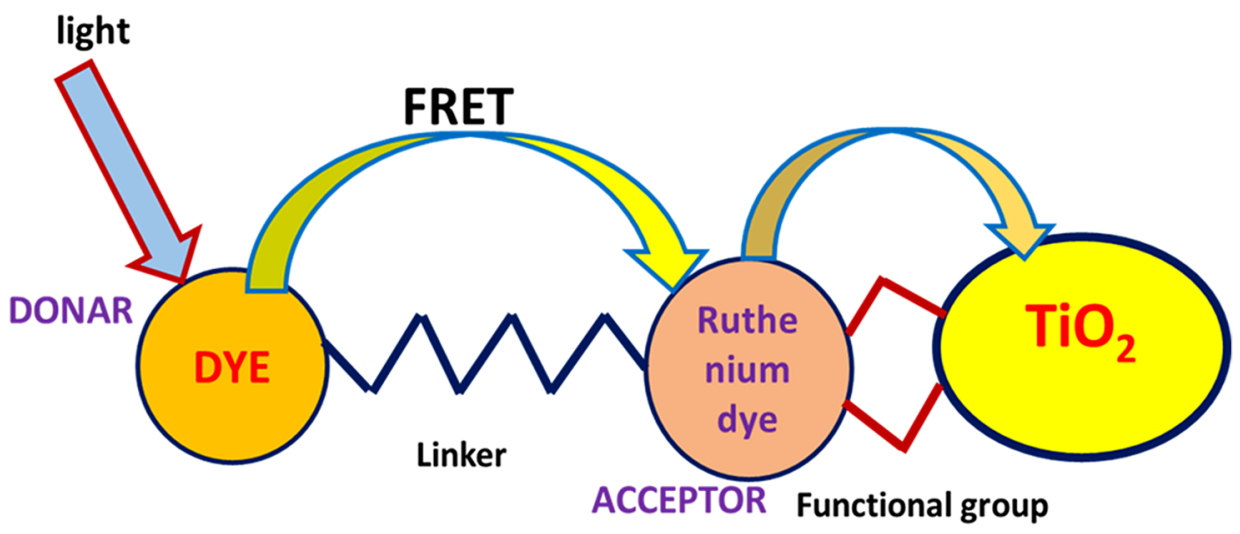

(b)

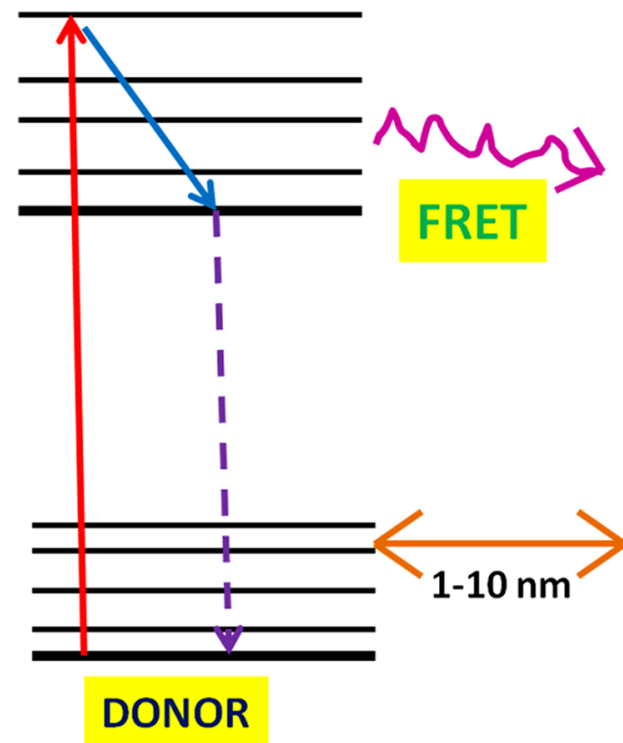

\subsubsection{Role of FRET in co-sensitization of dyes}

In recent years, co-sensitization is effectively achieved through FRET mechanism in which the dipole-dipole attraction of two chromophoric components occurs via an electric field. In this process, absorption of light causes the molecular excitation of donor and this is transferred to a nearby acceptor molecule having lower excitation energy through exchange of virtual photon [11]. Here, the donor molecule non-radiatively transfers excitation energy to an acceptor molecule through an exchange of photon [178]. In another way, there is no physical contact or charge exchange happening in FRET [11]. The strong overlap of absorption and emission spectrum of the 'relay' and 'sensitizing dye' is the selection rule for this phenomena [40]. The conditions also include (1) an energy donor with high fluorescence quantum yield, (2) a small interchromophore distance, (3) a molecular orientation allowing suitable dipole-dipole interactions and (4) the donor and acceptor molecules should be within one Forster radius $[11,230]$. Moreover, the interference between HOMO and LUMO levels of the dye should also be avoided [82]. Tuning of this mechanism is effectively achieved with the suitable selection of donor and acceptor molecules that possessing right electronic and geometrical properties [189]. The schematic diagram of process and mechanism of FRET process is given in Fig. 16a, b. Even though this mechanism is mostly exploited for organometallic dye and QDs combination, there are some reports dealing about enhancement of photovoltaic performance by dyes through FRET mechanism. Yum et al. [279] analysed the effect of addition of phthalocyanine dyes on the interaction of energy relay dyes (ERD, a novel concept where multiple dyes are incorporated in electrolyte to harvest huge photons through FRET) Rhodamine B and DCM9, about 35\% increase in the performance of photovoltaic device was achieved through 
FRET. Yum et al. [277-279] analysed the effect of energy relay dye (ERD) N877 (a phenanthroline ruthenium (II) sensitizer) which transfers energy to a NIR squaraine dye (SQ1) anchored on $\mathrm{TiO}_{2}$ surface. The device performance through ERD was enhanced $30 \%$ in $\mathrm{J}_{\mathrm{sc}}$ and $29 \%$ in power conversion efficiency. Without ERD, the efficiency ( $\eta$ ) was $1.40 \%\left(V_{o c}=807 \mathrm{mV}, J_{\mathrm{sc}}=2.98, F F=0.58\right)$ whereas with $E R D$, $\eta=1.80 \%\left(V_{o c}=786 \mathrm{mV}, J_{s c}=3.87, F F=0.59\right)$. The actual process of FRET mostly happening as inter-type FRET but it is also possible to happen as intra-type FRET by end capping the energy donor on the energy acceptor [43]. Zong et al. [295] used Marcus theory and proposed that the photoinduced energy transfer in the FRET process is equal to the reorganization energy which lead to the barrier-less charge transfer. Dryza and Bieske [46] found that orientation of dye molecules on the surface of the metal oxide surface critically influencing the FRET process. The authors used IR125 dye as FRET acceptor and separately tested with D149 and D35 FRET donor dyes. It was found that because of the parallel orientation of D149 dye, the rate of FRET in the D149+IR125 combination was higher than the D35 + D149 pair.

Applying energy relay dyes for DSSCs is one of the most efficient method to improve the efficiency [78]. Yum et al. [279] have found that the incorporation of more than two energy relay dyes successfully provided the panchromatic light absorption. Interestingly, a donor-acceptor dyad (both donor and acceptor combined in a same compound) system could perform well compared with the individual donor and acceptor molecules. Such effect was also observed in the ruthenium complex (acceptor)-Fulorol $7 \mathrm{GA}$ (donor) dyad system [230]. It is a known fact that depending upon the fabricating conditions the efficiency is determined. For instance, a step-by step sensitization of $\mathrm{TiO}_{2}$ photo electrode through two different dyes under pressurized $\mathrm{CO}_{2}$ conditions result enhancement in efficiency [93]. The functional group present in the structure of dye molecule also contribute large extent in the FRET process. Ruthenium complexes are having long life times, high photostability, high strokes shift and large absorption in the visible region. All these properties can significantly be altered by inserting suitable additional organic molecule in the structure. FRET mechanism has also been used in solid-state DSSCs. Fluorescent material like 4-(dicyanomethylene)-2-methyl-6-(4dimethylaminostyryl)-4H-pyran (DCM-pyran) is efficiently transferring the energy to dyes and improved performance has been observed [280].

\subsubsection{Miscellaneous}

Other than ruthenium based dyes, organic and metalfree dyes, natural dyes oriented co-sensitization through successive absorption of two different natural dyes also attempted. Yadav et al. [261, 262] analyzed the sensitization effect of various transition metal complexes (in DCM/DMSO solution) with N719 dye (in ethanol) on the mesoporous $\mathrm{TiO}_{2}$ layer. The authors found that zinc ( $\mathrm{Zn}$ ) based complexes resulted highest efficiency (7.10\%) over other complexes. Moreover, biomolecule such as bacteriorhodopsin (bR) has been found as useful in enhancing the efficiency [171]. When co-sensitization is carried out using N719 dye and a conducting polymer like poly-3-hexyl thiophene (P3OT), a doped system of $\mathrm{TiO}_{2}$ nanoparticles photoelectrode could perform better manner due to the favorable energy levels [283, 284, 286]. Recently, Chen et al. [29] synthesized two different kind of liquid crystals $(3 \mathrm{~N}-1, \mathrm{AZ6})$ with pyridyl terminal and the authors achieved efficiency of $6.60 \%$ through co-sensitization. Though co-sensitization through dyes has several advantages, problems such as chemical incompatibility and the competition of two dyes during sensitization process affects the performance of DSSCs significantly $[192,193]$. However, these results and efforts clearly predict that the future breakthrough in new novel dyes and methodology of deposition of dyes would solve all these problems. The overall summary of the cosensitization of molecular dyes and their influence in efficiency of solar cells are collectively given in Table 1. More than two dyes also play good performance in sensitization process. A tri-sensitized $\mathrm{TiO}_{2}$ photo electrode analysed by Chen et al. [30] revealed the successful response in increasing efficiency. Holliman et al. [82] carried out a tri-sensitization by ultrafast sensitization method for N719, SQ1, D149 dyes and this method was found to be very useful in producing efficiency up to $8.1 \%$. By tuning the molar ratio of the three sensitizers one could achieve high efficiency with less aggregation of dyes [252]. This tri-sensitization process is sensitive to the composition of the dyes. For example, for the mixed type of D131/D149/N3 dyes mixture, the optimized composition ratio was found as $1 / 2$ D149/1/2 N3 [263]. One of the problem in co-sensitization process is molecular aggregates on the surface of the $\mathrm{TiO}_{2}$ nanoparticles surface terribly affect the device performance in most of the cases. However, it could be minimized by introducing the co-adsorbents with the sensitizing dyes [75]. Future studies in this direction will unravel mechanism existing in improving the performance of DSSCs.

\subsection{Co-sensitization by quantumdots (QDs) on $\mathrm{TiO}_{2}$ photoelectrode}

\subsubsection{Importance of co-sensitization by QDs and structural configuration for co-sensitization}

Eventhough organic dyes are used for the co-sensitization process, their demerits such as aggregation on the $\mathrm{TiO}_{2}$ 
Table 1 Co-sensitization using different dyes discussed in this review and their solar cell performance with other parameters

\begin{tabular}{|c|c|c|c|c|c|c|c|c|}
\hline \multirow[t]{2}{*}{ S. no. } & \multirow{2}{*}{$\begin{array}{l}\text { Dyes/org. mol- } \\
\text { ecules used for the } \\
\text { co-sensitization }\end{array}$} & \multirow{2}{*}{$\begin{array}{l}\text { Basic structural } \\
\text { moiety/m-spacer } \\
\text { present in the } \\
\text { compound }\end{array}$} & \multirow{2}{*}{$\begin{array}{l}\text { Solvent(s) used for } \\
\text { the co-sensitization }\end{array}$} & \multicolumn{4}{|c|}{ Solar cell parameters } & \multirow[t]{2}{*}{ References } \\
\hline & & & & $\mathrm{V}_{\mathrm{oc}}(\mathrm{V})$ & $\mathrm{J}_{\mathrm{sc}}\left(\mathrm{mA} / \mathrm{cm}^{2}\right)$ & $\mathrm{FF}$ & $\eta(\%)$ & \\
\hline \multirow[t]{2}{*}{1} & Ant 3 & Anthracene & $\mathrm{ACN}, t-\mathrm{BuOH}$ & 0.69 & 18.01 & 0.65 & 8.08 & Lin et al. [150] \\
\hline & SQ 2 & Squaraine & & & & & & \\
\hline \multirow[t]{2}{*}{2} & NKX2677 & Coumarin & NA & 0.68 & 17.25 & 0.74 & 8.89 & Song et al. [234] \\
\hline & $\mathrm{HC}-\mathrm{A}$ & Carbazole & & & & & & \\
\hline \multirow[t]{2}{*}{3} & HSQ1 & Squaraine & $\mathrm{ACN}, t-\mathrm{BuOH}$ & 0.68 & 15.76 & 0.76 & 8.14 & Qin et al. [199] \\
\hline & N3 & Bipyridine & & & & & & \\
\hline \multirow[t]{2}{*}{4} & C106 & Bipyridine & $\mathrm{DMF}, \mathrm{ACN}, t-\mathrm{BuOH}$ & 0.76 & 20.6 & 0.70 & 11.1 & Nguyen et al. [181] \\
\hline & D131 & Indoline & & & & & & \\
\hline \multirow[t]{2}{*}{5} & N719 & Bipyridyl & $\mathrm{ACN}, t-\mathrm{BuOH}$ & 0.51 & 18.0 & 0.50 & 4.6 & $\begin{array}{l}\text { Ranasinghe et al. } \\
\text { [201] }\end{array}$ \\
\hline & SQ & Terpyridyl & & & & & & \\
\hline \multirow[t]{2}{*}{6} & $\mathrm{ZnP}$ & Porphyrin & $\mathrm{ACN}, t-\mathrm{BuOH}$ & 0.79 & 19.61 & 0.69 & 10.1 & Chang et al. [25]. \\
\hline & PT-C6 & Phenothiazine & & & & & & \\
\hline \multirow[t]{2}{*}{7} & $\mathrm{Ru}$ & Bipyridine & $\mathrm{ACN}, t-\mathrm{BuOH}$ & 0.60 & 14.32 & 0.73 & 6.29 & Singh et al. [232] \\
\hline & Y3 & Thiophene & & & & & & \\
\hline \multirow[t]{2}{*}{8} & $\mathrm{RhCL}$ & Rhodamine & $\mathrm{EtOH}$ & 0.73 & 10.54 & 0.69 & 5.34 & Saxena et al. [216] \\
\hline & N719 & Bipyridyl & & & & & & \\
\hline \multirow[t]{2}{*}{9} & SQ1 & Bithiophene & $\mathrm{EtOH}$ & 0.66 & 13.62 & 0.70 & 6.41 & Kuang et al. [123] \\
\hline & JK2 & Indole & & & & & & \\
\hline \multirow[t]{2}{*}{10} & SQ2 & Squaraine & $\begin{array}{l}\text { ACN, } t-\mathrm{BuOH}, \\
\text { DMSO }\end{array}$ & 0.60 & 18.82 & 0.59 & 6.70 & Chang et al. [24] \\
\hline & $5 C$ & Pyrenoimidazole & & & & & & \\
\hline \multirow[t]{3}{*}{11} & N719 & Bipyridyl & $\mathrm{ACN}, t-\mathrm{BuOH}$ & 0.71 & 11.42 & 0.62 & 5.10 (N719/FL) & Lee et al. [136] \\
\hline & Black dye (BD) & Terpyridyl & & 0.65 & 9.77 & 0.59 & 3.78 (BD/FL) & \\
\hline & $\mathrm{FL}$ & Fluorine & & & & & & \\
\hline \multirow[t]{2}{*}{12} & A & Cyanine & $\mathrm{ACN}, t-\mathrm{BuOH}$ & 0.44 & 15.18 & 0.45 & 3.00 & Wu et al.[253] \\
\hline & B & Cyanine & & & & & & \\
\hline \multirow[t]{2}{*}{13} & N719 & Bipyridyl & $\mathrm{EtOH}, t-\mathrm{BuOH}$ & 0.71 & 17.81 & 0.64 & 8.1 & Holliman et al. [83] \\
\hline & D149 & Indoline & & & & & & \\
\hline \multirow[t]{2}{*}{14} & PcS15 & Indole & Toluene & 0.63 & 15.3 & 0.64 & 6.2 & Kimura et al. [120] \\
\hline & D131 & & & & & & & \\
\hline \multirow[t]{2}{*}{15} & Black dye & Terpyridyl & $\mathrm{ACN}, t-\mathrm{BuOH}$ & 0.70 & 21.8 & 0.60 & 9.16 & Inakazu et al. [93] \\
\hline & NK3705 & $\begin{array}{l}\text { Benzothia- } \\
\text { zolylidene }\end{array}$ & & & & & & \\
\hline \multirow[t]{2}{*}{16} & Zn-tri-PcNc-1 & $\begin{array}{l}\text { Zinc phthalocya- } \\
\text { nine }\end{array}$ & $\mathrm{EtOH}, \mathrm{THF}$ & 0.56 & 17.94 & 0.66 & 6.61 & Yu et al. [271] \\
\hline & $\mathrm{DH}-44$ & Bithiophene & & & & & & \\
\hline \multirow[t]{3}{*}{17} & $Y$ & Mesocyanine & $\mathrm{MeOH}$ & 0.52 & 15.8 & 0.63 & 6.5 & Chen et al. [30] \\
\hline & $\mathrm{R}$ & Hemicyanine & & & & & & \\
\hline & B & $\begin{array}{l}\text { Blue squarylium } \\
\text { cyanine }\end{array}$ & & & & & & \\
\hline 18 & CuPc & Phthalocyanine & $\mathrm{EtOH}$ & 0.74 & 21.12 & 0.60 & 9.48 & Yang et al. [265] \\
\hline & N719 & Bipyridyl & & & & & & \\
\hline 19 & DCM & $\begin{array}{l}\text { Dicyanomethylene } \\
\text { aminostyryl }\end{array}$ & $\mathrm{EtOH}$ & 0.57 & 9.81 & 0.70 & 3.97 & Yum et al. [279] \\
\hline & Rhodamine B & Fluorine & & & & & & \\
\hline & TTI & Phthalocyanine & & & & & & \\
\hline 20 & SQ2 & Squaraine & $\mathrm{ACN}, t-\mathrm{BuOH}$ & 0.64 & 15.13 & 0.66 & 6.36 & Lin et al. [149] \\
\hline
\end{tabular}


Table 1 (continued)

\begin{tabular}{|c|c|c|c|c|c|c|c|c|}
\hline \multirow[t]{2}{*}{ S. no. } & \multirow{2}{*}{$\begin{array}{l}\text { Dyes/org. mol- } \\
\text { ecules used for the } \\
\text { co-sensitization }\end{array}$} & \multirow{2}{*}{$\begin{array}{l}\text { Basic structural } \\
\text { moiety/m-spacer } \\
\text { present in the } \\
\text { compound }\end{array}$} & \multirow{2}{*}{$\begin{array}{l}\text { Solvent(s) used for } \\
\text { the co-sensitization }\end{array}$} & \multicolumn{4}{|c|}{ Solar cell parameters } & \multirow[t]{2}{*}{ References } \\
\hline & & & & $\overline{\mathrm{V}_{\mathrm{oc}}(\mathrm{V})}$ & $\mathrm{J}_{\mathrm{sc}}\left(\mathrm{mA} / \mathrm{cm}^{2}\right)$ & $\mathrm{FF}$ & $\eta(\%)$ & \\
\hline & JD1 & $\begin{array}{l}\text { Diarylaminoflu- } \\
\text { orene }\end{array}$ & & & & & & \\
\hline \multirow[t]{2}{*}{21} & TTI & Cyanine & $\mathrm{EtOH}, \mathrm{THF}$ & 0.66 & 16.20 & 0.72 & 7.74 & Cid et al. [38] \\
\hline & JK2 & Squaraine & & & & & & \\
\hline \multirow[t]{3}{*}{22} & YD2-0C8 & Porphyrin & $\mathrm{EtOH}$ & 0.75 & 19.28 & 0.71 & 10.4 & Wu et al. [252] \\
\hline & CD4 & Triarylamine & & & & & & \\
\hline & YDD6 & Porphyrin & & & & & & \\
\hline \multirow[t]{2}{*}{23} & JD10 & Squaraine & $\mathrm{EtOH}$ & 0.74 & 9.9 & 0.59 & 4.42 & Dualeh et al. [47] \\
\hline & D35 & & & & & & & \\
\hline \multirow[t]{2}{*}{24} & N877 & Phenanthroline & $\mathrm{EtOH}$ & 0.78 & 3.87 & 0.59 & 1.80 & Yum et al. [277] \\
\hline & SQ1 & Squaraine & & & & & & \\
\hline \multirow[t]{2}{*}{25} & $A$ & $\begin{array}{l}\text { Pentamethylcya- } \\
\text { nine }\end{array}$ & $\mathrm{EtOH}$ & 0.52 & 5.8 & 0.47 & 3.4 & Guo et al. [70] \\
\hline & B & Trimethylcyanine & & & & & & \\
\hline \multirow[t]{3}{*}{26} & D131 & Indoline & $\mathrm{EtOH}$ & 0.85 & 14.45 & 0.76 & 9.52 & Yang et al. [263] \\
\hline & D149 & Indoline & & & & & & \\
\hline & N3 & Bipyridyl & & & & & & \\
\hline \multirow[t]{2}{*}{27} & $\mathrm{DC}-\mathrm{H}_{2} \mathrm{P}$ & Arylamine & $\mathrm{CHCl}_{3}, \mathrm{EtOH}, \mathrm{THF}$ & 0.76 & 13.45 & 0.75 & 7.68 & Sharma et al. [226] \\
\hline & $\mathrm{ZnP}$ & Phthalocyanine & & & & & & \\
\hline \multirow[t]{2}{*}{28} & JK2 & Fluorine & THF, EtOH & 0.69 & 17.6 & 0.70 & 8.65 & Choi et al. [33] \\
\hline & SQ1 & Squaraine & & & & & & \\
\hline \multirow[t]{2}{*}{29} & Dyestuff & $\begin{array}{l}\text { Triazoloisoquino- } \\
\text { line }\end{array}$ & DMF & 0.70 & 10.68 & 0.69 & 5.15 & Lee et al. [132] \\
\hline & N719 & Bipyramidal & & & & & & \\
\hline \multirow[t]{3}{*}{30} & N719 & Bipyridyl & $\mathrm{EtOH}$ & 0.73 & 16.05 & 0.55 & 6.5 & Holliman et al. [82] \\
\hline & 5 & Triarylamine & & & & & & \\
\hline & 6 & & & & & & & \\
\hline \multirow[t]{2}{*}{31} & N719 & Bipyridyl & $\mathrm{EtOH}$ & 0.72 & 13.41 & 0.75 & 7.34 & Honda et al. [84] \\
\hline & D131 & Indoline & & & & & & \\
\hline \multirow[t]{2}{*}{32} & PcS15 & Phthalocyanine & toluene & 0.63 & 15.3 & 0.64 & 6.2 & Kimura et al. [120] \\
\hline & D131 & Indole & & & & & & \\
\hline \multirow[t]{2}{*}{33} & LD12 & Porphyrin & EtOH, toluene & 0.73 & 16.74 & 0.73 & 9.0 & Lan et al. [131] \\
\hline & CD5 & Organic dye & & & & & & \\
\hline \multirow[t]{2}{*}{34} & Black dye & Terpyridine & $\mathrm{EtOH}$ & 0.74 & 20.88 & 0.72 & 11.28 & Han et al. [75] \\
\hline & Y1 & $\begin{array}{l}\text { Butyloxyl-substi- } \\
\text { tuted phenyl }\end{array}$ & & & & & & \\
\hline \multirow[t]{2}{*}{35} & YD 2 & Porphyrin & $\mathrm{EtOH}$ & 0.74 & 12.6 & 0.73 & 6.9 & Bessho et al. [13] \\
\hline & D 205 & Indoline & $t-\mathrm{BuOH}, \mathrm{ACN}$ & & & & & \\
\hline \multirow[t]{2}{*}{36} & ZnP-traiazine-(gly)2 & Porphyrin & $\mathrm{THF}, \mathrm{EtOH}$ & 0.70 & 14.78 & 0.71 & 7.34 & Sharma et al. [224] \\
\hline & $\begin{array}{l}\text { Tertiary arylamine } \\
\text { D }\end{array}$ & Triarylamine & & & & & & \\
\hline \multirow[t]{2}{*}{37} & FNE59 & Porphyrin & THF, EtOH & 0.68 & 17.03 & 0.70 & 8.14 & Fan et al. [52] \\
\hline & FNE46 & Triarylamine & & & & & & \\
\hline 38 & WS-5 & Benzotriazole & $\mathrm{CHCl}_{3} \& \mathrm{EtOH}$ & 0.77 & 18.79 & 0.72 & 10.41 & Liu et al. [155] \\
\hline & XW4 & Porphyrin & Toluene \& EtOH & & & & & \\
\hline 39 & ADEKA-1 & $\begin{array}{l}\text { Oligothiophene- } \\
\text { alkoxysilyl anchor }\end{array}$ & Toluene, EtOH & 1.01 & 18.27 & 0.77 & 14.3 & Kakiage et al. [110] \\
\hline & LEG4 & $\begin{array}{l}\text { Oligothiophene- } \\
\text { carboxy anchor }\end{array}$ & & & & & & \\
\hline
\end{tabular}


Table 1 (continued)

\begin{tabular}{|c|c|c|c|c|c|c|c|c|}
\hline \multirow[t]{2}{*}{ S. no. } & \multirow{2}{*}{$\begin{array}{l}\text { Dyes/org. mol- } \\
\text { ecules used for the } \\
\text { co-sensitization }\end{array}$} & \multirow{2}{*}{$\begin{array}{l}\text { Basic structural } \\
\text { moiety/m-spacer } \\
\text { present in the } \\
\text { compound }\end{array}$} & \multirow{2}{*}{$\begin{array}{l}\text { Solvent(s) used for } \\
\text { the co-sensitization }\end{array}$} & \multicolumn{4}{|c|}{ Solar cell parameters } & \multirow[t]{2}{*}{ References } \\
\hline & & & & $\overline{\mathrm{V}_{\mathrm{oc}}(\mathrm{V})}$ & $\mathrm{J}_{\mathrm{sc}}\left(\mathrm{mA} / \mathrm{cm}^{2}\right)$ & $\mathrm{FF}$ & $\eta(\%)$ & \\
\hline \multirow[t]{2}{*}{40} & PZT-2 & $\begin{array}{l}\text { Dithiafulvenyl- } \\
\text { phenothiazine }\end{array}$ & $\mathrm{MeOH}, \mathrm{EtOH}$ & 0.67 & 16.37 & 0.74 & 8.12 & Luo et al. [159] \\
\hline & N719 & Bipyridyl & & & & & & \\
\hline \multirow[t]{2}{*}{41} & DBA-2 & Indole & $\mathrm{ACN}, t-\mathrm{BuOH}$ & 0.7 & 16.54 & 0.66 & 8.06 & Babu et al. [8] \\
\hline & HD-2 & Bipyridine & & & & & & \\
\hline \multirow[t]{2}{*}{42} & N1-3 & $\begin{array}{l}\text { Indole \& thiophene } \\
\text { units }\end{array}$ & $\mathrm{ACN}, t-\mathrm{BuOH}$ & 0.67 & 21.29 & 0.65 & 9.26 & Babu et al. [7] \\
\hline & HD-1 & Bipyridyl & & & & & & \\
\hline \multirow[t]{2}{*}{43} & WS-1 & Indole & $\mathrm{CHCl}_{3} / \mathrm{CH}_{3} \mathrm{OH}$ & 0.70 & 17.73 & 0.72 & 9.0 & Zhang et al. [286] \\
\hline & VG1-C8 & Squaraine & $\mathrm{ACN}, t-\mathrm{BuOH}$ & & & & & \\
\hline \multirow[t]{2}{*}{44} & LP-2 & Porphyrin & $\mathrm{EtOH} / \mathrm{THF}$ & 0.76 & 14.30 & 0.69 & 7.72 & Zhao et al. [291] \\
\hline & N719 & Bipyridyl & $\mathrm{EtOH}$ & & & & & \\
\hline \multirow[t]{2}{*}{45} & ZncTPBP & Bipyridyl & $\mathrm{ACN}, t-\mathrm{BuOH}$ & 0.73 & 9.56 & 0.69 & 4.83 & $\begin{array}{l}\text { Lodermeyer et al. } \\
\text { [158] }\end{array}$ \\
\hline & N719 & & & & & & & \\
\hline \multirow[t]{2}{*}{46} & AZ260 & Triarylamine & $\mathrm{ACN}, t-\mathrm{BuOH}$ & 0.69 & 15.4 & 0.67 & 7.22 & Su et al. [237] \\
\hline & $\mathrm{T}-\mathrm{CO}$ & & & & & & & \\
\hline \multirow[t]{4}{*}{47} & $D-205$ & Indoline & $\mathrm{ACN}, t-\mathrm{BuOH}$ & 0.74 & 7.36 & 0.66 & 3.59 & Md. Molla et al. [166] \\
\hline & D-131 & Indoline & & & & & & \\
\hline & YO-0-C8 & Porphyrin & $\mathrm{EtOH}$ & 0.88 & 8.78 & 0.68 & 5.25 & \\
\hline & Y123 & Triarylamine & & & & & & \\
\hline \multirow[t]{2}{*}{48} & T4BTD-A & Benzothiadiazole & $\mathrm{ACN}, t-\mathrm{BuOH}$ & 0.58 & 18.09 & 0.73 & 7.77 & Islam et al. [94] \\
\hline & HSQ4 & Squaraine & & & & & & \\
\hline \multirow[t]{2}{*}{49} & Dyenamoblue & $\begin{array}{l}\text { Diketopyrrolopyr- } \\
\text { role }\end{array}$ & $\mathrm{ACN}, t-\mathrm{BuOH}$ & 0.79 & 15.60 & 0.70 & 8.7 & Hao et al. [77] \\
\hline & D35 & Triarylamine & & & & & & \\
\hline \multirow[t]{2}{*}{50} & FW 1 & Porphyrin & $\mathrm{CHCl}_{3}, \mathrm{EtOH}$ & 0.75 & 18.15 & 0.71 & 9.72 & Wu et al. [254] \\
\hline & WS-5 & Indoline & & & & & & \\
\hline \multirow[t]{2}{*}{51} & RK-1 & Triarylamine & $\mathrm{MeOH}$ & 0.88 & 18.10 & 0.57 & 9.23 & $\begin{array}{l}\text { Mehmood et al. } \\
\text { [168] }\end{array}$ \\
\hline & N3 & Bipyridyl & & & & & & \\
\hline \multirow[t]{2}{*}{52} & LI-102 & $N$-alkylpyrrole & $\mathrm{ACN}, t-\mathrm{BuOH}$ & 0.71 & 16.62 & 0.63 & 7.44 & Fang et al. [54] \\
\hline & SQ2 & Squaraine & & & & & & \\
\hline \multirow[t]{2}{*}{53} & DBA-4 & Indole & $\mathrm{ACN}, t-\mathrm{BuOH}$ & 0.71 & 22.69 & 0.62 & 10.12 & Babu et al. [9] \\
\hline & NCSU-10 & Bipyridyl & & & & & & \\
\hline \multirow[t]{2}{*}{54} & XW22 & Porphyrin & $\mathrm{EtOH}$ & 0.73 & 16.42 & 0.71 & 8.60 & Pan et al. [185] \\
\hline & XW24 & Porphyrin & & & & & & \\
\hline \multirow[t]{3}{*}{55} & LD14 & Porphyrin & Toluene \& EtOH & 0.71 & 18.76 & 0.72 & 9.72 & Wang et al. [243] \\
\hline & $\mathrm{H}_{2} \mathrm{LD} 14$ & Porphyrin & & & & & & \\
\hline & AN-3 & Anthracene & & & & & & \\
\hline \multirow[t]{2}{*}{56} & SM342 & Porphyrin & THF \& EtOH & 0.94 & 17.76 & 0.77 & 12.76 & Yella et al. [268] \\
\hline & Y123 & Triarylamine & & & & & & \\
\hline 57 & TA-St-CA & Triarylamine & $\mathrm{ACN}, t-\mathrm{BuOH}$ & 0.68 & 16.22 & 0.75 & 8.27 & $\begin{array}{l}\text { Eisenmenger et al. } \\
\text { [49] }\end{array}$ \\
\hline & N719 & Bipyridyl & & & & & & \\
\hline 58 & $\mathrm{NL}-11$ & Thienopyrazine & THF, EtOH & 0.67 & 15.7 & 0.75 & 8.1 & Liyanage et al. [157] \\
\hline & D35 & Triyarylamine & & & & & & \\
\hline
\end{tabular}


Table 1 (continued)

\begin{tabular}{|c|c|c|c|c|c|c|c|c|}
\hline \multirow[t]{2}{*}{ S. no. } & \multirow{2}{*}{$\begin{array}{l}\text { Dyes/org. mol- } \\
\text { ecules used for the } \\
\text { co-sensitization }\end{array}$} & \multirow{2}{*}{$\begin{array}{l}\text { Basic structural } \\
\text { moiety/m-spacer } \\
\text { present in the } \\
\text { compound }\end{array}$} & \multirow{2}{*}{$\begin{array}{l}\text { Solvent(s) used for } \\
\text { the co-sensitization }\end{array}$} & \multicolumn{4}{|c|}{ Solar cell parameters } & \multirow[t]{2}{*}{ References } \\
\hline & & & & $\overline{\mathrm{V}_{\mathrm{oc}}(\mathrm{V})}$ & $\mathrm{J}_{\mathrm{sc}}\left(\mathrm{mA} / \mathrm{cm}^{2}\right)$ & $\mathrm{FF}$ & $\eta(\%)$ & \\
\hline \multirow[t]{2}{*}{59} & SQ2 & Squaraine & $\mathrm{ACN}, t-\mathrm{BuOH}$ & 0.67 & 10.11 & 0.63 & 4.32 & Zani et al. [281] \\
\hline & L1 & Triarylamine & & & & & & \\
\hline \multirow[t]{2}{*}{60} & DBA-8 & Indole & $\mathrm{ACN}, t-\mathrm{BuOH}$ & 0.69 & 25.14 & 0.61 & 10.68 & Babu et al. [10] \\
\hline & NCSU-10 & Bipyridyl & & & & & & \\
\hline \multirow[t]{2}{*}{61} & AFL3 & Triarylamine & $\mathrm{THF}, \mathrm{CHCl}_{3}$ & 0.74 & 13.00 & 0.67 & 6.44 & Xie et al. [257] \\
\hline & D1 & Triarylamine & & & & & & \\
\hline \multirow[t]{2}{*}{62} & NCSU-10 & Porphyrin & $\begin{array}{l}\text { ACN, } t-\mathrm{BuOH}, \\
\text { DMSO }\end{array}$ & 0.67 & 58.6 & 0.58 & 8.75 & Naik et al. [174] \\
\hline & C1-4 & Carbazole & & & & & & \\
\hline \multirow[t]{2}{*}{63} & NCSU-10 & Porphyrin & $\begin{array}{l}\text { ACN, } t-\mathrm{BuOH}, \\
\text { DMSO }\end{array}$ & 0.68 & 19.25 & 63.7 & 8.32 & Naik et al. [175] \\
\hline & $\mathrm{D}_{3}$ & Carbazole & & & & & & \\
\hline \multirow[t]{2}{*}{64} & NCSU-10 & Porphyrin & $\begin{array}{l}\text { ACN, } t-\mathrm{BuOH}, \\
\text { DMSO }\end{array}$ & 0.65 & 19.87 & 0.67 & 8.73 & Naik et al. [173] \\
\hline & $\mathrm{N}_{3}$ & Carbazole & & & & & & \\
\hline \multirow[t]{2}{*}{65} & NCSU-10 & Porphyrin & $\begin{array}{l}\text { ACN, } t-\mathrm{BuOH}, \\
\text { DMSO }\end{array}$ & 0.67 & 22.85 & 62.2 & 9.55 & Naik et al. [176] \\
\hline & S1 & Carbazole & & & & & & \\
\hline \multirow[t]{2}{*}{66} & NCSU-10 & Porphyrin & $\begin{array}{l}\text { ACN, } t-\mathrm{BuOH}, \\
\text { DMSO }\end{array}$ & 0.68 & 19.29 & 59.6 & 7.82 & Naik et al. [177] \\
\hline & E1 & Carbazole & & & & & & \\
\hline \multirow[t]{2}{*}{67} & N719 & Porphyrin & $\mathrm{MeOH}$ & 0.73 & 25.12 & 0.51 & 9.45 & $\begin{array}{l}\text { Umer Mehmood } \\
\text { et al. [169] }\end{array}$ \\
\hline & SK-1 & Diphenylamine & & & & & & \\
\hline \multirow[t]{2}{*}{68} & RDAB1 & Bipyridyl & $\mathrm{MeOH}$ & 0.74 & 13.32 & 0.72 & 7.09 & Athanas et al. [6] \\
\hline & $\mathrm{CT}$ & Carbazole & & & & & & \\
\hline \multirow[t]{2}{*}{69} & SM315 & Porphyrin & THF & 0.91 & 18.1 & 0.78 & 13 & Ding et al. [45] \\
\hline & WS-5 & Benzotriazole & & & & & & \\
\hline \multirow[t]{2}{*}{70} & KP-Zn-PZT & Porphyrin & DMF, DCM & 0.73 & 17.4 & 0.70 & 8.80 & Prakash et al. [194] \\
\hline & N719 & Porphyrin & $\mathrm{EtOH}$ & & & & & \\
\hline \multirow[t]{2}{*}{71} & $3 N$ & Pyridyl & $\mathrm{MeCN}, \mathrm{DCM}$ & 0.68 & 12.40 & 0.64 & 6.60 & Chen et al. [29] \\
\hline & AZ6 & Triphenyl & & & & & & \\
\hline \multirow[t]{2}{*}{72} & $\mathrm{JH}-1$ & Triphenyl & $\mathrm{EtOH}$ & 0.75 & 12.32 & 0.68 & 6.31 & Lee et al. [134] \\
\hline & SQ2 & Squaraine & & & & & & \\
\hline \multirow[t]{2}{*}{73} & AP3 & Thienopyrazine & THF, EtOH, DMF & 0.56 & 2.4 & 0.75 & 1.4 & $\begin{array}{l}\text { Peddapuram et al. } \\
\text { [191] }\end{array}$ \\
\hline & D35 & Triphenyalmine & & & & & & \\
\hline \multirow[t]{3}{*}{74} & T181 & Triphenylamine & $\begin{array}{c}\text { THF, acetone, } \\
t \text {-BuOH }\end{array}$ & 0.78 & 13.3 & 0.7 & 7.4 & Hilal et al. [80] \\
\hline & T202 & Triphenylamine & & 0.79 & 12.8 & 10.59 & 6.0 & \\
\hline & DB & Triphenylamine & & & & & & \\
\hline \multirow[t]{2}{*}{75} & SK6 & Porphyrin & THF, EtOH & 0.73 & 12.04 & 0.71 & 10.91 & Reddy et al. [206] \\
\hline & CW10 & Anthracene & & & & & & \\
\hline 76 & D131 & & $\mathrm{ACN}, t-\mathrm{BuOH}$ & 0.57 & 11.9 & 0.69 & 4.53 & Magne et al. [163] \\
\hline & D149 & Indoline & & & & & & \\
\hline & D206 & & & & & & & \\
\hline 77 & $\mathrm{Y} 1$ & Thiophene & $\mathrm{EtOH}$ & 0.64 & 5.33 & 0.59 & 5.98 & Salvatori et al. [215] \\
\hline & $\mathrm{Y} 2$ & Thiophene & & & & & & \\
\hline & N749 & Terpyridyl & & & & & & \\
\hline
\end{tabular}


Table 1 (continued)

\begin{tabular}{|c|c|c|c|c|c|c|c|c|}
\hline \multirow[t]{2}{*}{ S. no. } & \multirow{2}{*}{$\begin{array}{l}\text { Dyes/org. mol- } \\
\text { ecules used for the } \\
\text { co-sensitization }\end{array}$} & \multirow{2}{*}{$\begin{array}{l}\text { Basic structural } \\
\text { moiety/m-spacer } \\
\text { present in the } \\
\text { compound }\end{array}$} & \multirow{2}{*}{$\begin{array}{l}\text { Solvent(s) used for } \\
\text { the co-sensitization }\end{array}$} & \multicolumn{4}{|c|}{ Solar cell parameters } & \multirow[t]{2}{*}{ References } \\
\hline & & & & $\mathrm{V}_{\mathrm{oc}}(\mathrm{V})$ & $\mathrm{J}_{\mathrm{sc}}\left(\mathrm{mA} / \mathrm{cm}^{2}\right)$ & $\mathrm{FF}$ & $\eta(\%)$ & \\
\hline \multirow[t]{2}{*}{78} & TP3 & Phenothiazine & $\mathrm{ACN}, t-\mathrm{BuOH}$ & 0.72 & 19.18 & 0.71 & 9.84 & Hua et al. [87] \\
\hline & YR6 & Squaraine & & & & & & \\
\hline \multirow[t]{3}{*}{79} & Y1 & Thiophene & $\mathrm{ACN}, t-\mathrm{BuOH}$ & 0.60 & 17.57 & 0.70 & 7.48 & Islam et al. [95] \\
\hline & TP2A & Bodipy & & & & & & \\
\hline & HSQ4 & Squaraine & & & & & & \\
\hline \multirow[t]{3}{*}{80} & MR-3 & Terthiophene & $\begin{array}{l}\text { ACN, } t-\mathrm{BuOH}, \\
\text { DMSO }\end{array}$ & 0.71 & 21.12 & 0.60 & 9.09 & Elmorsy et al. [50] \\
\hline & MR-4 & Terthiophene & & & & & & \\
\hline & NCSU-10 & Porphyrin & & & & & & \\
\hline \multirow[t]{2}{*}{81} & $\mathrm{BD}$ & Triphenylamine & $\mathrm{ACN}, t-\mathrm{BuOH}$ & 0.66 & 12.98 & 0.60 & 5.14 & Wanwong et al. [250] \\
\hline & N719 & Porphyrin & & & & & & \\
\hline
\end{tabular}

ACN acetonitrile, $t$-BuOH tertiary-butyl alcohol, $M e O H$ methanol, EtOH ethyl alcohol, THF tetrahydrofuran, DMSO dimethyl sulfoxide, DMF dimethyl formamide, DCM, dichloromethane, NA not available

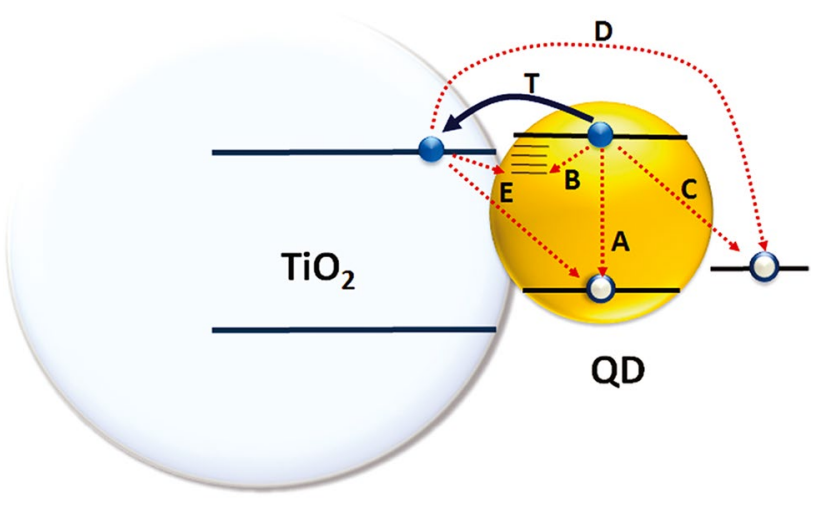

Fig. 17 Electron transport and charge recombination processes in QDSSCs. (A) Recombination of electron in the QDs conduction band and hole in the QDs valence band, (B) trapping of the exited electrons by the surface states of QDs; recombination of the hole acceptors in the electrolyte and electrons in QDs (C) or $\mathrm{TiO}_{2}(\mathrm{D}),(\mathrm{E})$ back electron injection from $\mathrm{TiO}_{2}$ to $\mathrm{QDs}$ and ( $\mathrm{T}$ ) electron injection from QDs to $\mathrm{TiO}_{2}$ crystalline. Reprinted with permission from Ref. [276] Copyright $\odot 2011$ American Chemical Society

nanoparticles surface, less photo stability have lead the usage of QDs as alternative sensitizers. Furthermore, the electron injection into the low lying valence state of $\mathrm{TiO}_{2}$ nanoparticles may recombine with oxidized dye molecules $[214,215]$. The foremost advantages of QDs compared with organic dyes lead to several applications in solar cells. Multiple exciton generation (MEG), size-dependent band-gap tuning, high molar extinction co-efficient than organic dyes etc. [289] are the important properties of QDs which excel organic/organometallic dyes. The application of QDs layers on $\mathrm{TiO}_{2}$ working electrode through FRET is a good way to reach novel architecture such as rainbow solar cells. The schematic diagram explaining about the electron transport and recombination process in QDSSCs is given in Fig. 17. The major factors affecting the efficiency of QDSSCs such as (a) light absorption intensity, (b) electron transport, (c) charge recombination rate etc. have to be managed in order to obtain the high efficiency. By coupling the suitable semiconductor (i.e., co-sensitizer) which satisfies the energy levels for the charge transfer, these problems could be rectified. Though many nanoparticles are used for the co-sensitization process, cadmium chalcogenides like CdS, CdSe and CdTe nanoparticles are delivering better performance due to their cascade energy level arrangement and visible light harvesting nature. In this, $\mathrm{TiO}_{2} / \mathrm{CdS} / \mathrm{CdSe}$ cascade like structure is more efficient in enlarging the charge separation compared with $\mathrm{TiO}_{2} /$ $\mathrm{CdS}$ and $\mathrm{TiO}_{2} / \mathrm{CdSe}$ type configurations $[275,276]$. The schematic diagram of this process is represented in Fig. 18. Due to the corrosion of QDs layer by the iodide electrolyte, which is often used in DSSCs, sulphide based electrolyte only employing for the fabrication of QDSSCs. Other than this, lithium salt based electrolyte also has produced interesting results $[105,106]$. Novel materials such as polyoxometalates, transition metal complexes also utilized for the co-sensitization in DSSCs and QDSSCs [71, 259-262, 274].

As already discussed, semiconducting nanoparticles belong to II-VI group, CdS, CdSe which are having favourable energy level for charge transfer, and also harvesting photons at two different regions are much studied for cosensitization process compared with other semiconductor nanomaterials. $\mathrm{CdS}$ has a narrow band gap $\left(\mathrm{E}_{\mathrm{g}}=2.25 \mathrm{eV}\right.$ in bulk) and absorb photons at $500 \mathrm{~nm}$ whereas the $\mathrm{CdSe}$ $\left(E_{g}=1.7 \mathrm{eV}\right.$ in bulk) harvesting photons in most of the visible part and close to NIR region. Moreover, the conduction band energy level of CdS is located above to the 


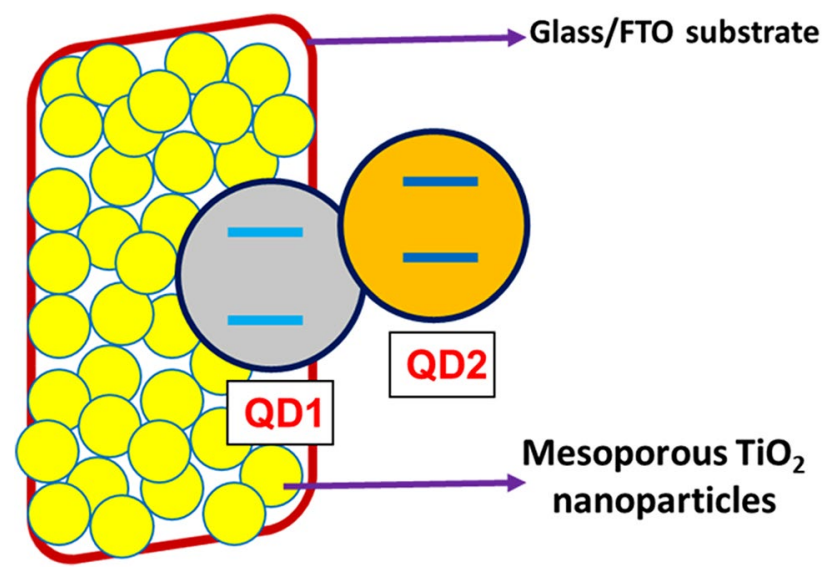

Fig. 18 Schematic diagram of co-sensitization of QDs on mesoporous $\mathrm{TiO}_{2}$ layer with favorable energy levels for charge transfer $(\mathrm{QD} 1$ = Quantum dot 1; QD2 = Quantum dot 2)

conduction band of $\mathrm{TiO}_{2}$. Hence, a systematic charge transfer is possible through the co-sensitization $\mathrm{TiO}_{2} / \mathrm{CdS} / \mathrm{CdSe}$ cascade type structure. The conduction band energy of these materials in the order of $\mathrm{TiO}_{2}>\mathrm{CdS}>\mathrm{CdSe}$ favours the charge transfer very efficiently. Co-sensitization of different sized nanoparticles of same material on the photo anode also has been reported [235]. Apart from the sensitizing by two different semiconductors, the proper alignment for charge transfer also very important criteria to improve efficiency. If the band arrangement is $\mathrm{CdS} / \mathrm{CdSe}$, such structure is called type I band alignment where as if the arrangement is $\mathrm{CdSe} / \mathrm{CdS}$, such type is called type Il band alignment. Pan et al. [186] studied the effect of deposition of presynthesized $\mathrm{CdS} / \mathrm{CdSe}$ core-shell nanostructures on the MPA treated $\mathrm{TiO}_{2}$ photoelectrode. The authors achieved about $5.32 \%$ efficiency $\left(\mathrm{V}_{\text {oc }}=527 \mathrm{mV}\right.$, $\left.\mathrm{J}_{\mathrm{sc}}=18.02 \mathrm{~mA} \mathrm{~cm}^{-2}, \mathrm{FF}=0.56\right)$. Distribution of nanoparticles on $\mathrm{TiO}_{2}$ layer during the sensitization is severely affecting the charge transport. This distribution of nanoparticles is dependent on deposition method and the essential condition includes intimate contact between the nanoparticles, avoiding aggregation on the surface etc. Important parameters affect the performance of cosensitization of QDSSCs are thickness of the deposited layer, type of mesoporous layer and annealing [109] etc. Also, recombination control is extremely essential in order to achieve efficient charge transfer process and also for high efficiency. When the mixture of mesoporous beads and nanoparticles used for the co-sensitization, improved efficiency was observed compared with nanoparticles alone due to the scattering effect [293]. Interestingly, it was found that when two different size of the same QDs of $\mathrm{CdS}$ were utilized for the co-sensitization, the efficiency was comparatively better than the individual one [27].
Selection of materials which absorbs the light at extremely two different wavelengths also one of the best way to improve the collection of solar spectrum in co-sensitization process.

To improve the QDs loading, hierarchical structures have more space compared with the other type of morphologies. Xu et al. [260] fabricated a device based on the 3D hierarchical branched $\mathrm{TiO}_{2}$ nanowires (NWs)-coated $\mathrm{TiO}_{2}$ hallow spheres (HBTHSs). The authors obtained a remarkable efficiency about $6.01 \%$ with an in situ fabricated $\mathrm{Cu}_{2} \mathrm{~S}$ based counter electrode. Yu et al. [271, 272] analysed the influence of $\mathrm{CdS} / \mathrm{CdSe}$ co-sensitization (CBD method) on hydrothermally formed $\mathrm{TiO}_{2}$ nanoflowernanorods structures on FTO substrate. About $2.31 \%$ PCE was achieved with $\mathrm{J}_{\mathrm{sc}}=13.46 \mathrm{~mA} \mathrm{~cm}^{-2}, \mathrm{~V}_{\mathrm{oc}}=0.42 \mathrm{~V}$. Here, the bottom area was covered with 1D nanorods which enhanced electron transport whereas the surface grown 3D hierarchical nanostructures enhanced the QDs absorption. Other than nanoparticles, rutile phase $\mathrm{TiO}_{2}$ nanorods could also improve the charge transport and efficiency. Advanced technique such as pulsed laser deposition (PLD) supersede over other methods in obtaining hierarchical $\mathrm{TiO}_{2}$ nanostructures. Park et al. [187] analysed the efficiency of $\mathrm{CdS} / \mathrm{CdSe}$ co-sensitized solar cell on hierarchically formed $\mathrm{TiO}_{2}$ nanospheres through pulsed layer deposition (PLD). This method could produce $\mathrm{TiO}_{2}$ nanostructures with high diffusion length of about $33 \mu \mathrm{m}$. The fabricated device was able to produce about $5.57 \%$ $\left(J_{\mathrm{sc}}=17.7 \mathrm{~mA} \mathrm{~cm}^{-2}, \mathrm{~V}_{\mathrm{oc}}=0.52 \mathrm{~V}, \mathrm{FF}=61 \%\right)$ efficiency which was about $43 \%$ higher than the device with $\mathrm{TiO}_{2}$ photoanode only (3.84\%). Due to the high electron transport over particles, vertically grown $\mathrm{TiO}_{2}$ nanorods on FTO substrate plays an important role in co-sensitization. When $\mathrm{CdSe} / \mathrm{CdS}$ co-sensitization was carried out electrochemically on the hydrothermal grown $\mathrm{TiO}_{2}$ nanowires(NWs), the efficiency was influenced by the type of $\mathrm{TiO}_{2} \mathrm{NWs}$ [203]. For example, it was observed that the smooth surface of $\mathrm{TiO}_{2} \mathrm{NWs}$ gave $3.23 \%$ efficiency whereas for the hierarchical $\mathrm{TiO}_{2} \mathrm{NWs}$, it was $4.20 \%$ efficiency ( 30\% PCE enhancement).

\subsubsection{Methods and methodologies in co-sensitization of QDs}

Co-sensitization by QDs on metal oxide photoanode is carried out by well-known methods which includes in-situ deposition, CBD, SILAR, electrochemical deposition, direct/linker assisted absorption, spray pyrolysis, polymer brush template method, electrochemical atomic layer deposition (ECALD) etc. Out of these, SILAR method is mostly exploited owing to its advantages like easy deposition process, extension from bi-layer to multilayer's deposition of QDs etc. Here, the active 
layer is made through careful deposition of QDs dispersed in a suitable solvent on the surface of the $\mathrm{TiO}_{2}$ photoelectrode. Since the maximum efficiency can be reached only at a particular cycle of deposition of QDs, meticulous tuning of the thickness of layers provide high efficiency. Increasing thickness of the layer would certainly help to harvest large amount of photons but this may retard the diffusion of electrons across the QDs layers. Moreover, solvents utilized for the co-sensitization process are essential as this also has some effect on the formation of surface traps on the nanoparticles. With suitable materials, improvement in the separation of electron-hole pairs can be observed via co-sensitization process. The first report on the co-sensitization of $\mathrm{CdS} / \mathrm{CdSe}$ nanostructures with $\mathrm{TiO}_{2}$ working electrode was achieved by Niitsoo et al. [179] through CBD approach. The authors achieved about $2.8 \%$ efficiency $\left(\mathrm{V}_{\mathrm{oc}}=660 \mathrm{mV}, \mathrm{J}_{\mathrm{sc}}=10.5 \mathrm{~mA}, \mathrm{FF}=39.5 \%\right)$ which triggered further research in this area. A dual type of methodology (Ex: both SILAR and CBD) also involved in the deposition process [213, 266]. Zhang et al. [289] analysed the influence of SILAR cycles in efficiency of $\mathrm{CdS} / \mathrm{CdSe}$ QDs co-sensitized solar cell. The authors found that the excess deposition of CdS favours the improvement in efficiency through increase of short-circuit current density $\left(J_{\mathrm{sc}}=9.72 \mathrm{~mA} \mathrm{~cm}^{-2}, \eta=2.26 \%\right)$ whereas excessive CdSe QDs reduces the photocurrent $\left(J_{\mathrm{sc}}=6.88 \mathrm{~mA} \mathrm{~cm}^{-2}\right.$, $\eta=1.59 \%)$. The number of $\mathrm{CdS}$ layers deposition through SILAR method also affect the $V_{o c}$ and other parameters of the device, for instance, it was found that more than four (4) layers of CdS through SILAR eliminates the barrier for charge transport $[283,284,286]$. In this regard, CdS nanoparticles with additives such as triethanolamine (TEA) also helping to improve the efficiency considerably [101]. The efficiency of core-shell QDSSCs also suffer due to the poor adsorption of QDs but this could be improved by optimizing the physical parameters such as $\mathrm{pH}$, temperature etc. [212]. The efficiency of layer by layer deposited CdS/CdSe QDSSC can further be improved through additional post-treatment like thermal annealing [198].

(a)
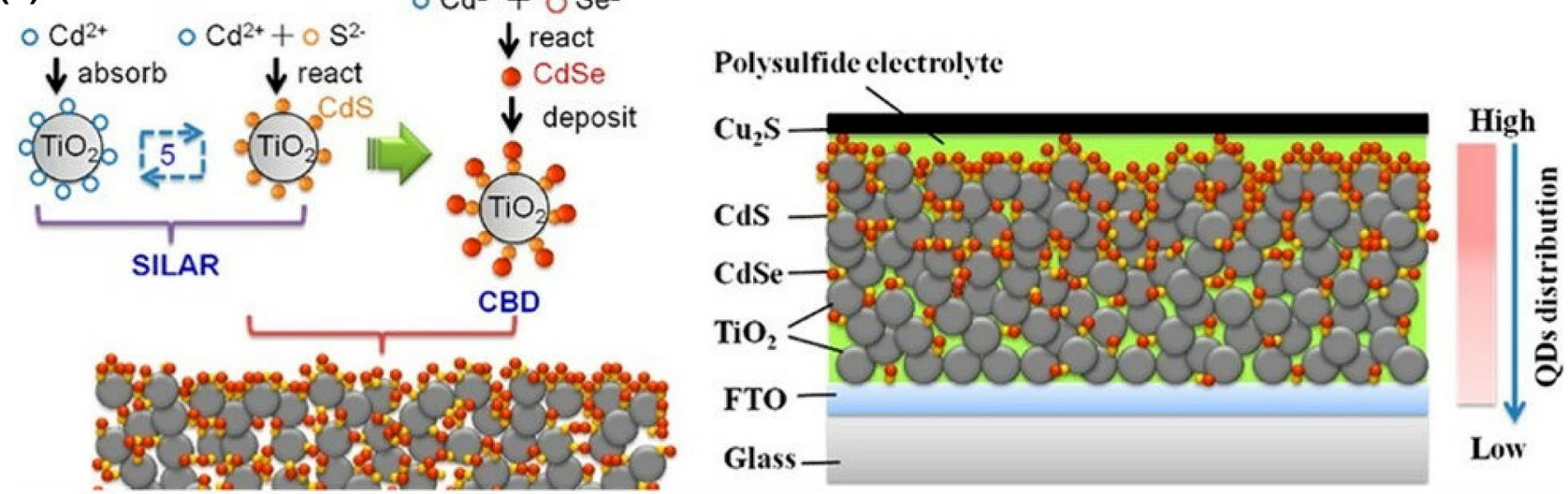

Glass -

Low

(b)

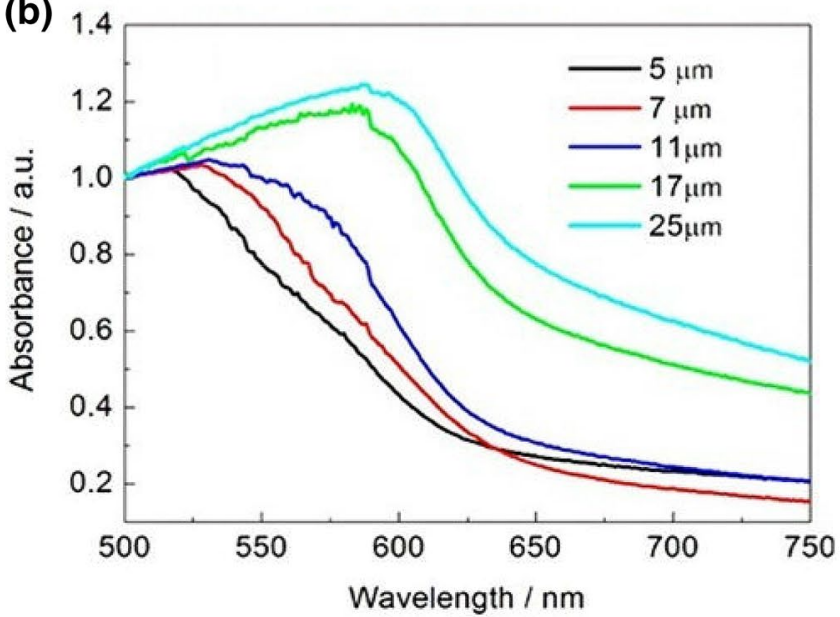

(c)

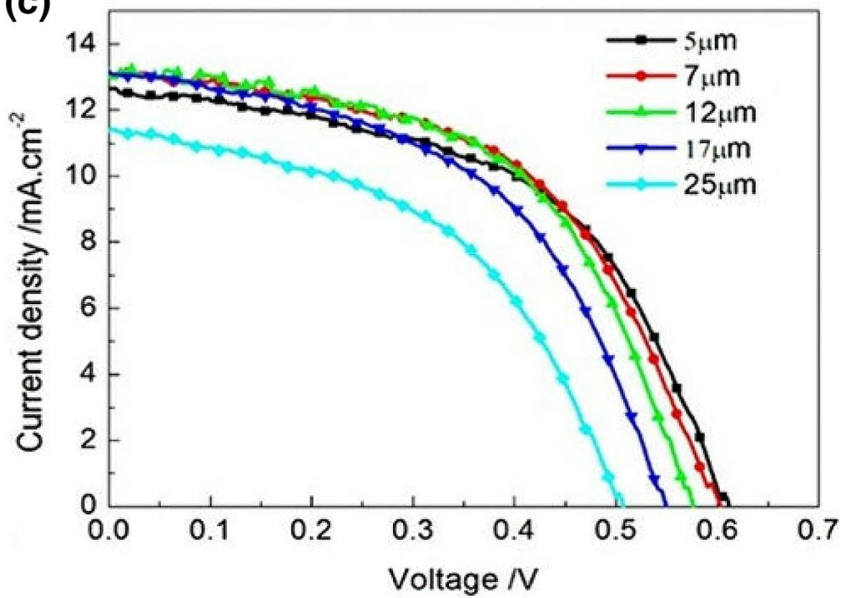

Fig. 19 a Schematic diagram of formation and distribution of QDs in a solar cell, $\mathbf{b}$ UV-visible spectra of the films with different TiO ${ }_{2}$ film thickness and $\mathbf{c} I-V$ curve of the devices with different $\mathrm{TiO}_{2}$ film thickness. Reference [241] Copyright $\odot 2012$ American Chemical Society 

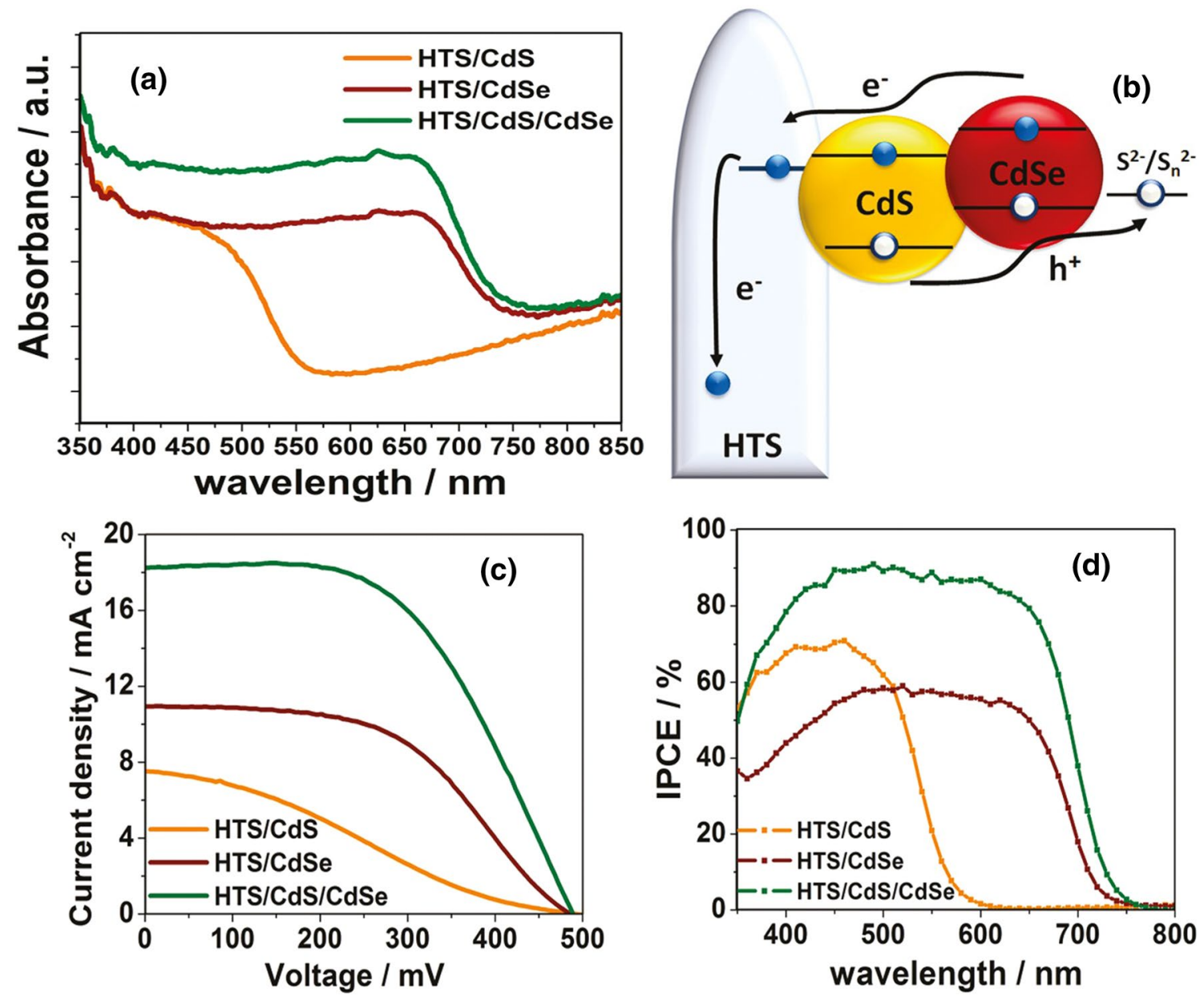

Fig. 20 a UV-Visible diffused reflectance spectra of the single sensitized and co-sensitized layers on hierarchical $\mathrm{TiO}_{2}$ sphere (HTS) $\mathbf{b}$ Schematic diagram of injection of photogenerated electron and its

transportation through HTS c I-V curve of the assembled devices d IPCE curves of the QDSSCs. Reprinted with permission from Ref. [276] Copyright $\odot 2011$ American Chemical Society

Tian et al. [241] fabricated CdS/CdSe co-sensitized solar cell with different thickness of $\mathrm{TiO}_{2}$ photoanode layer. Here, the co-sensitization was achieved by SILAR deposited CdS nanoparticles and CBD deposited CdSe nanoparticles on $\mathrm{CdS} / \mathrm{TiO}_{2}$ substrate. For the $10.3 \mu \mathrm{m}$ thickness of $\mathrm{TiO}_{2}$ film, the authors achieved about $4.62 \%$ efficiency with $\mathrm{V}_{\mathrm{oc}}=0.59 \mathrm{~V}, \mathrm{~J}_{\mathrm{sc}}=14.23 \mathrm{~mA} \mathrm{~cm}^{-2}, \mathrm{FF}=0.55$ (Fig. 19a, b, c). In case of $\mathrm{ZnO}$ photoanode, in addition to the $\mathrm{PbS}$ layer, formation of $\mathrm{TiO}_{2}$ layer around the $\mathrm{ZnO}$ core has been found as useful in improving efficiency [59]. Compared with CBD, electrodeposition of nanoparticles on $\mathrm{TiO}_{2}$ photoanode results uniform coverage. Yu et al. [276] studied the insitu electrochemically deposited $\mathrm{CdS} / \mathrm{CdSe}$ nanoparticles on hierarchical $\mathrm{TiO}_{2}$ nanoparticles for QDSSCs and achieved about $4.81 \%$ efficiency $\left(\mathrm{V}_{\mathrm{oc}}=489 \mathrm{mV}, \mathrm{J}_{\mathrm{sc}}=18.23 \mathrm{~mA} \mathrm{~cm}^{-2}, \eta=4.81 \%\right)$. The UV-visible spectra, photogenerated electron transfer, I-V and IPCE curves of this study is given in Fig. 20a, b, c, d. Recently, CdSe nanoparticles sensitized CdS

nanostructures have shown better performance in the photoelectrochemical solar hydrogen generation applications $[74,76,114]$ and hence, such interesting morphologies for solar cells would be ideal for construction of future energy devices.

\subsubsection{Role of $\mathrm{PbS}$ and CdTe nanoparticles in co-sensitization}

Lead sulphide $(\mathrm{PbS})$ nanoparticles are photosensitive to the infra-red region and when these nanoparticles are sensitized with visible light sensitizer like CdS, the efficiency could be enhanced. Due to the instability of the $\mathrm{PbS}$ nanoparticles against electrolyte, they are more vulnerable for the photoelectrochemical cell applications. But, deposition of a CdS or ZnS layer on the PbS could solve this problem. Besides, the SILAR deposition of CdS nanoparticles on $\mathrm{PbS}$ nanoparticles have been found as improving the stability of the solar cell $[17,141,142,145]$. 
Using PbS nanoparticles as under layer, the efficiency of $\mathrm{CdS} / \mathrm{CdSe}$ nanoparticles sensitization on the hydrothermally grown $\mathrm{TiO}_{2}$ nanorod arrays was observed as higher [273]. Direct incorporation of $\mathrm{Cd}^{2+}$ with $\mathrm{PbS}$ as $\mathrm{PbCdS}$ with CdS layer, doping of manganese $\left(\mathrm{Mn}^{2+}\right)$ ion also helped to improve the efficiency [116]. Punnoose et al. [196] studied about the influence of CBD and SILAR methods in the construction of $\mathrm{PbS} / \mathrm{CdS} / \mathrm{CdSe}$ structured QDSSC and found that $\mathrm{CBD}$ produced good uniform deposition of nanoparticles which provided high efficiency comparing with nanoparticles deposited by SILAR method. Same research group had also explored earlier that deposition of two insulating layers $\mathrm{MgO} / \mathrm{Al}_{2} \mathrm{O}_{3}$ on the $\mathrm{TiO}_{2}$ nanoparticle layer greatly suppresses the recombination which boost the lifetime of electrons and efficiency [197]. Upon doping with $\mathrm{Mn}^{2+}$ ion with $\mathrm{CdS}$, an impressive improved efficiency of up to $3.55 \%$ with $\mathrm{V}_{\text {oc }}$ of $0.56 \mathrm{~V}$ was observed in $\mathrm{PbS} / \mathrm{Mn}-\mathrm{CdS}$ co-sensitized solar cell [115]. Here, addition of manganese $\left(\mathrm{Mn}^{2+}\right)$ ion creates additional energy states in the host material which helped to improve the charge separation process. Recently, Zhang et al. [287] have obtained an iconic achievement of $5.11 \%$ efficiency using SILAR deposited $2 \mathrm{PbS} / \mathrm{CdS} / \mathrm{CdSe}$ on the $\mathrm{TiO}_{2}$ layer $(18 \mu \mathrm{m})$ which consisted of nanoparticles and micro particles. The authors also observed a higher value of charge recombination resistance $\left(R_{\text {rec }}\right)$ which clearly show the reduction of recombination of photoelectrons at the interface. Solubility product value of binary semiconductor plays a key role in the deposition and ion exchange of core-shell type nanomaterials. For example, during the deposition of $\mathrm{TiO}_{2} / \mathrm{PbS} / \mathrm{CdS}$, due to the close values of solubility product of PbS $\left(1 \times 10^{-28}\right)$ and $\mathrm{CdS}\left(8 \times 10^{-27}\right)$, a blue shift in the absorption spectra was observed after deposition of $\mathrm{CdS}$ layer $[159,162]$. This blue shift was attributed due to the cation exchange process which was absent in the materials with extremely different solubility product values. Instead of PbS nanoparticles, when less toxic materials like $\mathrm{Bi}_{2} \mathrm{~S}_{3}$ nanoparticles are co-sensitized with $\mathrm{CdS}$ nanoparticles, about $4.26 \%$ was achieved through the $\mathrm{TiO}_{2} / \mathrm{Bi}_{2} \mathrm{~S}_{3} /$ $\mathrm{CdS} / \mathrm{Au}$ nanorods $\left(0.51 \mathrm{~cm}^{2}\right)$ device configuration [238]. Similarly, co-sensitization of $\mathrm{Ag}_{2} \mathrm{~S} \mathrm{Bi}_{2} \mathrm{~S}_{3}$ nanoparticles on vertically grown $\mathrm{TiO}_{2}$ nanorods produced high efficiency with good $\mathrm{J}_{\mathrm{sc}}$ value [32]. Similar kind of $\mathrm{TiO}_{2}$ nanorods were also used for the co-sensitization of $\mathrm{Bi}_{2} \mathrm{~S}_{3} / \mathrm{Sb}_{2} \mathrm{~S}_{3}$ deposited through ECALD method but they had produced a very less efficiency [143].

When cadmium telluride nanoparticles ( $\mathrm{CdTe}$, band gap: $1.5 \mathrm{eV}$ in bulk form) are used as the sensitizer along with CdS shell, a type II band alignment is created and hence this is more interesting in charge-transfer point of view. With the wet chemically synthesized ligand capped
CdTe nanoparticles, a maximum efficiency of $3.8 \%$ was achieved [275]. This was further enhanced by Sahasrabudhe and Bhattacharyya [212] to $6.41 \%$ by inserting an additional quasi-shell of $\mathrm{CdS}$ in the device structure. Here, the quasi-shell of $\mathrm{CdS}$ passivate the trap states of core $\mathrm{CdTe}$ nanoparticles as well as $\mathrm{TiO}_{2}$ which reduces the recombination. Through improved QDs loading on the $\mathrm{TiO}_{2}$ photoanode surface and optimizing its thickness, this was further improved as $6.76 \%[245,249]$. With the optimization of alloyed $\mathrm{CdSe}_{x} \mathrm{~S}_{1-x}$ nanoparticles layer thickness, a type II configuration of $\mathrm{CdTe} / \mathrm{CdSe}_{x} \mathrm{~S}_{1-x}$ QDs resulted $7.24 \%$ of efficiency which is the highest one [264] in comparing with the $\mathrm{CdSe} \mathrm{Te}_{1-x}-\mathrm{CdS}$ sensitized solar cells [160]. Surprisingly, if the CdTe is replaced by the wide bandgap ZnTe, due to the large conduction band offset, an impressive value of $7.17 \%$ efficiency was achieved [103]. These results clearly show that further optimization of composition and thickness of the layers would lead to impressive results.

\subsubsection{Role of non- $\mathrm{TiO}_{2}$ photoanodes in co-sensitization of QDs}

Other than $\mathrm{TiO}_{2}$ photo electrodes, co-sensitization has also been successively achieved using $\mathrm{Zn}_{2} \mathrm{SnO}_{4}$ [117], different nanostructures of $\mathrm{ZnO}$ such as nanorods [154, 204], nanoballs [205], NWs [28, 221] and nanoporous film [98], ceria $\left(\mathrm{CeO}_{2}\right)$ nanoparticles [217] and $\mathrm{SnO}_{2}$ based electrodes sensitization by QDs [85, 255]. Due to the enhanced charge transport of carriers over other morphologies, hierarchical structures of $\mathrm{ZnO}$ improved the charge transport and further modification by the chalcogenide nanoparticles was found to enhance the efficiency [152]. A combination of different hierarchical morphologies of $\mathrm{TiO}_{2}$ and $\mathrm{ZnO}$ could also serve as excellent photoanode [21]. Through the $\mathrm{SnO}_{2}$ inverse opal structure as photoelectrode, the efficiency was reached about $4.37 \%$ with $\mathrm{V}_{\mathrm{oc}}=700 \mathrm{mV}$ by co-sensitization. Also, the hierarchical nanosheets-micro flowers of $\mathrm{SnO}_{2} / \mathrm{ZnO}$ and $\mathrm{SnO}_{2}$ nanosheets/ $/ \mathrm{TiO}_{2}$ nanocomposites also perform much better than the nanoparticles morphology in improving the performance of CdS/CdSe QDSSCs [26, 31, 153]. The higher recombination resistance, faster charge transport, and more efficient charge separation properties of $\mathrm{SnO}_{2}$ nanostructures are assuring the promising avenue in future solar cell architectures [85]. Other tin compound like SnS, whose energy level is favorable with $\mathrm{CdS}$ and $\mathrm{TiO}_{2}$ to transfer the electrons, also used for the co-sensitization to extend the photon absorption [256]. $\mathrm{Li}$ et al. [140] who utilized Ag nanoparticles co-sensitized with $\mathrm{SnO}_{2}$ nanoparticles on $\mathrm{TiO}_{2}$ photoanode for 
the protection of stainless steel from corrosion further strengthen additional hope on $\mathrm{SnO}_{2}$ nanostructures. Therefore, future analysis on $\mathrm{SnO}_{2}$ nanostructures would reveal many interesting results in constructing high performance devices.

In addition to $\mathrm{TiO}_{2}$, using $\mathrm{ZnO}$ nanorods as photoelectrode, improvement in $\mathrm{J}_{\mathrm{sc}}$ was observed in $\mathrm{CdSe} / \mathrm{CdS} /$ $\mathrm{PbS}$ nanoparticles structure due to the improved photon harvesting capability of PbS nanoparticles [200]. When a compact $\mathrm{TiO}_{2}$ layer was deposited on $\mathrm{ZnO}$ nanorods, considerable enhancement in efficiency was observed [118]. Later, it was also observed that treatment on $\mathrm{ZnO}$ nanoflowers by strong base like ammonia still enhances the efficiency [119]. Moreover, it is known that different morphologies of $\mathrm{ZnO}$ photoanode greatly influence on the performance of a solar cell. Therefore, in addition to developing materials, strategies for co-sensitization, extremely favourable morphology is needed for the effective QDs adsorption. Co-sensitization of $\mathrm{CdS} / \mathrm{CdSe}$ nanoparticles on the aluminium (Al) doped $\mathrm{ZnO}$ nanoparticles also found as interesting method to improve the efficiency [42]. It has been found that compared with the nanorods, bundle-like $\mathrm{ZnO}$ nanorods improve the efficiency considerable extent due to the improvement in QDs loading [233]. Li et al. [141] developed a macroporous $\mathrm{ZnSO}_{4}-\mathrm{ZnO}$ nanorod composite photoanode on FTO substrate by hydrothermal method for the effective QDs loading. Here, the CdS/CdSe QDs cosensitization was achieved through electrodeposition and the authors attained about $2.01 \%$ efficiency for the $9 \mu \mathrm{m}$ thickness of $\mathrm{ZnSO}_{4}-\mathrm{ZnO}$ layer. A similar kind approach of core-shell type $\mathrm{ZnO}$ nanorods $/ \mathrm{TiO}_{2}$ structure as photoanode also helped to improve charge transport considerably [59]. This ascertain that growing one-dimensional nanostructures on photoanode would be a new approach for effective co-sensitization. Tri-sensitization of nanoparticles has also shown promising results. It means that because of low temperature process of depositing (ex: CBD, SILAR) nanoparticles on photoanode, the nanoparticles are consisted of large number of surface defects. Ultimately, due to these surface defects, the electrons are quenched and decrease of efficiency results even after careful fabrication. Additional layer(s) of another binary (or) ternary semiconductor nanoparticles with suitable bandgap around the deposited nanoparticles could minimize this issue and improve the charge transport. Here, during the deposition of this additional layer, the dangling bonds present on the surface of the nanoparticles are covered by the shell and hence the recombination is prohibited. Furthermore, this additional layer could transfer the holes and electrons into their respective electrodes without loss. The influence of ligands and additional layer around the core of the nanoparticles affects the optical properties as well as electrical properties considerably [37].

\subsubsection{Role of ZnS layer in co-sensitization of QDs}

Like $\mathrm{ZnO}$, zinc sulphide ( $\mathrm{ZnS}$ ), a wide bandgap material (bulk band gap: $3.54 \mathrm{eV}$ ) also a suitable candidate for the passivation of QDs layer. Addition of ZnS layer has already proven as effectively retarding the recombination process in QDSSCs [138]. By depositing the ZnS layer on the CdSe nanoplatelets layer, accumulation of holes in the valence band of $\mathrm{ZnS}$ raised the $\mathrm{V}_{\text {oc }}$ of solar cell due to the formation of type-II band alignment [161]. Lee et al. analysed the deposition of $\mathrm{ZnS}$ layer on the $\mathrm{CdS} / \mathrm{CdSe}$ layer in $\mathrm{TiO}_{2}$ photoelectrode. The authors found that the deposition of ZnS improves $\mathrm{J}_{\mathrm{sc}}$ as well as efficiency [135]. Also, compared with $\mathrm{CdS} / \mathrm{CdSe}$ system, $\mathrm{ZnS}$ has more negative conductive band edge $\left(\mathrm{E}_{\mathrm{cb}}\right)$ which prevent the electron transfer to electrolyte [88]. Compared with aqueous solution, when $\mathrm{ZnS}$ is deposited in alcoholic solution (here methanol), improvement in the efficiency is observed due to the more diffusion of $\mathrm{Zn}^{2+}$ ion into the mesoporous $\mathrm{TiO}_{2}$ electrode [223]. Counter electrode also playing important role in the transport of hole from redox electrolyte. Various counter electrodes are used for QDSSCs instead of Pt electrode. Among others, copper chalcogenides having prominent place owing to their high electrocatalytic behaviour. With the $\mathrm{Cu}_{2} \mathrm{~S}$ counter electrode, a recent report describing that the hierarchical nanostructure of $\mathrm{TiO}_{2}$ photoelectrode delivered about $3.46 \%$ efficiency through co-sensitization of $\mathrm{CdS} / \mathrm{CdSe} / \mathrm{ZnS}$ nanoparticles [19]. The authors also concluded that increasing porosity of the film by the addition of ethyl cellulose as the binder would help for the uniform distribution of QDs. A recent analysis by Zhang et al. [288] showing that modification in the CuS counter electrode by depositing PbS film significantly influences on the co-sensitization effect. Such kind of attempts will still improve the performance to higher level in near future. Improvement in stability of solar cell was also observed with the $\mathrm{PbS} / \mathrm{CdS} / \mathrm{ZnS}$ tri layer deposition [135]. A ZnS overlayer of $\mathrm{PbS} / 3 \mathrm{CdS}$ nanoparticles sensitization resulted about $5.7 \%$ efficiency [165]. It is because, $\mathrm{ZnS}$ nanoparticles not only serve as the passivating layer, but also functioning as larger electron injection driving force [161].

Choi et al. [35] studied the influence of mode of electrophoretic sequential deposition of $\mathrm{CdS}$ and $\mathrm{CdSe}$ NWs on $\mathrm{TiO}_{2}$ electrode. The authors have found that CdS NWs/ CdSe NWs structure delivered more efficiency (1.08\%) than CdSe NWs/CdS NWs (0.36\%) for the optimized thickness. This kind of thickness dependent efficiency has also been observed in the CdSe nanoplatelets/ZnS layer sensitized solar cell recently [161]. Approache like insertion of reduced graphene oxide (RGO) with photoanode component can considerably enhance the efficiency through $\mathrm{CdS} / \mathrm{CdSe}$ co-sensitization [61]. 


\subsubsection{Role of ZnSe layer in co-sensitization of QDs}

Other than ZnS, Zinc selenide (ZnSe, bandgap: $2.7 \mathrm{eV}$ ) could also serve as good passivation layer for the $\mathrm{CdS} /$ $\mathrm{CdSe}$ system owing to its higher energy level of $\mathrm{E}_{\mathrm{cb}}$ and $E_{\mathrm{vb}}$. A comparative experimental analysis by Huang et al. between $\mathrm{ZnS}$ and $\mathrm{ZnSe}$ as passivation layer also clearly revealed that compared with $\mathrm{CdS} / \mathrm{CdSe}$ nanoparticles, ZnSe possesses more negative minimum conduction band edge $\left(E_{c b}\right)$ but has less positive maximum valence band edge $\left(\mathrm{E}_{\mathrm{vb}}\right)$ [88]. Here the authors used three (3) SILAR cycle deposited $\mathrm{ZnSe}$ layer with nanostructured $\mathrm{Cu}_{2} \mathrm{~S}$ as the counter electrode to construct the QDSSC. This $\mathrm{ZnSe}$ layer helping to avoid back transfer of electrons and facilitates the hole transfer to the electrolyte. Through this, the authors achieved $6.39 \%$ of efficiency using $\mathrm{ZnSe}$ as passivation layer which was higher than the efficiency of the device using ZnS passivation layer (4.91\%). Therefore, it can be concluded that compared with ZnS, passivating activity of $\mathrm{ZnSe}$ show better performance. When two passivation layers of $\mathrm{ZnSe}$ nanoparticles, i.e., around the CdS/ $\mathrm{CdSe}$ nanoparticles and around the $\mathrm{TiO}_{2}$ layer are deposited, the efficiency was found as still higher. Huang et al. adopted this idea and the authors were able to obtain $7.24 \%$ efficiency and this enhanced efficiency was attributed due to the reduced surface recombination [88].

\subsubsection{Use of ternary nanoparticles in co-sensitization}

Other than binary nanoparticles, co-sensitization has also been attempted with ternary nanoparticles to harvest photons in the visible region. The band energy values of $\mathrm{PbS}$ is favorable to transfer of electrons from the $\mathrm{CulnS}_{2}$ and hence improving the efficiency. With the optimization of number of cycles of SILAR deposition, Peng et al. [190] obtained $2.93 \%$ of efficiency with the $\mathrm{TiO}_{2} / 3 \mathrm{PbS} / 4 \mathrm{CulnS} \mathrm{S}_{2}$ nanoparticles based solar cell. Wang et al. fabricated SILAR and CBD methods based QDSSC having the architecture of $\mathrm{FTO} / \mathrm{TiO}_{2} / \mathrm{CulnS}_{2} \mathrm{QDs} / \mathrm{In}_{2} \mathrm{~S}_{3} /$ Electrolyte $/ \mathrm{Cu}_{2} \mathrm{~S} / \mathrm{FTO}$ and achieved $1.62 \%$ efficiency with $\mathrm{J}_{\mathrm{sc}}=6.49 \mathrm{~mA} \mathrm{~cm}{ }^{-2}$, $\mathrm{V}_{\text {oc }}=0.50 \mathrm{~V}, \mathrm{FF}=0.50$ [249]. When visible light harvesting compound like CulnS ${ }_{2}$ is coupled with the near infrared semiconductor like PbS, careful attention should be paid on their band alignment. Peng et al. [190] observed that when the device structure was $\mathrm{TiO}_{2} / 3 \mathrm{CulnS}_{2} / \mathrm{PbS}$, the efficiency was $0.74 \%$ only whereas when the device structure was $\mathrm{TiO}_{2} / 3 \mathrm{PbS} / \mathrm{CulnS}_{2}$, the efficiency reached $2.78 \%$. Due to the low band energy level of $\mathrm{PbS}$ compared with $\mathrm{CulnS}_{2}$, transfer of electrons was not possible in the former case whereas it was greatly enhanced in the latter case. The authors further optimized the condition and $\mathrm{TiO}_{2} / 3 \mathrm{PbS} / 4 \mathrm{CulnS} \mathrm{S}_{2}$ device structure showed $2.93 \%$ efficiency. These results clearly predict that ternary and quaternary nanoparticles are also suitable to co-sensitization process if appropriate methods are adopted. These results have also given a strong hope on the emergence of co-sensitization as a good method to reach the high efficiency solar cells. The effect of co-sensitization between two QDs through various methods and their influence in the efficiency of solar cells is given in Table 2 .

\subsubsection{Co-sensitization by quantumdots on $\mathrm{TiO}_{2}$ nanotube array photoelectrode}

Co-sensitization on $\mathrm{TiO}_{2}$ nanotubes by $\mathrm{QDs}$ is very advantageous due to the vertical oriented electron transport nature. Moreover, compared with mesoporous layer, the incorporation of metal chalcogenide nanoparticles with $\mathrm{TiO}_{2}$ structure can be enhanced when tubular like structure is used. For the preparation of $\mathrm{TiO}_{2}$ nanotubes, mostly electrochemical anodization is employed due to its versatility over other methods and produces long length, vertically oriented, highly ordered $\mathrm{TiO}_{2}$ nanotubes. During the sensitization of $\mathrm{TiO}_{2}$ nanotubes by semiconductor nanoparticles, ligands present in the QDs attach on the surface of nanotubes and form a direct contact (Fig. 21). If it is a short chain ligand, the charge transport is greatly enhanced whereas the charge transport is suppressed for the longer chain ligands. Sensitization of $\mathrm{TiO}_{2}$ nanotubes and other hierarchical structures by inorganic semiconductor nanoparticles are widely studied for the photocatalytic applications $[23,182,246,247,270]$. But, in recent years there are considerable research also focused for the solar cell applications. The detailed literature analysis of co-sensitization of QDs on $\mathrm{TiO}_{2}$ nanotubes for efficient solar cells can be found in our previous article [5]. For the effective sensitization, many parameters to be optimized such as nature of ligand on the nanoparticles, diameter of the pores of $\mathrm{TiO}_{2}$ nanotubes, solvent medium, method used for the co-sensitization etc. Over time co-sensitization of the nanoparticles on $\mathrm{TiO}_{2}$ nanotubes also make a great problem which resulted nanoparticles layer with high thickness. Methods such as CBD [60], SILAR [294] and combination of these two methods [130] were mostly followed to co-sensitize the $\mathrm{TiO}_{2}$ nanotubes. In these two methods, the nanoparticles are mostly deposited by in situ process. Advanced method like atomic layer deposition (ALD) has also proven as promising approach for co-sensitization of $\mathrm{TiO}_{2}$ nanotubes [282]. When $\mathrm{ZnS}$ barrier layer was deposited over the $\mathrm{CdS} / \mathrm{CdSe}$ nanostructures, impressive efficiency was achieved under standard conditions $\left(\mathrm{V}_{\mathrm{oc}}=0.52 \mathrm{~V}_{,} \mathrm{J}_{\mathrm{sc}}=17.59 \mathrm{~mA} \mathrm{~cm}^{-2}, \mathrm{FF}=59.82, \eta=4.56 \%\right)$. Moreover, IPCE of about $72 \%$ was achieved through sequential assisted chemical bath deposition of $\mathrm{ZnS}$ layer on CdS/CdSe nanostructures [147]. The cascade type of $\mathrm{TiO}_{2} / \mathrm{CdS} / \mathrm{CdSe}$ arrangement boosts higher efficiency over 
Table 2 Co-sensitization using different QDs discussed in this review and their solar cell performance with other parameters

\begin{tabular}{|c|c|c|c|c|c|c|c|c|}
\hline \multirow[t]{2}{*}{ S. no. } & \multirow{2}{*}{$\begin{array}{l}\text { Co-sensitized quantum } \\
\text { dots (QDs) device layers } \\
\text { between photocathode and } \\
\text { photoanodes }\end{array}$} & \multirow{2}{*}{$\begin{array}{l}\text { Method of synthesis/depo- } \\
\text { sition of QDs }\end{array}$} & \multirow[t]{2}{*}{ Electrolyte } & \multicolumn{4}{|c|}{ Solar cell parameters } & \multirow[t]{2}{*}{ References } \\
\hline & & & & $\mathrm{V}_{\mathrm{oc}}(\mathrm{V})$ & $\mathrm{J}_{\mathrm{sc}}$ & $\mathrm{FF}$ & $\eta(\%)$ & \\
\hline \multirow[t]{2}{*}{1} & $\mathrm{SnO}_{2} / \mathrm{CdS} / \mathrm{CdSe} / \mathrm{E} / \mathrm{Cu}_{2} \mathrm{~S}$ & SILAR & Polysulphide & 0.47 & 17.40 & 0.44 & 3.68 & Hossain et al. [85] \\
\hline & $\mathrm{TiO}_{2} / \mathrm{CdS} / \mathrm{CdSe} / \mathrm{E} / \mathrm{Cu}_{2} \mathrm{~S}$ & & & 0.53 & 13.17 & 0.55 & 3.88 & \\
\hline 2 & $\mathrm{TiO}_{2} / \mathrm{CdS} / \mathrm{CdSe} / \mathrm{E} / \mathrm{Cu}_{2} \mathrm{~S}$ & SILAR and spray pyrolysis & Polysulphide & 0.6 & 11.69 & 0.44 & 3.18 & Salaramoli et al. [213] \\
\hline \multirow[t]{2}{*}{3} & $\mathrm{TiO}_{2} / \mathrm{CdS} / \mathrm{CdSe} / \mathrm{E} / \mathrm{PbS}$ & SILAR & Polysulphide & 0.52 & 12.6 & 0.58 & 3.84 & Park et al. [187] \\
\hline & $\mathrm{TiO}_{2}(\mathrm{PLD}) / \mathrm{CdS} / \mathrm{CdSe} / \mathrm{E} / \mathrm{PbS}$ & & & 0.54 & 16.8 & 0.60 & 5.43 & \\
\hline 4 & $\mathrm{TiO}_{2} / \mathrm{CdS} / \mathrm{CdSe} / \mathrm{E} / \mathrm{Pt}$ & Electrodeposition & Polysulphide & 0.48 & 18.23 & 0.54 & 4.81 & Yu et al. [276] \\
\hline 5 & $\mathrm{TiO}_{2} / \mathrm{PbS} / \mathrm{CdSe} / \mathrm{E} / \mathrm{Pt}$ & SILAR & Polysulphide & 0.47 & 10.40 & 0.27 & 1.30 & Li et al. [145] \\
\hline 6 & $\mathrm{TiO}_{2} / \mathrm{CdS} / \mathrm{CdSe} / \mathrm{ZnS} / \mathrm{E} / \mathrm{Cu}_{2} \mathrm{~S}$ & Immobilization & Polysulphide & 0.52 & 18.02 & 0.56 & 5.32 & Pan et al. [186] \\
\hline 7 & $\mathrm{TiO}_{2} / \mathrm{CdS} / \mathrm{CdSe} / \mathrm{ZnS} / \mathrm{E} / \mathrm{Pt}$ & SILAR & Polysulphide & 0.48 & 13.52 & 0.53 & 3.44 & Lee et al. [135] \\
\hline 8 & $\mathrm{TiO}_{2} / \mathrm{CdS} / \mathrm{CdSe} / \mathrm{ZnS} / \mathrm{E} / \mathrm{Cu}_{2} \mathrm{~S}$ & SILAR \& CBD & Polysulphide & 0.58 & 15.14 & 0.53 & 4.65 & Zhou et al. [293] \\
\hline 9 & $\mathrm{TiO}_{2} / \mathrm{CdS} / \mathrm{CdSe} / \mathrm{E} / \mathrm{Pt}$ & SILAR & Polysulphide & 0.49 & 9.72 & 0.47 & 2.26 & Zhang et al. [289] \\
\hline 10 & $\mathrm{TiO}_{2} / \mathrm{CdS} / \mathrm{CdSe} / \mathrm{E} / \mathrm{Pt}$ & SILAR & Polysulphide & 0.45 & 13.46 & 0.34 & 2.15 & Jung et al. [109] \\
\hline 11 & $\mathrm{TiO}_{2} / \mathrm{CdS} / \mathrm{CdSe} / \mathrm{E} / \mathrm{Cu}_{2} \mathrm{~S}$ & SILAR, CBD & Polysulphide & 0.59 & 14.23 & 0.55 & 4.62 & Tian et al. [241] \\
\hline 12 & $\mathrm{TiO}_{2} / \mathrm{CdS} / \mathrm{CdSe} / \mathrm{E} / \mathrm{Pt}$ & Electrodeposition & Polysulphide & 0.46 & 17.98 & 0.50 & 4.20 & Rao et al. [203] \\
\hline 13 & $\mathrm{TiO}_{2} / \mathrm{CdS} / \mathrm{CdSe} / \mathrm{E} / \mathrm{Pt}$ & SILAR & Polysulphide & 0.45 & 15.75 & 40.5 & 2.92 & Qiao et al. [198] \\
\hline 14 & $\mathrm{TiO}_{2} / \mathrm{CdS} / \mathrm{CdSe} / \mathrm{E} / \mathrm{Pt}$ & CBD & Polysulphide & 0.42 & 13.46 & 0.41 & 2.31 & Yu et al. [272] \\
\hline 15 & $\mathrm{TiO}_{2} / \mathrm{PbS} / \mathrm{CdS} / \mathrm{E} / \mathrm{Cu}_{2} \mathrm{~S}$ & SILAR \& CBD & Polysulphide & 0.44 & 18.84 & 0.45 & 3.82 & Zhou et al. [292] \\
\hline 16 & $\mathrm{TiO}_{2} / \mathrm{CdS} / \mathrm{CdSe} / \mathrm{E} / \mathrm{Cu}_{2} \mathrm{~S}$ & Electrodeposition & Polysulphide & 0.53 & 19.32 & 0.58 & 6.01 & Xu et al. [260] \\
\hline 17 & $\mathrm{TiO}_{2} / \mathrm{CulnS}_{2} / \mathrm{In}_{2} \mathrm{~S}_{3} / \mathrm{E} / \mathrm{Cu}_{2} \mathrm{~S}$ & CBD & Polysulphide & 0.50 & 6.49 & 0.50 & 1.62 & Wang et al. [249] \\
\hline 18 & $\mathrm{TiO}_{2} / \mathrm{CdTe} / \mathrm{CdS} / \mathrm{CdS} / \mathrm{E} / \mathrm{Cu}_{2} \mathrm{~S}$ & Dipping, SILAR & Polysulphide & 0.61 & 20.19 & 0.51 & 6.32 & $\begin{array}{l}\text { Sahasrabudhe and Bhat- } \\
\text { tacharyya [212] }\end{array}$ \\
\hline 19 & $\mathrm{TiO}_{2} / \mathrm{PbS} / \mathrm{CdSe} / \mathrm{E} / \mathrm{Pt}$ & SILAR & Polysulphide & 0.47 & 10.40 & 0.27 & 1.30 & Li et al. [145] \\
\hline 20 & $\mathrm{TiO}_{2} / \mathrm{Bi}_{2} \mathrm{~S}_{3} / \mathrm{Sb}_{2} \mathrm{~S}_{3} / \mathrm{E} / \mathrm{Pt}$ & ECALD & Polysulphide & 0.35 & 4.83 & 0.40 & 0.67 & Li et al. [143] \\
\hline 21 & $\mathrm{TiO}_{2} / \mathrm{PbS} / \mathrm{CdS} / \mathrm{CdSe} / \mathrm{E} / \mathrm{Cu}_{2} \mathrm{~S}$ & SILAR & Polysulphide & 0.43 & 14.18 & 0.42 & 2.56 & Yu et al. [273] \\
\hline 22 & $\mathrm{TiO}_{2} / \mathrm{CdS} / \mathrm{CdSe} / \mathrm{ZnS} / \mathrm{E} / \mathrm{Pt}$ & SILAR & Polysulphide & 0.68 & 7.12 & 0.71 & 3.46 & Buatong et al. [19] \\
\hline 23 & $\begin{array}{l}\mathrm{TiO}_{2} / \mathrm{PbS} / \mathrm{CulnS}_{2} / \mathrm{ZnS} / \mathrm{E} / \\
\mathrm{Cu}_{2} \mathrm{~S}\end{array}$ & SILAR & Polysulphide & 0.53 & 14.56 & 37.9 & 2.93 & Peng et al. [190] \\
\hline 24 & $\mathrm{TiO}_{2} / \mathrm{PbS} / \mathrm{CdS} / \mathrm{ZnS} / \mathrm{E} / \mathrm{Cu}_{2} \mathrm{~S}$ & SILAR & Polysulphide & 0.50 & 22.8 & 50.2 & 5.7 & $\begin{array}{l}\text { Manjceevan and Bandara } \\
\text { [165] }\end{array}$ \\
\hline 25 & $\mathrm{TiO}_{2} / \mathrm{Bi}_{2} \mathrm{~S}_{3} / \mathrm{CdS} / \mathrm{Au} / \mathrm{MWCNTs}$ & SILAR & $\mathrm{Na}_{2} \mathrm{~S}$ solution & 0.81 & 13.5 & 0.39 & 4.26 & Subramanyam et al. [238] \\
\hline 26 & $\mathrm{TiO}_{2} / \mathrm{PbS} / \mathrm{CdS} / \mathrm{CdSe} / \mathrm{E} / \mathrm{CuS}$ & CBD & Polysulphide & 0.59 & 14.78 & 0.55 & 4.58 & Punnoose et al. [196] \\
\hline \multirow[t]{2}{*}{27} & $\mathrm{TiO}_{2} / \mathrm{CdS} / \mathrm{CdSe} / \mathrm{ZnS} / \mathrm{E} / \mathrm{Pt}$ & CBD, SILAR & Polysulphide & 0.55 & 15.71 & 0.57 & 4.91 & Huang et al. [88] \\
\hline & $\mathrm{TiO}_{2} / \mathrm{CdS} / \mathrm{CdSe} / \mathrm{ZnSe} / \mathrm{E} / \mathrm{Pt}$ & & & 0.58 & 20.11 & 0.55 & 6.39 & \\
\hline 28 & $\mathrm{TiO}_{2} / \mathrm{Bi}_{2} \mathrm{~S}_{3} / \mathrm{PbS} / \mathrm{E} / \mathrm{Pt}$ & Hydrothermal, SILAR & Polysulphide & 0.72 & 4.70 & 0.33 & 1.13 & Cai et al. [20] \\
\hline 29 & $\begin{array}{l}\mathrm{TiO}_{2} / \mathrm{CdS} / \mathrm{CdSe} / \mathrm{ZnS} / \mathrm{E} / \mathrm{Pb} / \\
\mathrm{PbS}\end{array}$ & SILAR, CBD & Polysulphide & 0.50 & 18.47 & 0.64 & 5.94 & Zhang et al. [283] \\
\hline 30 & $\mathrm{TiO}_{2} / \mathrm{CdS} / \mathrm{CdSe} / \mathrm{ZnS} / \mathrm{E} / \mathrm{CuS}$ & SILAR, CBD & Polysulphide & 0.59 & 14.42 & 0.55 & 4.68 & Jiang et al. [101] \\
\hline 31 & $\mathrm{TiO}_{2} / \mathrm{ZnO} / \mathrm{CdS} / \mathrm{CdSe} / \mathrm{E} / \mathrm{Cu}_{2} \mathrm{~S}$ & Electrodeposition & Polysulphide & 0.53 & 17.15 & 0.46 & 4.21 & Cao et al. [21] \\
\hline 32 & $\mathrm{TiO}_{2} / \mathrm{CdTe} / \mathrm{CdSe} / \mathrm{ZnS} / \mathrm{E} / \mathrm{Cu}_{2} \mathrm{~S}$ & SILAR & Polysulphide & 0.60 & 19.59 & 0.56 & 6.76 & Wang et al. [245] \\
\hline 33 & $\mathrm{TiO}_{2} / \mathrm{CdS} / \mathrm{CdTe} / \mathrm{E} / \mathrm{CuS}$ & SILAR & Polysulphide & -0.29 & 1.39 & 0.30 & 0.16 & Gualdron-Reyes et al. [69] \\
\hline 34 & $\mathrm{TiO}_{2} / \mathrm{CdS} / \mathrm{CdTe} / \mathrm{E} / \mathrm{CuS} / \mathrm{PbS}$ & SILAR & Polysulphide & 0.55 & 19.81 & 0.53 & 5.54 & Zhang et al. [288] \\
\hline 35 & $\mathrm{TiO}_{2} / \mathrm{PbS} / \mathrm{CdS} / \mathrm{CdSe} / \mathrm{E} / \mathrm{CuS}$ & SILAR & Polysulphide & 0.54 & 19.32 & 0.50 & 5.11 & Zhang et al. [287] \\
\hline 36 & $\mathrm{TiO}_{2} / \mathrm{Al}_{2} \mathrm{O}_{3} / \mathrm{MgO} / \mathrm{PbS} / \mathrm{CdS}$ & SILAR & Polysulphide & 0.63 & 11.40 & 0.56 & 3.25 & Punnoose et al. [197] \\
\hline 37 & $\mathrm{ZnO} / \mathrm{TiO}_{2} / \mathrm{CdS} / \mathrm{CdSe} / \mathrm{E} / \mathrm{CuS}$ & CBD & Polysulphide & 0.57 & 11.17 & 0.24 & 1.55 & Kim et al. [118] \\
\hline 38 & $\mathrm{ZnO} / \mathrm{CdS} / \mathrm{CdSe} / \mathrm{E} / \mathrm{Pt}$ & CBD & Polysulphide & 0.66 & 5.19 & 0.41 & 1.42 & Chen et al. [28] \\
\hline 39 & $\begin{array}{l}\mathrm{ZnO} / \mathrm{CdS}(\mathrm{big}) / \mathrm{CdS} \\
\quad(\mathrm{small}) / \mathrm{E} / \mathrm{Pt}\end{array}$ & CBD & lodide & 0.55 & 1.95 & 0.45 & 0.48 & Song et al. [235] \\
\hline
\end{tabular}


Table 2 (continued)

\begin{tabular}{|c|c|c|c|c|c|c|c|c|}
\hline \multirow[t]{2}{*}{ S. no. } & \multirow{2}{*}{$\begin{array}{l}\text { Co-sensitized quantum } \\
\text { dots (QDs) device layers } \\
\text { between photocathode and } \\
\text { photoanodes }\end{array}$} & \multirow{2}{*}{$\begin{array}{l}\text { Method of synthesis/depo- } \\
\text { sition of QDs }\end{array}$} & \multirow[t]{2}{*}{ Electrolyte } & \multicolumn{4}{|c|}{ Solar cell parameters } & \multirow[t]{2}{*}{ References } \\
\hline & & & & $\overline{V_{o c}(V)}$ & $\mathrm{J}_{\mathrm{sc}}$ & $\mathrm{FF}$ & $\overline{\eta(\%)}$ & \\
\hline 40 & $\begin{array}{l}\mathrm{Cu}-\mathrm{ZnO} / \mathrm{CdS} / \mathrm{CdSe} / \mathrm{ZnS} / \mathrm{E} / \\
\mathrm{CuS}\end{array}$ & CBD, SILAR & Polysulphide & 0.61 & 9.86 & 0.42 & 2.61 & Jeong et al. [98] \\
\hline 41 & $\mathrm{ZnO} / \mathrm{CdS} / \mathrm{CdSe} / \mathrm{ZnS} / \mathrm{E} / \mathrm{Pt}$ & CBD & Polysulphide & 0.50 & 7.29 & 0.36 & 1.33 & Rawal et al. [204] \\
\hline 42 & $\mathrm{ZnO} / \mathrm{CdSe} / \mathrm{CdS} / \mathrm{E} / \mathrm{Cu}_{2} \mathrm{~S} / \mathrm{RGO}$ & EPD & Polysulphide & 0.50 & 4.34 & 0.49 & 1.08 & Choi et al. [35] \\
\hline 43 & $\begin{array}{l}\text { ZnO/Graphene/CdS/CdSe/ } \\
\text { ZnS/E/Cu } / \mathrm{Cu}_{2} \mathrm{~S}\end{array}$ & SILAR & Polysulphide & 0.57 & 8.72 & 0.44 & 2.20 & Ghoreishi et al. [61] \\
\hline 44 & $\mathrm{ZnSO}_{4}-\mathrm{ZnO} / \mathrm{CdS} / \mathrm{CdSe} / \mathrm{E} / \mathrm{Pt}$ & Electrodeposition & Polysulphide & 0.49 & 11.32 & 0.37 & 2.08 & Li et al. [141] \\
\hline 45 & $\mathrm{ZnO} / \mathrm{CdS} / \mathrm{CdSe} / \mathrm{ZnS} / \mathrm{E} / \mathrm{CuS}$ & SILAR & Polysulphide & 0.62 & 15.5 & 0.55 & 5.36 & Li et al. [143] \\
\hline 46 & $\begin{array}{l}\mathrm{ZnO} / \mathrm{SnO}_{2} / \mathrm{CdS} / \mathrm{CdSe} / \\
\mathrm{ZnS} / \mathrm{E} / \mathrm{CuS}\end{array}$ & SILAR, spin-SILAR & Polysulphide & 0.60 & 14.3 & 0.57 & 4.98 & Lin et al. [153] \\
\hline 47 & $\mathrm{ZnO} / \mathrm{TiO}_{2} / \mathrm{CdS} / \mathrm{PbS} / \mathrm{E} / \mathrm{Pt}$ & SILAR, DA & Polysulphide & 0.46 & 9.73 & 0.36 & 1.59 & Gao et al. [59] \\
\hline 48 & $\mathrm{ZnS} / \mathrm{TiO}_{2} / \mathrm{POM} / \mathrm{CdS} / \mathrm{E} / \mathrm{Pt}$ & CBD \& SILAR & $\mathrm{LI}+\mathrm{I}_{2}$ in $\mathrm{ACN}$ & 0.71 & 4.90 & 0.41 & 1.61 & Yu et al. [274] \\
\hline 49 & $\mathrm{SnO}_{2} / \mathrm{CdS} / \mathrm{CdSe} / \mathrm{E} / \mathrm{Cu} 2 \mathrm{~S}$ & CBD & Polysulphide & 0.70 & 10.13 & 0.61 & 4.37 & Xiao et al. [255] \\
\hline 50 & $\mathrm{SnO}_{2} / \mathrm{TiO}_{2} / \mathrm{CdS} / \mathrm{CdSe} / \mathrm{E} / \mathrm{CuS}$ & SILAR & Polysulphide & 0.51 & 13.0 & 52.2 & 3.49 & Chen et al. [31] \\
\hline
\end{tabular}

SILAR successive ionic layer and absorption, CBD chemical bath deposition, EPD electrophoretic deposition, DA direct adsorption, ECALD electrochemical atomic layer deposition, $P L D$ pulsed laser deposition, E electrolyte, $A C N$ acetonitrile, $P O M$ poly-oxy metallate

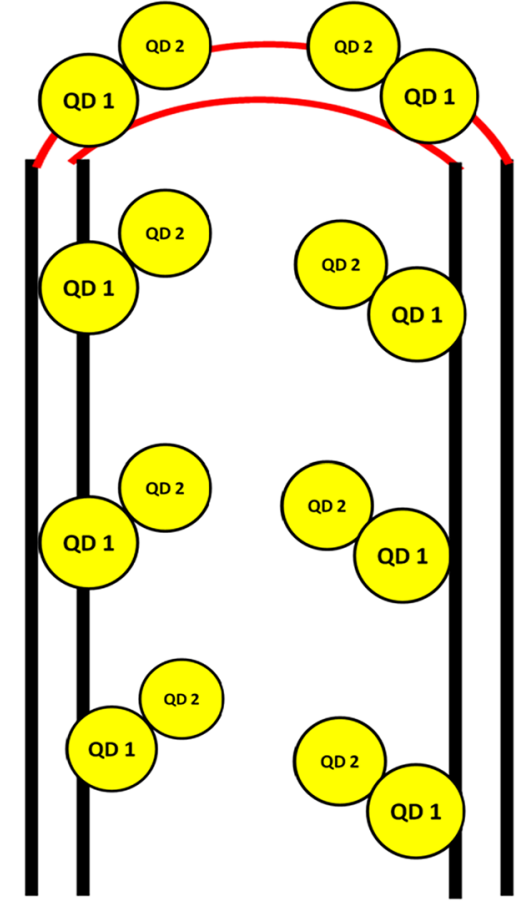

Fig. 21 Schematic diagram of co-sensitization of semiconductor nanoparticles on the inner side of a $\mathrm{TiO}_{2}$ nanotube

$\mathrm{TiO}_{2} / \mathrm{CdS}$ and $\mathrm{TiO}_{2} / \mathrm{CdSe}$ single cells due to the reduced recombination and proper fermi level arrangement. Ren et al. [207] have proposed that insertion of CdS layer rearranges the band edge position and form a stepwise structure which enhances the light absorption. In many cases, either the anodized electrode or the delaminated $\mathrm{TiO}_{2}$ layer which was attached on the FTO electrode was utilized as photoanode for the co-sensitization. Compared with the roughly anodized $\mathrm{TiO}_{2}$ nanotube electrode, fibrous type of electrode has shown improved efficiency upto $3.18 \%$ [90]. Choi et al. achieved over $9 \%$ efficiency by decorating $\mathrm{TiO}_{2}$ nanoparticles on double side opened $\mathrm{TiO}_{2}$ nanotubes [36] which clearly indicating the existence of promising results in this area. Other than cadmium chalcogenides, compounds such as $\mathrm{PbS}$ and $\mathrm{Bi}_{2} \mathrm{~S}_{3}$ have also found as suitable for improving the efficiency through co-sensitization process [20]. Besides, co-sensitization of $\mathrm{Ag}_{2} \mathrm{~S}$ (3 SILAR cycles) and $\mathrm{Bi}_{2} \mathrm{~S}_{3}$ (3 SILAR cycles) nanoparticles with $\mathrm{TiO}_{2}$ nanotubes produced high photocurrent which clearly shows that optimum level of deposition cycle is required to achieve high photocurrent and beyond that, decrease in photocurrent is observed [246]. Process such as doping of foreign atom into the titanium lattice of $\mathrm{TiO}_{2}$ nanotubes could improve the performance through co-sensitization [69]. However, when co-sensitization of nanoparticles is carried out on $\mathrm{TiO}_{2}$ nanotubes, some of the problems like clogging of the nanoparticles due to the excess deposition and large size of the nanoparticles on the surface reduces the performance. Moreover, surface chemistry of $\mathrm{TiO}_{2}$ nanotubes also to be studied well for the co-sensitization process. It is expected that functionalization and increase in surface area of $\mathrm{TiO}_{2}$ nanotubes are expected to give considerable improvement in efficiency in near future. 


\subsection{Co-sensitization by hybrid (dye/quantumdots) on $\mathrm{TiO}_{2}$ photoelectrode}

Semiconductor QDs could also function as the effective mediator of charge transfer with dyes in DSSCs. Coupling QDs with dyes rely on many advantages which includes (1) to get panchromatic absorption spectrum, (2) to reduce the internal charge recombination by fast hole collection from QDs and efficient spatial separation of electrons and holes, (3) improved charge extraction by reducing the recombination losses etc. [79]. This hybrid sensitization has also been applied for the hydrogen generation through tandem structure [64]. The another advantage is, cosensitization of QDs with organometallic dyes enhances the hole transfer from the nanoparticles and the effective annihilation is suppressed [236]. The first analysis on coupling of QDs with dye was studied by Fang et al. [53] who demonstrated the enhancement of absorption through $\mathrm{CdSe}$ nanoparticles-zinc phthalocyanine ( $\mathrm{ZnTcPc})-\mathrm{TiO}_{2}$ architecture. Generally, incorporation of dyes with QDs play important role in regeneration of photo oxidized QDs [172]. Moreover, when QDs are coupled with dyes, they can either be dispersed in the electrolyte or penetrate into the $\mathrm{TiO}_{2}$ photoanode. Presence of QDs in the electrolyte minimizes absorption loss due to the process called "photon filtering" [1]. Thus, quantum dots are functioning like "antenna' and act as donor to dyes. Functioning of this antenna like structure has lot of benefits which includes (1) avoiding donor quenching, (2) improvement of energy transfer efficiency, (3) improvement of photostability of QDs etc. [14]. The charge transfer through co-sensitization of a hybrid is more trivial and crucial one compared with co-sensitization by QDs and dyes alone. Charge transfers between organic dye and inorganic QDs are separated at particular distance (generally $1-10 \mathrm{~nm}$ ) and is mostly achieved through FRET mechanism. The Forster radius $\left(R_{o}\right)$ which is defined as the $50 \%$ energy transfer efficiency can be described by the following equation [11],

$R_{o}=9000 \ln (10) k^{2} \Phi_{D} / 128 \pi^{2} N_{A} n^{4}\left[\infty \int_{0} F_{D}(\lambda) \ni_{A}(\lambda) \lambda^{4} d \lambda\right]$

where, $k$, orientation factor between donor and acceptor dipoles ( $k^{2}$ is equal to $2 / 3$ for random orientation); $\Phi_{D}$, donor fluorescence quantum yield in the absence of the acceptor; $\mathrm{N}_{\mathrm{A}}$ Avogadro constant $\left(6.022 \times 10^{23}\right) ; \mathrm{N}$, index of refraction for the medium surrounding the donor and acceptor; $F_{D}(\lambda)$, fluorescence of the donor normalized to unit area; $\ni_{A}(\lambda)$, molar absorption spectrum of the acceptor.

For efficient FRET, the separation distance must be a smaller one. Efficiency of FRET can be estimated through the transient fluorescence measurements. Reduction in the life time of donor in presence of acceptor and increase of lifetime of acceptor in presence of the donor is the best evidence of FRET phenomena. The schematic diagram of FRET process is given in Fig. 22. FRET has been observed in organic donor and acceptor molecules, dye/QDs, metallo organic frame work (MOF)-QDs etc. [100, 104, 211]. Etger et al. [51] analysed the FRET process of CdSe/squaraine system with cobalt electrolyte and observed improvement in efficiency (from 0.79 to $1.48 \%$ ) through FRET. To avoid the corrosion of QDs by the redox electrolyte, Itzhakov et al. [97] utilized a novel method which resulted remarkable
Fig. 22 Schematic diagram of FRET transfer process in N3 dye and CdSe nanoparticles co-sensitized on $\mathrm{TiO}_{2}$ nanoparticles photoanode

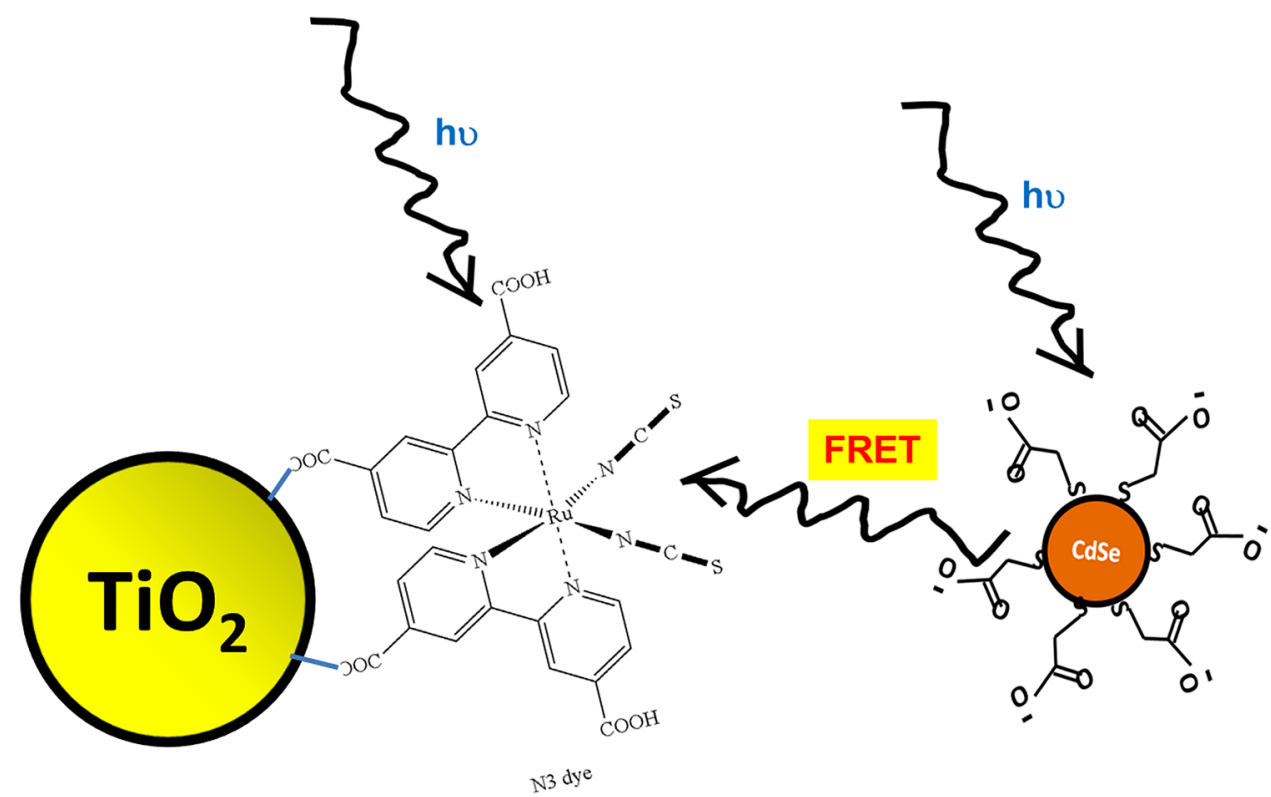


FRET performance. The authors used a thin coating of a $\mathrm{TiO}_{2}$ on the QDs which connected the mesoporous $\mathrm{TiO}_{2}$ layer to make a contact between QDs and squaraine dye (i.e., QDs are buried on the mesoporous $\mathrm{TiO}_{2}$ ). Through this method, nearly $70 \%$ of FRET efficiency was achieved. Since, the QDs are not affected by the sulphide electrolyte, maximization of overlap integral is possible. Several dyes have been studied for the co-sensitization which include organometallic ruthenium complexes, squaraine, corrole (aromatic derivatives of corrins) etc. During co-sensitization, efficient charge transfer was observed between dye and QDs through strong PL quenching even in the presence of the additional coating layer [172]. Shen et al. [228] found that the IPCE was improved about four times when zinc tetracarboxyl phthalocyanine (ZnTcPc) was deposited with $\mathrm{CdSe}$ nanoparticles. Later, for the construction of highly efficient solar cells, Shalom et al. studied deposition of amorphous $\mathrm{TiO}_{2}$ layer in between CdS/N719 hybrid where the CdS nanoparticles and dye were sequentially deposited on the electrophoretically deposited $\mathrm{TiO}_{2}$ layer [222]. The authors reached about $26.3 \%$ of efficiency improvement (from 0.57 to $1.51 \%$ ) through bisensitization. This behaviour of CdS/N719 hybrid is due to the effective collection of holes by N719 dye. With $\mathrm{ZnO}$ as photoanode, about $1.9 \%$ of efficiency was observed through optimizing the sensitization time (20 h) [236]. Similarly, Lin et al. [151] analysed the influence of atomic layer deposited $\mathrm{TiO}_{2}$ layer in between the CdS quantum dots and N719 dye. In addition, by slowing down the back electron transfer, it was found that the interfacial layer enhances $\mathrm{J}_{\mathrm{sc}}$ considerably (from 4.25 to $5.25 \mathrm{~mA} \mathrm{~cm}^{-2}$ ) and the device performance also improved from 1.67 to $2.36 \%$. A recent study of CdS nanoparticles deposited through CBD resulted about $5.57 \%$ efficiency (higher than $6 \%$ with pure $\mathrm{TiO}_{2}$ nanoparticles) when co-sensitized with N719 [142]. Similarly, the in situ-chemical bath deposited $\mathrm{PbS}$ nanoparticles on $\mathrm{TiO}_{2}$ layer could produce about $6.35 \%$ efficiency from $5.95 \%$ through co-sensitization by N719 dye [156]. One of the expectable major problems associated with the hybrid (QDs/dye) co-sensitization is selection of appropriate electrolyte while constructing devices. Meng et al. [170] developed a thiolate-disulfide electrolyte for the co-sensitization of QDs with N719 Dye. The efficiency of 3.93\% was obtained through co-sensitization of N719 dye with CdS nanoparticles (SILAR) and 4.18\% was obtained for SILAR deposited PbS nanoparticles. Similarly, a detailed study carried out by Jun et al. [107] showed that though devices with iodide based electrolyte give higher efficiency, dye/ QDs co-sensitized solar cell with cobalt based electrolytes showed high stability. These results clearly illustrate the need of common electrolyte system which could balance both QDs and molecular dyes. When PbS/CdS nanoclusters are deposited together on $\mathrm{TiO}_{2}$ layer through SILAR method, improvement of photocurrent density from 0.017 to $0.28 \mathrm{~mA} \mathrm{~cm}^{-2}$ was observed [285]. For the DSSC application, co-sensitization of PbS/CdS NPs (SILAR) on hierarchical pore structure of $\mathrm{TiO}_{2}$ layer promoted efficiency up to $3.82 \%$ [292]. During the co-sensitization of $\mathrm{PbS} / \mathrm{CdS}$ nanoparticles with N719 dye, the dye could function as efficient hole-scavenger and with $\mathrm{ZnS}$ as additional layer, the efficiency was improved up to $6.22 \%$ in the presence of cobalt electrolyte [162]. Choi et al. [34] examined about the dual behaviour of squaraine dye when coupling with the electrophoretically deposited CdS nanoparticles. The performance of fabricated solar cell was improved from $0.02 \%$ (CdS NPs alone) to $0.44 \%$ (CdS NPs + SQ). Here, in addition with extending the absorption spectrum, the self-assembled squaraine dye acted as hole collector [35]. The charge transfer process, schematic diagram of structures, absorption spectra of components and the I-V curve of this analysis is given in Fig. 23. The optimized designing of aqueous synthesized CdSe/CdS QDs coupled with D719 dye produced nearly about $7 \%$ efficiency $\left(V_{o c}=747.1 \mathrm{mV}\right.$, $\mathrm{J}_{\mathrm{sc}}=13.3 \mathrm{~mA} \mathrm{~cm}^{-2}, \mathrm{FF}=0.71$ ) through FRET and covered a wide solar spectrum simultaneously. Here, the CdS layer was working as a barrier which prevented electron injection into $\mathrm{TiO}_{2}$ electrode [133].

In case of ternary sensitizers, Culn ${ }_{(1-x)} \mathrm{Ga}_{x} \mathrm{Se}_{2}$ (CIGS) QDs are playing important role in QDSSCs. Lin et al. [148] found that compared with pristine CIGS QDs, the Ga-rich CIGS QDs co-sensitized with N719 produced about $8.02 \%$ efficiency with improved $J_{s c}$ value. Here, due to the tuned conduction band level of Ga-rich CIGS QDs, efficient electron transfer to $\mathrm{TiO}_{2}$ was feasible. Role of FRET in core/shell/ shell type structure of semiconductor nanoparticles is an interesting one. The $\mathrm{CdSe} / \mathrm{CdS} / \mathrm{ZnS}$ donor molecule with squaraine dye together with amorphous $\mathrm{TiO}_{2}$ coating was found to be covering the entire visible spectrum in IPCE [14]. Narayanan et al. [178] have found that the insertion of carbon QDs with phthalocyanine in the layer of ZnS/ $\mathrm{CdS} / \mathrm{ZnS}$ assembly in the solid state device improved the efficiency about 5.76 times. When thin layer of $\mathrm{ZnS}$ coating was deposited on the QDs, improvement in quantum yield was observed [172]. Here, the deposition of thin ZnS layer reduces recombination by improving $\mathrm{V}_{\mathrm{oc}}$ and $\mathrm{J}_{\mathrm{s},}$ and also reduces leakage current which ultimately enhance efficiency [227]. Moreover, the insertion of ZnS layer around QDs also improves the stability of the device. When $\mathrm{ZnO}$ layer sensitized by dye alone, chemical instability arises which strongly affecting the charge transport. Co-sensitization by QDs/dye hybrid on $\mathrm{TiO}_{2}$ nanotubes was also attempted [4]. But still this approach has to be improved due to the hydrophilic nature of $\mathrm{TiO}_{2}$ nanotubes. Co-sensitization by hybrid on $\mathrm{ZnO}$ photoanode was found to be improving efficiency through $\mathrm{CulnS}_{2} / \mathrm{N} 3$ combination [144]. Interestingly, hierarchical structure of $\mathrm{ZnO} / \mathrm{ZnS}$ 
(a)

\section{E[V] vs NHE}
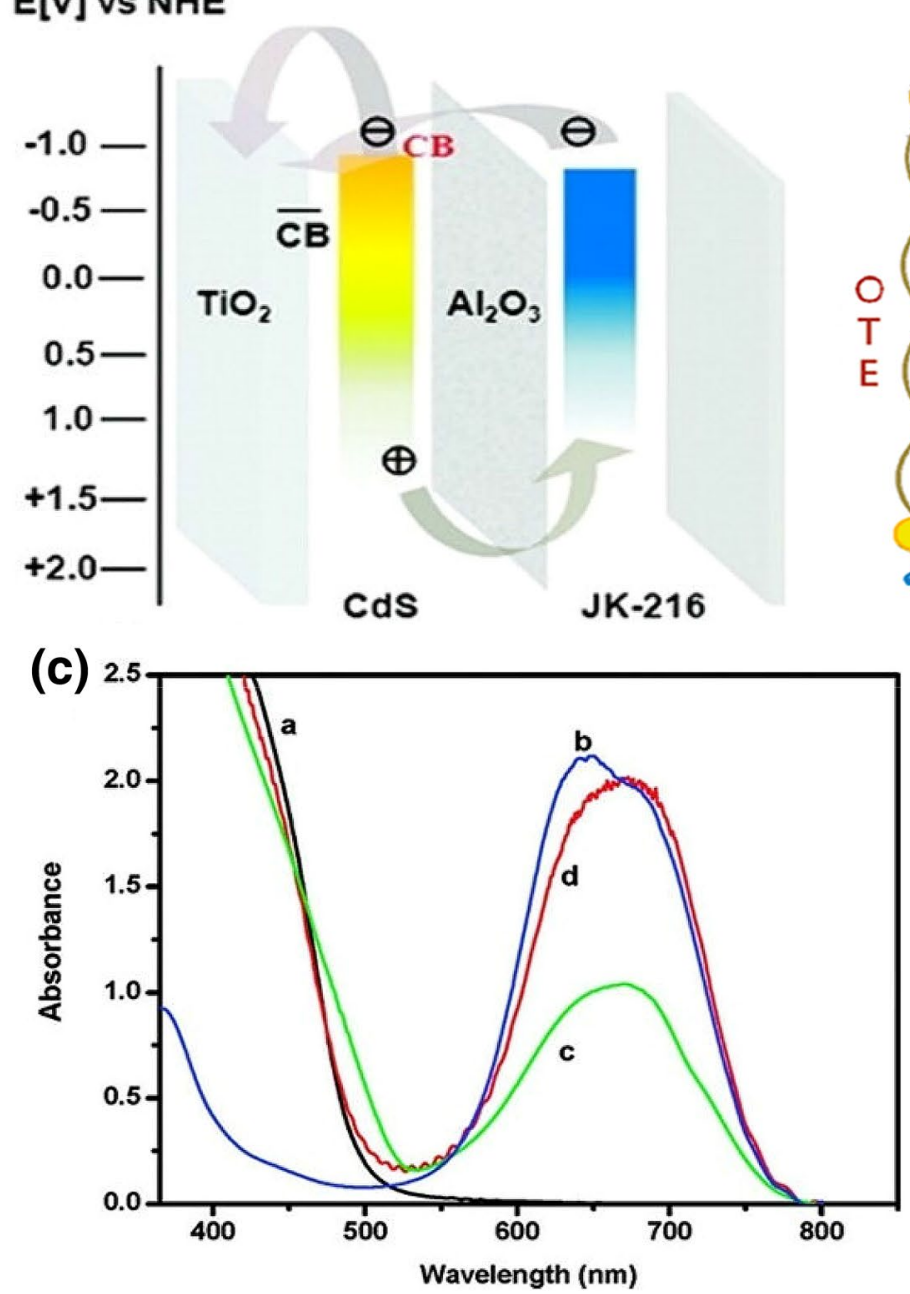

(b)

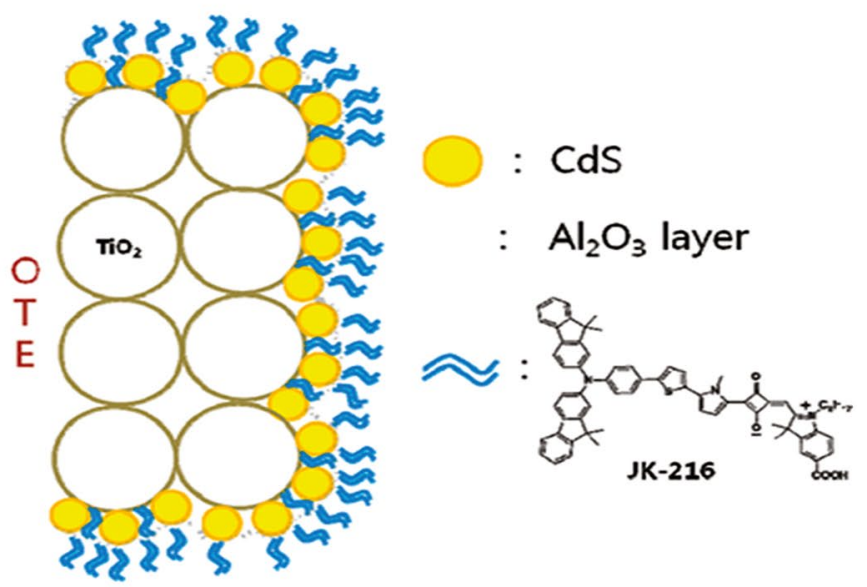

Fig. 23 Charge transfer in multilayer supersensitized nanocrystalline $\mathrm{TiO}_{2}$ film b schematic diagram of $\mathrm{TiO}_{2} / \mathrm{CdS} / \mathrm{Al}_{2} \mathrm{O}_{3} / \mathrm{JK}-216$ system and $\mathbf{c}, \mathbf{d}$ absorption spectra and I-V characteristics of the $\mathbf{a} \mathrm{CdS}, \mathbf{b}$

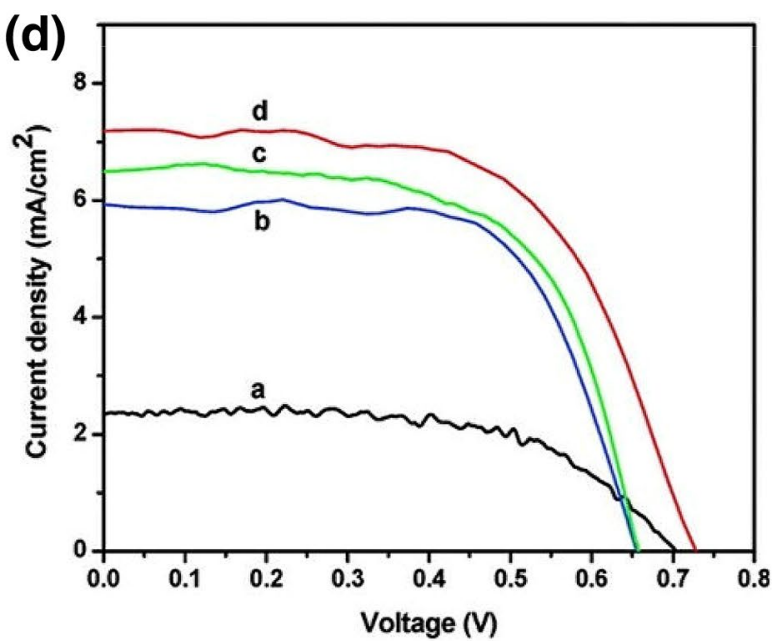

JK-216, c CdS/JK216, d CdS/ $\mathrm{Al}_{2} \mathrm{O}_{3} / \mathrm{JK} 216$ films. Reprinted with permission from Ref. [34] Copyright $\odot 2011$ American Chemical Society on $\mathrm{ZnO}$ nanorods improved efficiency from 1.16 to $1.59 \%$ through co-sensitization [73]. A good interface between $\mathrm{CdS}$ and CdSe layers is important to obtain the high carrier transport in the fabricated device. It has been found that due to the ion diffusion from $\mathrm{CdSe}$ to $\mathrm{CdS}$ layer, the strain field of $\mathrm{CdS}$ region is relaxed in $\mathrm{CdSe} / \mathrm{CdS} / \mathrm{ZnO}$ structure [108]. Due to this relaxation, strain in the CdS layer is effectively reduced.

Though $\mathrm{ZnO}$ based photoelectrodes provide lower efficiency compared with $\mathrm{TiO}_{2}$ photoelectrode, with the insertion of zinc phthalocyanine ( $\mathrm{ZnPc})$, the $\mathrm{CdS} /$ $\mathrm{CdSe}$ co-sensitized inverse opal structured $\mathrm{ZnO}$ yielded $4 \%$ efficiency [26]. Co-sensitization has also attempted for the construction of solid-state dye-sensitized solar cells but very less efficiency was observed with ZnS nanoparticles [180]. Future studies in this direction with new approaches would alleviate the existing problems in solid-state DSSCs.

FRET has been accepted as promising concept in solar cells due to its characteristic properties. Nevertheless, difficulties associated with FRET includes [11] (1) distinguishing the charge transfer and energy transfer, (2) visualizing the actual donor-acceptor distances in the cell, (3) correlating the solar cell performance with charge/energy transfer dynamics etc. Optimization of dyes which possess suitable chromophores and QDs with favorable band gap are needed for the efficient energy transfer. Future efforts in this area would pave a new way to overcome the current problems. 


\section{Conclusion and perspectives of co-sensitization}

This discussion clearly identifies about the methods and efficiency achieved through co-sensitization process in organic/organometallic dyes and semiconductor QDs. From this discussion, it is clear that co-sensitization has important effect on the construction of future generation high efficiency solar cell devices. The different aspects of co-sensitization clearly reveal its inevitable role in constructing the future generation solar cells. However, there is a clear mechanistic strategy is required to select proper dyes (or) QDs and to construct efficient solar cells through co-sensitization process. In particular, the interface between layers of two different dyes (or) QDs has to be explored in order to improve the efficiency. Indeed, different $D-\pi-A$ and $D-A-\pi-A$ dyes are sensitized with newly developed organic dyes, the charge transfer between these two are very interesting for further analysis. Changing the component of donor and acceptor molecules in $D-\pi-A$ and $D-A-\pi-A$ systems is expected to pave additional interest for future generation highly stable dye-sensitized solar cells. Cosensitization has emerged as the inevitable source to improve the photon collection for high efficiency dye sensitized solar cells. Though co-sensitization process seems to be an effective tool to improve the conversion efficiency, there are some demerits associated with the process. In contrast to enhancement, there are some co-sensitization process which affects the conversion efficiency. The reasons for this effect is the deactivation of excited states and IPCE improvement of one portion is affected by another portion due to the detachment of second dye sensitizer from $\mathrm{TiO}_{2}$ surface. These kind of issues to be solved for efficient photons extraction. There are additional new dyes which have high molar extinction co-efficient are needed to tackle this problem. Even though FRET is the best way to achieve high efficiency devices, the traditional iodine/tri iodide electrolyte in the devices quenches the fluorescence of the donor which limits its performance. Co-sensitization with spatially separated chromophores has also been the best alternative method to improve the photocurrent collection. Additional efforts of using a common solvent system for the co-sensitization process would be a beneficial for future device applications. Further, detailed analysis of the FRET process is required to understand the kinetics behind its energy transfer. In QDs, it is essential to make attempts of extending the co-sensitization strategy with the newly emerged inorganic semiconductor nanomaterials such as perovskites. Also, efforts to improve the stability of fabricated solar cell in presence of efficient electrolyte is also a highly recommendable. Use of near infra-red region harvesting QDs to be improved for co-sensitization along with the visible light harvesting QDs. Also, much analysis has to be devoted for the ZnS, ZnTe nanoparticles layer in terms of efficiency enhancement. It is expected that the future development in this field will lead to new achievements. In addition to this, attempts to extend this concept to new emerging materials like inorganic and hybrid perovskites would also be a beneficial to construct highly efficient solar cell devices.

Acknowledgements The authors acknowledge Department of Science and Technology (DST), Govt. of India (DST/TMC/SERI/FR/90) and DST-PURSE for funding the research. S. Ananthakumar and J. Ram Kumar sincerely thanks Ministry of New and Renewable Energy (MNRE), Govt. of India for providing fellowships under National Renewable Energy Fellowship (NREF) scheme.

\section{Compliance with ethical standards}

Conflicts of interest The authors declare that they have no conflict of interest.

\section{References}

1. Adhyaksa GW, Lee Gl, Baek SW, Lee JY, Kang JK (2013) Broadband energy transfer to sensitizing dyes by mobile quantum dot mediators in solar cells. Sci Rep 3:1-8

2. Albero J, Clifford JN, Palomares E (2014) Quantum dot based molecular solar cells. Coord Chem Rev 263-264:53-64

3. Ahmad MS, Pandey AK, Rahim NA (2017) Advancements in the development of $\mathrm{TiO}_{2}$ photoanodes and its fabrication methods for dye sensitized solar cell (DSSC) applications. A review. Renew Sustain Energy Rev 77:89-108

4. Ananthakumar S, Ramkumar J, Babu SM (2014) Effect of cosensitization of $\mathrm{CdSe}$ nanoparticles with $\mathrm{N} 3$ dye on $\mathrm{TiO}_{2}$ nanotubes. Sol Energy 106:136-142

5. Ananthakumar S, Ramkumar J, Babu SM (2016) Semiconductor nanoparticles sensitized $\mathrm{TiO}_{2}$ nanotubes for high efficiency solar cell devices. Renew Sustain Energy Rev 57:1307-1321

6. Athanas AB, Thangaraj S, Kalaiyar S (2018) Co-sensitization of ruthenium(II) dye-sensitized solar cells by coumarin dyes. Chem Phys Lett 699:32-39

7. Babu DD, Elsherbiny D, Cheema H, El-Shafei A, Adhikari AV (2016) Highly efficient panchromatic dye-sensitized solar cells: synergistic interaction of ruthenium sensitizer with novel cosensitizers carrying different acceptor units. Dyes Pigments 132:316-328

8. Babu DD, Su R, El-Shafei A, Adhikari AV (2016) From molecular design to co-sensitization: high performance indole based photosensitizers for dye-sensitized solar cells. Electrochem Acta 198:10-21

9. Babu DD, Su R, El-Shafei A, Adhikari AV (2016) New indole based co-sensitizers for dye sensitized solar cells exceeding 10\% efficiency. RSC Adv 6:30205-30216

10. Babu DD, Su R, Naik P, El-Shafei A, Adhikari AV (2017) Synthesis and photovoltaic performance of a novel asymmetric 
dual-channel co-sensitizer for dye-sensitized solar cell beyond $10 \%$ efficiency. Dyes Pigments 141:112-120

11. Basham JI, Mor GK, Grimes CA (2010) Forster resonance energy transfer in dye-sensitized solar cells. ACS Nano 4(3):1253-1258

12. Baylis SL, Cole JM, Waddell PG, McKechnie S, Liu X (2014) Predicting solar-cell dyes for cosensitization. J Phys Chem C 118(26):14082-14090

13. Bessho T, Zakeeruddin SM, Yeh CY, Diau EW, Grätzel M (2010) Highly efficient mesoscopic dye-sensitized solar cells based on donor-acceptor-substituted porphyrins. Angew Chem Int Edit 49(37):6646-6649

14. Buhbut S, Itzhakov S, Tauber E, Shalom M, Hod I, Geiger T, Garini Y, Oron D, Zaban A (2010) Built-in quantum dot antennas in dye-sensitized solar cells. ACS Nano 4(3):1293-1298

15. Bisht R, Fairoos M, Singh AK, Nithyanandhan J (2017) Panchromatic sensitizer for dye-sensitized solar cells: unsymmetrical squaraine dyes incorporating benzodithiphene $\pi$-spacer with alkyl chains to extend conjugation, control the dye assembly on $\mathrm{TiO}_{2}$, and retard charge recombination. J Org Chem 82(4):1920-1930

16. Boro B, Gogoi B, Rajbongshi BM, Ramchiary A (2017) Nanostructured $\mathrm{TiO}_{2} / \mathrm{ZnO}$ nanocomposites for dye-sensitized solar cells application. A review. Renew Sustain Energy Rev 81(2):2264-2270

17. Braga A, Giménez S, Concina I, Vomiero A, Mora-Seró I (2011) Panchromatic sensitized solar cells based on metal sulfide quantum dots grown directly on nanostructured $\mathrm{TiO}_{2}$ electrodes. J Phys Chem Lett 2(5):454-460

18. Briscoe J, Dunn S (2016) The future of using earth-abundant elements in counter electrodes for dye-sensitized solar cells. Adv Mater 28:3802-3813

19. Buatong N, Tang IM, Pon-On W (2017) The study of metal sulfide as efficient counter electrodes on the performances of CdS/ $\mathrm{CdSe} / \mathrm{ZnS}$-co-sensitized hierarchical $\mathrm{TiO}_{2}$ sphere quantum dot solar cell. Nano Res Lett 12:170

20. Cai F, Pan M, Feng Y, Yan G, Zhang Y, Zhao Y (2017) Synthesis and photoelectrical performance of nanoscale $\mathrm{PbS}$ and $\mathrm{Bi}_{2} \mathrm{~S}_{3}$ co-sensitized on $\mathrm{TiO}_{2}$ nanotube arrays. J Mod Transp 25:52-57

21. Cao Y, Dong Y-J, Chen H-Y, Kuang D-B, Su C-Y (2016) CdS/CdSe co-sensitized hierarchical $\mathrm{TiO}_{2}$ nanofiber/ZnO nanosheets heterojunction photoanode for quantum dot-sensitized solar cells. RSC Adv 6:78202-78209

22. Carey GH, Abdelhady AL, Ning Z, Thon SM, Bakr OM, Sargent EH (2015) Colloidal quantum dot solar cells. Chem Rev 115(23):12732-12763

23. Chan C-H, Samikkannu P, Wang H-W (2016) $\mathrm{Fe}_{2} \mathrm{O}_{3} / \mathrm{CdS}$ co-sensitized titania nanotubes for hydrogen generation from photocatalytic splitting water. Int J Hydrog Energy 41:17818-17825

24. Chang J, Lee CP, Kumar D, Chen PW, Lin LY, Justin Thomas KR, Ho KC (2013) Co-sensitization promoted light harvesting for organic dye-sensitized solar cells using unsymmetrical squaraine dye and novel pyrenoimidazole-based dye. J Power Sources 240:779-785

25. Chang S, Wang H, Hua Y, Li Q, Xiao X, Wong WK, Wong WY, Zhu $X$, Chen T (2013) Conformational engineering of co-sensitizers to retard back charge transfer for high-efficiency dye-sensitized solar cells. J Mater Chem 1(38):11553-11558

26. Chen C, Cheng Y, Jin J, Dai Q, Song H (2016) CdS/CdSe quantum dots and ZnPc dye co-sensitized solar cells with Au nanoparticles/graphene oxide as efficient modified layer. J Colloid Int Sci 480:49-56

27. Chen H, Li W, Liu H, Zhu L (2011) Performance enhancement of $\mathrm{CdS}$-sensitized $\mathrm{TiO}_{2}$ mesoporous electrode with two different sizes of CdS nanoparticles. Microporous Mesoporous Mater 138(1):235-238
28. Chen J, Wu J, Lei W, Song JL, Deng WQ, Sun XW (2010) Co-sensitized quantum dot solar cell based on $\mathrm{ZnO}$ nanowire. Appl Surf Sci 256(24):7438-7441

29. Chen R, Weng Q, An Z, Zhu S, Wang Q, Chen X, Chen P (2018) Investigation of 4-pyridyl liquid crystals on the photovoltaic performance and stability of dye sensitized solar cells by the co-sensitization. Dyes Pigments 159:527-532

30. Chen Y, Zeng Z, Li C, Wang W, Wang X, Zhang B (2005) Highly efficient co-sensitization of nanocrystalline $\mathrm{TiO}_{2}$ electrodes with plural organic dyes. New J Chem 29(6):773-776

31. Chen Z, Wei C, Li S, Diao C, Li W, Kong W, Zhang Z, Zhang W (2016) CdS/CdSe co-sensitized solar cells based on hierarchically structured $\mathrm{SnO}_{2} / \mathrm{TiO}_{2}$ hybrid films. Nano Res Lett 11:295

32. Cheng L, Ding $\mathrm{H}$, Chen C, Wang N (2016) $\mathrm{Ag}_{2} \mathrm{~S} / \mathrm{Bi}_{2} \mathrm{~S}_{3}$ co-sensitized $\mathrm{TiO}_{2}$ nanorod arrays prepared on conductive glass as a photoanode for solar cells. J Mater Sci Mater Electron 27:3234-3239

33. Choi H, Kim S, Kang SO, Ko J, Kang MS, Clifford JN, Forneli A, Palomares E, Nazeeruddin MK, Gratzel M (2008) Stepwise cosensitization of nanocrystalline $\mathrm{TiO}_{2}$ films utilizing $\mathrm{Al}_{2} \mathrm{O}_{3}$ layers in dye-sensitized solar cells. Angew Chem Int Ed 47(43):8259-8263

34. Choi H, Nicolaescu R, Paek S, Ko J, Kamat PV (2011) Supersensitization of $\mathrm{CdS}$ quantum dots with a near-infrared organic dye: toward the design of panchromatic hybrid-sensitized solar cells. ACS Nano 5(11):9238-9245

35. Choi H, Radich JG, Kamat PV (2013) Sequentially layered $\mathrm{CdSe} / \mathrm{CdS}$ nanowire architecture for improved nanowire solar cell performance. J Phys Chem C 118(1):206-213

36. Choi J, Kwon YS, Park T (2014) Doubly open-ended $\mathrm{TiO}_{2}$ nanotube arrays decorated with a few $\mathrm{nm}$-sized $\mathrm{TiO}_{2}$ nanoparticles for highly efficient dye-sensitized solar cells. J Mater Chem A 2(35):14380-14385

37. Choi S, Jin H, Bang J, Kim S (2012) Layer-by-layer quantum dot assemblies for the enhanced energy transfers and their applications toward efficient solar cells. J Phys Chem Lett 3(23):3442-3447

38. Cid JJ, Yum JH, Jang SR, Nazeeruddin MK, Martínez-Ferrero E, Palomares E, Ko J, Grätzel M, Torres T (2007) Molecular cosensitization for efficient panchromatic dye-sensitized solar cells. Angew Chem 119(44):8510-8514

39. Clifford JN, Palomares E, Nazeeruddin MK, Thampi R, Gratzel $M$, Durrant JR (2004) Multistep electron transfer processes on dye co-sensitized nanocrystalline $\mathrm{TiO}_{2}$ films. J Am Chem Soc 126(18):5670-5671

40. Clifford JN, Martínez-Ferrero E, Viterisi A, Palomares E (2011) Sensitizer molecular structure-device efficiency relationship in dye sensitized solar cells. Chem Soc Rev 40(3):1635-1646

41. Concina I, Vomiero A (2015) Metal oxide semiconductors for dye- and quantum-dot-sensitized solar cells. Small 11:1744-1774

42. Deng J, Wang M, Ye W, Fang J, Zhang P, Yang Y (2017) CdS/ CdSe-sensitized solar cell on Al-doped $\mathrm{ZnO}$ nanoparticles prepared by the decomposition of zinc acetate solid solution. Solid-State Electron 127:38-44

43. Ding W-L, Li Q-S, Li Z-S (2015) Anti-aggregation and intratype Forster resonance energy transfer in bulky indoline sensitizers for dye-sensitized solar cells: a combined DFT/ TDDFT and molecular dynamics study. J Mater Chem A 3:19948-19959

44. Ding W-L, Peng X-L, Li Z-S (2016) Influence of oligothiophene-functionalized co-sensitizer on the electron injection efficiency for multiple dye- $\mathrm{TiO}_{2}$ interface. Org Electron 38:384-395 
45. Ding WL, Cui YM, Yang LN, Li QS, Li ZS (2017) Rational design of near-infrared $\mathrm{Zn}$-porphyrin dye utilized in co-sensitized solar cell toward high efficiency. Dyes Pigments 136:450-457

46. Dryza V, Bieske EJ (2014) Suppressing forster resonance energy transfer between organic dyes on a cosensitized metal oxide surface. J Phys Chem C 118:19646-19654

47. Dualeh A, Delcamp JH, Nazeeruddin MK, Grätzel M (2012) Nearinfrared sensitization of solid-state dye-sensitized solar cells with a squaraine dye. Appl Phys Lett 100(17):173512

48. Ehret A, Stuhl L, Spitler MT (2001) Spectral sensitization of $\mathrm{TiO}_{2}$ nanocrystalline electrodes with aggregated cyanine dyes. J Phys Chem B 105(41):9960-9965

49. Eisenmenger ND, Delaney KT, Ganesan V, Fredrickson GH, Chabinyc ML (2014) Improving energy relay dyes for dye sensitized solar cells by increasing donor homotransfer. J Phys Chem C 118(26):14098-14106

50. Elmorsy MR, Su R, Fadda AA, Etman HA, Tawfik EH, El-Shafei A (2018) Co-sensitization of Ru(II) complex with terthiophenebased $D-\pi-\pi-A$ metal-free organic dyes for highly efficient dye-sensitized solar cells: influence of anchoring group on molecular geometry and photovoltaic performance. New J Chem 42:11430-11437

51. Etgar L, Park J, Barolo C, Lesnyak V, Panda SK, Quagliotto P, Hickey SG, Nazeeruddin MK, Eychmüller A, Viscardi G, Grätzel $M$ (2012) Enhancing the efficiency of a dye sensitized solar cell due to the energy transfer between CdSe quantum dots and a designed squaraine dye. RSC Adv 2(7):2748-2752

52. Fan S, Lu X, Sun H, Zhou G, Chang YJ, Wang ZS (2016) Effect of the co-sensitization sequence on the performance of dyesensitized solar cells with porphyrin and organic dyes. Phys Chem Chem Phys 18(2):932-938

53. Fang J, Mao H, Wu J, Zhang X, Lu Z (1997) The photovoltaic study of co-sensitized microporous $\mathrm{TiO}_{2}$ electrode with porphyrin and phthalocyanine molecules. Appl Surf Sci 119(3):237-241

54. Fang M, Li H, Li Q, Li Z (2016) Co-sensitization of "H"-type dyes with planar squaraine dyes for efficient dye-sensitized solar cells. RSC Adv 6:40750-40759

55. Favereau L, Warnan J, Anne FB, Pellegrin Y, Blart E, Jacquemin D, Odobel F (2013) Diketopyrrolopyrrole-zinc porphyrin, a tuned panchromatic association for dye-sensitized solar cells. J Mater Chem A 1(26):7572-7575

56. Freitag M, Boschloo $G$ (2017) The revival of dye-sensitized solar cells. Curr Opin Electrochem 2:111-119

57. Freitag M, Yang W, Fredin LA, D'Amario L, Karlsson M, Hagfeldt A, Boschloo G (2016) Supramolecular hemicage cobalt mediators for dye-sensitized solar cells. Chemsuschem 17:3845-3852

58. Freitag M, Teuscher J, Saygili Y, Zhang X, Giordano F, Liska P, Hua J, Zakeeruddin SM, Moser J-E, Gratzel M, Hagfeldt A (2017) Dye-sensitized solar cells for efficient power generation under ambient lighting. Nat Photonics 11:372-378

59. Gao F, Chen Q, Zhang X, Wang H, Huang T, Zhou L (2018) ZnO/ $\mathrm{TiO}_{2}$ core-shell heterojunction for $\mathrm{CdS}$ and $\mathrm{PbS}$ quantum dotsensitized solar cells. Curr Appl Phys 18:546-550

60. Gao XF, Sun WT, Ai G, Peng LM (2010) Photoelectric performance of $\mathrm{TiO}_{2}$ nanotube array photoelectrodes co-sensitized with CdS/CdSe quantum dots. Appl Phys Lett 96(15):153104

61. Ghoreishi FS, Ahmadi V, Samadpour M (2014) Improved performance of $\mathrm{CdS} / \mathrm{CdSe}$ quantum dots sensitized solar cell by incorporation of $\mathrm{ZnO}$ nanoparticles/reduced graphene oxide nanocomposite as photoelectrode. J Power Sources 271:195-202

62. Giannouli M, Tziogkidou G, Leftheriotis G (2017) Co-sensitization of $\mathrm{ZnO}$ solar cells by organic dyes. J Renew Sustain Energy 9:013503
63. Gong J, Sumathy K, Qiao Q, Zhou Z (2017) Review on dye-sensitized solar cells (DSSCs): advanced techniques and research trends. Renew Sustain Energy Rev 68:234-246

64. González-Pedro V, Zarazua I, Barea EM, Fabregat-Santiago F, de la Rosa E, Mora-Seró I, Giménez S (2014) Panchromatic solarto- $\mathrm{H} 2$ conversion by a hybrid quantum dots-dye dual absorber tandem device. J Phys Chem C 118(2):891-895

65. Gräf K, Rahim MA, Das S, Thelakkat M (2013) Complementary co-sensitization of an aggregating squaraine dye in solid-state dye-sensitized solar cells. Dyes Pigments 99(3):1101-1106

66. Gratzel M (2003) Dye-sensitized solar cells. J Photochem Photobiol C Photochem Rev 4:145-153

67. Gratzel M (2005) Solar energy conversion by dye-sensitized photovoltaic cells. Inorg Chem 44(20):6841-6851

68. Griffith MJ, Mozer AJ, Tsekouras G, Dong Y, Wagner P, Wagner K, Wallace GG, Mori S, Officer DL (2011) Remarkable synergistic effects in a mixed porphyrin dye-sensitized $\mathrm{TiO}_{2}$ film. Appl Phys Lett 98(16):163502 (1-3)

69. Gualdron-Reyes AF, Cardenas-Arenas A, Martinez CA, Kouznetsov VV, Melendez AM (2017) Fabrication of transparent $\mathrm{TiO}_{2}$ nanotube-based photoanodes for $\mathrm{CdS} / \mathrm{CdTe}$ quantum cosensitized solar cells. J Phys Conf Ser 786:012044

70. Guo M, Diao P, Ren YJ, Meng F, Tian H, Cai SM (2005) Photoelectrochemical studies of nanocrystalline $\mathrm{TiO}_{2} \mathrm{CO}$-sensitized by novel cyanine dyes. Sol Energ Mater Sol Cells 88(1):23-35

71. Guo X-W, Li J-S, Sang X-J, Chen W-L, Su Z-M, Wang E-B (2016) Three kegging-type transition metal-substituted polyoxometalates as pure inorganic photosensitizers for p-type dye-sensitized solar cells. Chem Eur J 22:3234-3238

72. Hagfeldt A, Boschloo G, Sun L, Kloo L, Pettersson H (2010) Dyesensitized solar cells. Chem Rev 110(11):6595-6663

73. Han D, Sun Y, Yang J, Yang L, Jin S, Chen G, Song H (2013) Enhanced performance of dye/QDs co-sensitized solar cells via Förster resonance energy transfer. Electrochem Acta 109:291-297

74. Han HS, Han GS, Kim JS, Kim DH, Hong JS, Caliskan S, Jung HS, Cho IS, Lee J-K (2016) Indium-Tin-oxide nanowire array based $\mathrm{CdSe} / \mathrm{CdS} / \mathrm{TiO}_{2}$ one-dimensional heterojunction photoelectrode for enhanced solar hydrogen production. ACS Sustain Chem Eng 4(3):1161-1168

75. Han L, Islam A, Chen H, Malapaka C, Chiranjeevi B, Zhang S, Yang X, Yanagida M (2012) High-efficiency dye-sensitized solar cell with a novel co-adsorbent. Energy Environ Sci 5(3):6057-6060

76. Han Z, Wang M, Chen X, Shen S (2016) CdSe-sensitized branched CdS hierarchical nanostructures for efficient photoelectrochemical solar hydrogen production. Phys Chem Chem Phys 18:11460-11466

77. Hao Y, Saygili Y, Cong J, Eriksson A, Yang W, Zhang J, Polanski E, Nonomura K, Zakeeruddin SM, Gratzel M, Hagfeldt A, Boschloo $\mathrm{G}$ (2016) Novel blue organic dye for dye-sensitized solar cells achieving high efficiency in cobalt-based electrolytes and by co-sensitization. ACS Appl Mater Interfaces 8(48):32797-32804

78. Hardin BE, Hoke ET, Armstrong PB, Yum JH, Comte P, Torres T, Fréchet JM, Nazeeruddin MK, Grätzel M, McGehee MD (2009) Increased light harvesting in dye-sensitized solar cells with energy relay dyes. Nat Photonics 3(7):406-411

79. Hetsch F, Xu X, Wang H, Kershaw SV, Rogach AL (2011) Semiconductor nanocrystal quantum dots as solar cell components and photosensitizers: material, charge transfer, and separation aspects of some device topologies. J Phys Chem Lett 2(15):1879-1887

80. Hilal HM, El Bitar Nehme MA, Ghaddar TH (2018) Large enhancement of dye sensitized solar cell efficiency by 
co-sensitizing pyridyl- and carboxylic acid-based dyes. ACS Appl Energy Mater 1:2776-2783

81. Hodes G (2007) Semiconductor and ceramic nanoparticle films deposited by chemical bath deposition. Phys Chem Chem Phys 9:2181

82. Holliman PJ, Mohsen M, Connell A, Davies ML, Al-Salihi K, Pitak MB, Tizzard GJ, Coles SJ, Harrington RW, Clegg W, Serpa C (2012) Ultra-fast co-sensitization and tri-sensitization of dye-sensitized solar cells with N719, SQ1 and triarylamine dyes. J Mater Chem 22(26):13318-13327

83. Holliman PJ, Al-Salihi KJ, Connell A, Davies ML, Jones EW, Worsley DA (2014) Development of selective, ultra-fast multiple co-sensitization to control dye loading in dye-sensitized solar cells. RSC Adv 4(5):2515-2522

84. Honda M, Yanagida M, Han L (2013) Effect of co-adsorption dye on the electrode interface (Ru complex $/ \mathrm{TiO}_{2}$ ) of dye sensitized solar cells. AIP Adv 3(7):072113

85. Hossain MA, Jennings JR, Koh ZY, Wang Q (2011) Carrier generation and collection in $\mathrm{CdS} / \mathrm{CdSe}$-sensitized $\mathrm{SnO}_{2}$ solar cells exhibiting unprecedented photocurrent densities. ACS Nano 5(4):3172-3181

86. Hosseinnezhad M, Jafari R, Gharanjig K (2017) Characterization of a green and environmentally friendly sensitizer for a low cost dye-sensitized solar cell. Opto-Electron Rev 25:93-98

87. Hua Y, Lee LTL, Zhang C, Zhao J, Chen T, Wong W-Y, Wong W-K, Zhu X (2015) Co-sensitization of 3D bulky phenothiazine-cored photosensitizers with planar squaraine dyes for efficient dyesensitized solar cells. J Mater Chem 3:13848-13855

88. Huang F, Zhang Q, Xu B, Hou J, Wang Y, Masse RC, Peng S, Liu J, Cao G (2016) A comparison of ZnS and ZnSe passivation layers on CdS/CdSe co-sensitized quantum dot solar cells. J Mater Chem A 4:14773-14780

89. Huang J, Xu B, Yuan C, Chen H, Sun J, Sun L, Agren H (2014) Improved performance of colloidal CdSe quantum dot-sensitized solar cells by hybrid passivation. ACS Appl Mater Interfaces 6(21):18808-18815

90. Huang S, Zhang Q, Huang X, Guo X, Deng M, Li D, Luo Y, Shen Q, Toyoda T, Meng Q (2010) Fibrous CdS/CdSe quantum dot cosensitized solar cells based on ordered $\mathrm{TiO}_{2}$ nanotube arrays. Nanotechnology. 21(37):375201

91. Humphry-Baker N, Driscoll K, Rao A, Torres T, Snaith HJ, Friend RH (2012) Time-evolution of poly(3-hexylthiophene) as an energy relay dye in dye-sensitized solar cells. Nano Lett 12(2):634-639

92. Imahori H, Umeyama T, Ito S (2009) Large $\pi$-aromatic molecules as potential sensitizers for highly efficient dye-sensitized solar cells. Acc Chem Res 42(11):1809-1818

93. Inakazu F, Noma Y, Ogomi Y, Hayase S (2008) Dye-sensitized solar cells consisting of dye-bilayer structure stained with two dyes for harvesting light of wide range of wavelength. Appl Phys Lett 93(9):093304

94. Islam A, Akhtaruazzaman Md, Chowdhury TH, Qin C, Han L, Bedja IM, Stalder R, Schanze KS, Reynolds JR (2016) Enhanced photovoltaic performances of dye-sensitized solar cells by cosensitization of benzothiadiazole and squaraine-based dyes. ACS Appl Mater Interfaces 8(7):4616-4623

95. Islam A, Chowdhury TH, Qin C, Han L, Lee J-J, Bedja IM, Akhtaruzzaman Md, Sopian K, Mirloup A, Leclerc N (2018) Panchromatic absorption of dye sensitized solar cells by co-sensitization of triple organic dyes. Sustain Energy Fuels 2:209-214

96. Ito BS, Snaith H, Bach U, Kwiatkowski J, Grätzel M (2008) The function of $\mathrm{a} \mathrm{TiO}_{2}$ compact layer in dye-sensitized solar cells incorporating "planar" organic dyes. Nano Lett 8(4):977-981
97. Itzhakov S, Buhbut S, Tauber E, Geiger T, Zaban A, Oron D (2011) Design principles of FRET-based dye-sensitized solar cells with buried quantum dot donors. Adv Energy Mater 1(4):626-633

98. Jeong MS, Son MK, Kim SK, Park S, Prabakar K, Kim HJ (2014) $\mathrm{Cu}$-doped $\mathrm{ZnO}$ nanoporous film for improved performance of $\mathrm{CdS} / \mathrm{CdSe}$ quantum dot-sensitized solar cells. Thin Solid Films 570:310-314

99. Jeong NC, Son HJ, Prasittichai $C$, Lee $C Y$, Jensen RA, Farha OK, Hupp JT (2012) Effective panchromatic sensitization of electrochemical solar cells: strategy and organizational rules for spatial separation of complementary light harvesters on higharea photoelectrodes. J Am Chem Soc 134(48):19820-19827

100. Jiang G, Susha AS, Lutich AA, Stefani FD, Feldmann J, Rogach AL (2009) Cascaded FRET in conjugated polymer/quantum dot/ dye-labeled DNA complexes for DNA hybridization detection. ACS Nano 3(12):4127-4131

101. Jiang J, Wang K, Liu Q, Zhai J (2016) Optimizing CdS intermediate layer of $\mathrm{CdS} / \mathrm{CdSe}$ quantum dot-sensitized solar cells to increase light harvesting ability and improve charge separation efficiency. RSC Adv 6:99564-99569

102. Jiao S, Du J, Du Z, Long D, Jiang W, Pan Z, Li Y, Zhong X (2017) Nitrogen-doped mesoporous carbons as counter electrodes in quantum dot sensitized solar cells with a conversion efficiency exceeding 12\%. J Phys Chem Lett 8:559-564

103. Jiao S, Shen Q, Mora-Sero I, Wang J, Pan Z, Zhao K, Kuga Y, Zhong X, Bisquert J (2015) Band engineering in core/shell ZnTe/ CdSe for photovoltage and efficiency enhancement in exciplex quantum dot sensitized solar cells. ACS Nano 9(1):908-915

104. Jin S, Son HJ, Farha OK, Wiederrecht GP, Hupp JT (2013) Energy transfer from quantum dots to metal-organic frameworks for enhanced light harvesting. J Am Chem Soc 135(3):955-958

105. Jun HK, Buraidah MH, Noor MM, Kufian MZ, Majid SR, Sahraoui B, Arof AK (2013) Application of LiBOB-based liquid electrolyte in co-sensitized solar cell. Opt Mater 36(1):151-158

106. Jun HK, Careem MA, Arof AK (2013) Quantum dot-sensitized solar cells-perspective and recent developments: a review of $\mathrm{Cd}$ chalcogenide quantum dots as sensitizers. Renew Sustain Energy Rev 22:148-167

107. Jun HK, Careem MA, Arof AK (2016) Performance and impedance spectroscopy of co-sensitization of anthocyanin dye and semiconductor quantum dots in sensitizing solar cells. Int J Electrochem Sci 11:2909-2918

108. Jung K, Lee J, Kim Y-M, Kim J, Kim C-U, Lee M-J (2016) Influence of defects and nanoscale strain on the photovoltaic properties of $\mathrm{CdS} / \mathrm{CdSe}$ nanocomposite co-sensitized $\mathrm{ZnO}$ nanowire solar cells. Electrochim Acta 220:500-510

109. Jung SW, Park MA, Kim JH, Kim H, Choi CJ, Kang SH, Ahn KS (2013) Two-step annealed CdS/CdSe co-sensitizers for quantum dot-sensitized solar cells. Curr Appl Phys 13(7):1532-1536

110. Kakiage K, Aoyama Y, Yano T, Oya K, Fujisawa J-I, Hanaya M (2015) Highly-efficient dye-sensitized solar cells with collaborative sensitization by silyl-anchor and caroboxy-anchor dyes. Chem Commun 51:15894-15897

111. Kamat PV (2008) Quantum dot solar cells. Semiconductor nanocrystals as light harvesters. J Phys Chem C 112(48):18737-18753

112. Kamat PV (2013) Quantum dot solar cells. The next big thing in photovoltaics. J Phys Chem Lett 4(6):908-918

113. Kamat PV, Christians JA, Radich JG (2014) Quantum dot solar cells: hole transfer as a limiting factor in boosting the photoconversion efficiency. Langmuir 30(20):5716-5725

114. Kao LC, Liou SYH, Dong CL, Yeh PH, Chen CL (2016) Tandem structure of $\mathrm{QD}$ cosensitized $\mathrm{TiO}_{2}$ nanorod arrays for solar light driven hydrogen generation. ACS Sustain Chem Eng 4(1):210-218 
115. Kim H-J, Lee H-D, Kumar CSSP, Rao SS, Chung S-H, Punnoose D (2015) The effect of manganese in a CdS/PbS colloidal quantum dot sensitized $\mathrm{TiO}_{2}$ solar cell to enhance its efficiency. New J Chem 39:4805-4813

116. Kim H-J, Xu G-C, Gopi CVVM, Seo H, Venkata-Haritha M, Shiratani $M$ (2017) Enhanced light harvesting and charge recombination control with $\mathrm{TiO}_{2} / \mathrm{PbCdS} / \mathrm{CdS}$ based quantum dotsensitized solar cells. J Electroanal Chem 788:131-136

117. Kim K, Park JE, Park ES, Park YC, Kim J, Im C, Lee MJ (2014) ZnS-passivated CdSe/CdS co-sensitized mesoporous $\mathrm{Zn}_{2} \mathrm{SnO}_{4}$ based solar cells. Electrochim Acta 121:223-232

118. Kim SK, Son MK, Park S, Jeong MS, Savariraj D, Prabakar K, Kim $\mathrm{HJ}$ (2014) The effect of $\mathrm{TiO}_{2}$ compact layer in $\mathrm{ZnO}$ nanorod based CdS/CdSe quantum-dot sensitized solar cell. Phys Stat Solidi (a) 211(8):1839-1843

119. Kim SK, Park S, Son MK, Kim HJ (2015) Ammonia treated ZnO nanoflowers based CdS/CdSe quantum dot sensitized solar cell. Electrochim Acta 151:531-536

120. Kimura M, Nomoto H, Masaki N, Mori S (2012) Dye molecules for simple co-sensitization process: fabrication of mixed-dyesensitized solar cells. Angew Chem Int Edit 51(18):4371-4374

121. Kouhnavard M, Ikeda S, Ludin NA, Ahmad Khairudin NB, Ghaffari BV, Mat-Teridi MA, Ibrahim MA, Sepeai S, Sopian K (2017) A review of semiconductor materials as sensitizers for quantum dot-sensitized solar cells. Renew Sustain Energy Rev 37:397-407

122. Kouhnavard M, Ludin NA, Ghaffari BV, Sopian K, Ikeda S (2015) Carbonaceous materials and their advances as a counter electrode in dye-sensitized solar cells: challenges and prospects. Chemsuschem 8:1510-1533

123. Kuang D, Walter P, Nuesch F, Kim S, Ko J, Comte P, Zakeeruddin SM, Nazeeruddin MK, Gratzel M (2007) Co-sensitization of organic dyes for efficient ionic liquid electrolyte-based dyesensitized solar cells. Langmuir 23(22):10906-10909

124. Kumar KA, Subalakshmi K, Senthilselvan J (2015) Co-sensitization of natural dyes for improved efficiency in dye-sensitized solar cell application. AIP Conf Proc 1731:060017

125. Kumara NTRN, Ekanayake P, Lim A, Liew LYC, Iskandar M, Ming LC, Senadeera GKR (2013) Layered co-sensitization for enhancement of conversion efficiency of natural dye sensitized solar cells. J Alloys Compd 581:186-191

126. Kumara NTRN, Lim A, Lim CM, Petra MI, Ekanayake P (2017) Recent progress and utilization of natural pigments in dye sensitized solar cells: a review. Renew Sustain Energy Rev 78:301-317

127. Kumavat PP, Sonar P, Dalal DS (2017) An overview on basics of organic and dye sensitized solar cells, their mechanism and recent improvements. Renew Sustain Energy Rev 78:1262-1287

128. Kushwaha $S$, Bahadur $L$ (2015) Enhancement of power conversion efficiency of dye-sensitized solar cells by co-sensitization of phloxine $\mathrm{B}$ and bromophenol blue dyes on $\mathrm{ZnO}$ photoanode. J Lumin 161:426-430

129. Kwon OO, Lee HJ, Kim SW, Kim JH, Kim TY, Park KH, Lee JW (2015) Layered co-sensitization of gardenia and monascus for panchromatic light harvesting in dye sensitized solar cells. Photonics Nanostruct Fundam Appl 14:71-76

130. Lai Y, Lin Z, Zheng D, Chi L, Du R, Lin C (2012) CdSe/CdS quantum dots co-sensitized $\mathrm{TiO}_{2}$ nanotube array photoelectrode for highly efficient solar cells. Electrochim Acta 79:175-181

131. Lan CM, Wu HP, Pan TY, Chang CW, Chao WS, Chen CT, Wang CL, Lin CY, Diau EW (2012) Enhanced photovoltaic performance with co-sensitization of porphyrin and an organic dye in dyesensitized solar cells. Energy Environ Sci 5(4):6460-6464
132. Lee $\mathrm{CL}$, Lee $\mathrm{WH}$, Yang $\mathrm{CH}$, Yang HH, Chang JY (2013) Triazoloisoquinoline-based dual functional dyestuff for dye-sensitized solar cells. Mater Res Bull 48(1):146-150

133. Lee E, Kim C, Jang J (2013) High-performance Förster resonance energy transfer (FRET)-based dye-sensitized solar cells: rational design of quantum dots for wide solar-spectrum utilization. Chem Eur J 19(31):10280-10286

134. Lee H, Kim J, Kim DY, Seo Y (2018) Co-sensitization of metal free organic dyes in flexible dye sensitized solar cells. Org Electron 52:103-109

135. Lee HJ, Bang J, Park J, Kim S, Park SM (2010) Multilayered semiconductor (CdS/CdSe/ZnS)-sensitized $\mathrm{TiO}_{2}$ mesoporous solar cells: all prepared by successive ionic layer adsorption and reaction processes. Chem Mater 22(19):5636-5643

136. Lee KM, Hsu YC, Ikegami M, Miyasaka T, Justin Thomas KR, Lin JT, Ho KC (2011) Co-sensitization promoted light harvesting for plastic dye-sensitized solar cells. J Power Sources 196(4):2416-2421

137. Lee Y, Jang S-R, Vittal R, Kim K-J (2007) Dinuclear Ru(II) dyes for improved performance of dye-sensitized $\mathrm{TiO}_{2}$ solar cells. New J Chem 31:2120-2126

138. Lee Y-S, Gopi CVVM, Venkata-Haritha M, Kim H-J (2016) Recombination control in high-performance quantum dot-sensitized solar cells with a novel $\mathrm{TiO}_{2} / \mathrm{ZnS} / \mathrm{CdS} / \mathrm{ZnS}$ heterostructure. Dalton Trans 45:12914-12923

139. Li B, Wang L, Kang B, Wang P, Qiu Y (2006) Review of recent progress in solid-state dye-sensitized solar cells. Sol Energy Mater Sol Cells 90:549-573

140. Li H, Wang X, Liu Y, Hou B (2014) Ag and $\mathrm{SnO}_{2}$ co-sensitized $\mathrm{TiO}_{2}$ photoanodes for protection of $304 \mathrm{SS}$ under visible light. Corros Sci 82:145-153

141. Li LB, Wang YF, Rao HS, Wu WQ, Li KN, Su CY, Kuang DB (2013) Hierarchical macroporous $\mathrm{Zn}_{2} \mathrm{SnO}_{4}-\mathrm{ZnO}$ nanorod composite photoelectrodes for efficient $\mathrm{CdS} / \mathrm{CdSe}$ quantum dot co-sensitized solar cells. ACS Appl Mater Interfaces 5(22):11865-11871

142. Li J, Zhao L, Wang S, Hu J, Dong B, Lu H, Wan L, Wang P (2013) Great improvement of photoelectric property from co-sensitization of $\mathrm{TiO}_{2}$ electrodes with CdS quantum dots and dye N719 in dye-sensitized solar cells. Mater Res Bull 48(7):2566-2570

143. Li W, Yang J, Jiang Q, Luo Y, Hou Y, Zhou S, Xiao Y, Fu L, Zhou Z (2016) Electrochemical atomic layer deposition of $\mathrm{Bi}_{2} \mathrm{~S}_{3} / \mathrm{Sb}_{2} \mathrm{~S}_{3}$ quantum dots co-sensitized $\mathrm{TiO}_{2}$ nanorods solar cells. J Power Sources 307:690-696

144. Li Y, Liu Z, Liu C, Ya J, Zhao W, Chen Q, Bai J (2012) CulnS2, N3, co-sensitized $\mathrm{ZnO}$ nanorods with improved photovoltaic properties for solar cells. J Am Chem Soc 95(4):1343-1347

145. Li Y, Wei L, Chen X, Zhang R, Sui X, Chen Y, Jiao J, Mei L (2013) Efficient PbS/CdS co-sensitized solar cells based on $\mathrm{TiO}_{2}$ nanorod arrays. Nanoscale Res Lett 8(1):1-7

146. Li Y, Zhang Y, Xu W, Wang B, Zhang J (2017) Extending spectrum response of squaraine-sensitized solar cell by Forster resonance energy transfer. J Solid State Electrochem 21:2091-2098

147. Li ZX, Xie YL, Xu H, Wang TM, Xu ZG, Zhang HL (2011) Expanding the photoresponse range of $\mathrm{TiO}_{2}$ nanotube arrays by $\mathrm{CdS} /$ $\mathrm{CdSe} / \mathrm{ZnS}$ quantum dots co-modification. J Photochem Photobiol A 224(1):25-30

148. Lin C-A, Huang KP, Ho ST, Huang M-W, He J-H (2012) An energyharvesting scheme utilizing Ga-rich $\mathrm{Culn}_{(1-x)} \mathrm{Ga}_{x} \mathrm{Se}_{2}$ quantum dots for dye-sensitized solar cells. Appl Phys Lett 101:123901

149. Lin LY, Yeh MH, Lee CP, Chang J, Baheti A, Vittal R, Justin Thomas KR, Ho KC (2014) Insights into the co-sensitizer adsorption kinetics for complementary organic dye-sensitized solar cells. J Power Sources 247:906-914

150. Lin RYY, Lin HW, Yen YS, Chang CH, Chou HH, Chen PW, Hsu CY, Chen YC, Lin JT (2013) 2,6-conjucated anthracene sensitizers for 
high-performance dye-sensitized solar cells. Energy Environ Sci 6(8):2477-2486

151. Lin X, Yu K, Lu G, Chen J, Yuan C (2012) Atomic layer deposition of $\mathrm{TiO}_{2}$ interfacial layer for enhancing performance of quantum dot and dye co-sensitized solar cells. J Phys D Appl Phys 46(2):024004

152. Lin Y, Lin Y, Wu J, Zhang X, Fang B (2016) Optimization of CdSe layer on modified $\mathrm{ZnO}$ hierarchical spheres by spin-SILAR for efficient CdS/CdSe co-sensitized solar cells. J Mater Sci Mater Electron 27:6656-6664

153. Lin $Y$, Lin $Y$, Wu J, Zhang $X$, Fang B (2017) Fabrication of ZnO/ $\mathrm{SnO}_{2}$ hierarchical structures as the composite photoanodes for efficient CdS/CdSe co-sensitized solar cells. Appl Phys A 123:189

154. Liu C, Liu Z, Li Y, Ya J, Lei E, An L (2011) CdS/PbS co-sensitized $\mathrm{ZnO}$ nanorods and its photovoltaic properties. Appl Surf Sci 257(16):7041-7046

155. Liu J, Liu B, Tang Y, Zhang W, Wu W, Xie Y, Zhu WH (2015) Highly efficient cosensitization of $D-A-\pi-A$ benzotriazole organic dyes with porphyrin for panchromatic dye-sensitized solar cells. J Mater Chem C 3(42):11144-11150

156. Liu Y, Wang J (2010) Co-sensitization of $\mathrm{TiO}_{2}$ by $\mathrm{PbS}$ quantum dots and dye N719 in dye-sensitized solar cells. Thin Solid Films 518(24):e54-e56

157. Liyanage NP, Cheema H, Baumann AR, Zylstra AR, Delcamp JH (2017) Effect pf donor strength and bulk on thieno[3,4-b]pyrazine-based panchromatic dyes in dye-sensitized solar cells. Chemsuschem 10:2635-2641

158. Lodermeyer F, Costa RD, Malig J, Jux N, Guldi DM (2016) Benzoporphyrins: selective co-sensitization in dye-sensitized solar cells. Chem Eur J 22:7851-7855

159. Luo J, Wan Z, Jia C, Wang Y, Wu X, Yao X (2016) Co-sensitization of dithiafulvenyl-phenothiazine based organic dyes with N719 for efficient dye-sensitized solar cells. Electrochem Acta 211:364-374

160. Luo J, Wei H, Li F, Huang Q, Li D, Luo Y, Meng Q (2014) Microwave assisted aqueous synthesis of core-shell $\mathrm{CdSe}_{x} \mathrm{Te}_{1-x}-\mathrm{CdS}$ quantum dots for high performance sensitized solar cells. Chem Commun 50:3464-3466

161. Luo S, Kazes M, Lin H, Oron D (2017) Strain-induced type II band alignment control in CdSe nanoplatelet/ZnS-sensitized solar cells. J Phys Chem C 121(21):11136-11143

162. Luo S, Shen H, Hu W, Yao Z, Li J, Oron D, Wang N, Lin H (2016) Improved charge separation and transport efficiency in panchromatic-sensitized solar cells with co-sensitization of $\mathrm{PbS} / \mathrm{CdS} / \mathrm{ZnS}$ quantum dots and dye molecules. RSC Adv 6:21156-21164

163. Magne C, Urien M, Pauporte T (2013) Enhancement of photovoltaic performances in dye-sensitized solar cells by co-sensitization with metal-free organic dyes. RSC Adv 3:6315-6318

164. Malzner FJ, Willgert M, Constable EC, Housecroft CE (2017) The way to panchromatic copper (I) based dye-sensitized solar cells: co-sensitization with the organic dye SQ2. J Mater Chem A 5:13717-13729

165. Manjceevan A, Bandara J (2016) Robust surface passivation of trap sites in PbS q-dots by controlling the thickness of CdS layers in $\mathrm{PbS} / \mathrm{CdS}$ quantum dot solar cells. Sol Energy Mater Sol Cells 147:157-163

166. Md. Molla Z, Kawano M, Baranwal AK, Pandey SS, Ogomi Y, Ma T, Hayase $S$ (2016) Enhancing the performance of transparent conductive oxide-less back contact dye-sensitized solar cells by facile diffusion of cobalt species through $\mathrm{TiO}_{2}$ nanopores. RSC Adv 6:33353-33360

167. Md. Zaman M, Baranwal AK, Pandey SS, Ma T, Hayase S (2017) Transparent conductive oxide-less dye-sensitized solar cells consisting of dye-cocktail and cobalt based redox electrolyte. J Nanosci Nanotechnol 17:4748-4754

168. Mehmood U, Hussein IA, Harrabi K, Tabet N, Berdiyorov GR (2016) Enhanced photovoltaic performance with co-sensitization of a ruthenium (II) sensitizer and an organic dye in dyesensitized solar cells. RSC Adv 6:7897-7901

169. Mehmood U, Ahmad SHA, Khan AUH, Qaiser AA (2018) Cosensitization of graphene/ $/ \mathrm{TiO}_{2}$ nanocomposite thin films with ruthenizer and metal free organic photosensitizers for improving the power conversion efficiency of dye-sensitized solar cells (DSSCs). Sol Energy 170:47-55

170. Meng K, Surolia PK, Byrne O, Thampi KR (2015) Quantum dot and quantum dot-dye co-sensitized solar cells containing organic thiolate-disulfide redox electrolyte. J Power Sources 275:681-687

171. Mohammadpour R, Janfaza S, Zeinoddini M (2016) Potential of light-harvesting of bacteriorhodopsin co-sensitized with green fluorescence protein: a new insight into bioenergy application. Biomass Bioenergy 87:35-38

172. Mora-Seró I, Bisquert J (2010) Breakthroughs in the development of semiconductor-sensitized solar cells. J Phys Chem Lett 1(20):3046-3052

173. Naik P, Su R, El-Shafei A, Adhikari AV (2017) Improved photovoltaic performance of Ru(II) complex sensitized DSSCs by co-sensitization of carbazole based chromophores. Inorg Chem Commun 86:241-245

174. Naik P, Keremane KS, Elmorsy MR, Su R, El-Shafei A, Adhikari AV (2018) Highly efficient carbazole based co-sensitizers carrying electron deficient acid for NCSU-10 sensitized DSSCs. Sol Energy 169:386-391

175. Naik P, Su R, Elmorsy MR, El-Shafei A, Adhikari AV (2018) Investigation of new carbazole based metal-free dyes as active photo-sensitizers/co-sensitizers for DSSCs. Dyes Pigments 149:177-187

176. Naik P, Su R, Elmorsy MR, El-Shafei A, Adhikari AV (2018) New carbazole based dyes as effective co-sensitizers for DSSCs sensitized with ruthenium (II) complex (NCSU-10). J Energy Chem 27:351-360

177. Naik P, Su R, Elmorsy MR, El-Shafei A, Adhikari AV (2018) New di-anchoring $A-\pi-D-\pi-A$ configured organic chromophores for DSSC application: sensitization and co-sensitization studies. Photochem Photobiol Sci 17:302-314

178. Narayanan R, Deepa M, Srivastava AK (2013) Förster resonance energy transfer and carbon dots enhance light harvesting in a solid-state quantum dot solar cell. J Mater Chem A 1(12):3907-3918

179. Niitsoo O, Sarkar SK, Pejoux C, Rühle S, Cahen D, Hodes G (2006) Chemical bath deposited CdS/CdSe Co-sensitized porous $\mathrm{TiO}_{2}$ solar cells. J Photochem Photobiol A Chem 181(2):306-313

180. Nosheen E, Shah SM, Hussain H, Murtaza G (2016) Photo-sensitization of $\mathrm{ZnS}$ nanoparticles with renowned ruthenium dyes N3, N719 and Z907 for application in solid state dye sensitized solar cells: a comparative study. J Photochem Photobiol B Biol 162:583-591

181. Nguyen LH, Mulmudi HK, Sabba D, Kulkarni SA, Batabyal SK, Nonomura K, Gratzel M, Mhaisalkar G (2012) A selective co-sensitization approach to increase photon conversion efficiency and electron lifetime in dye-sensitized solar cells. Phys Chem Chem Phys 14(47):16182-16186

182. Nguyen V, Li W, Pham V, Wang L, Sheng P, Cai Q, Grimes C (2016) A CdS/ZnSe/ $/ \mathrm{TiO}_{2}$ nanotube array and its visible light photocatalytic activities. J Alloys Compd 462:389-396

183. Ooyama Y, Uenaka K, Kanda M, Yamada T, Shibayama N, Ohshita $J$ (2015) A new co-sensitization method employing D-ח-A dye 
with pyridyl group and D- $\pi-$ Cat dye with catechol unit for dyesensitized solar cells. Dyes Pigments 122:40-45

184. O'Regan B, Grätzel M (1991) A low cost, High efficiency solar cells based on dye-sensitized colloidal $\mathrm{TiO}_{2}$ films. Nature 353:737-740

185. Pan J, Song H, Lian C, Liu H, Xie Y (2017) Cocktail co-sensitization of porphyrin dyes with additional donors and acceptors for developing efficient dye-sensitized solar cells. Dyes Pigments 140:36-46

186. Pan Z, Zhang H, Cheng K, Hou Y, Hua J, Zhong X (2012) Highly efficient inverted type-I CdS/CdSe core/shell structure QDsensitized solar cells. ACS Nano 6(5):3982-3991

187. Park JH, Kim DH, Shin SS, Han HS, Lee MH, Jung HS, Noh JH, Hong KS (2014) A hierarchically organized photoelectrode architecture for highly efficient $\mathrm{CdS} / \mathrm{CdSe}$ sensitized solar cells. Adv Energy Mater 4(3):1300395

188. Park KH, Kim TY, Park JY, Jin EM, Yim SH, Choi DY, Lee JW (2013) Adsorption characteristics of gardenia yellow as natural photosensitizer for dye-sensitized solar cells. Dyes Pigments 96(2):595-601

189. Pastore M, Angelis FD (2012) First-principles computational modeling of fluorescence resonance energy transfer in cosensitized dye solar cells. J Phys Chem Lett 3(16):2146-2153

190. Peng Z, Liu Y, Chen W, Chen K, Chen J, Chen J (2017) Long wavelength optical absorption and photovoltaic performance enhancement on $\mathrm{CuInS}_{2}$ and $\mathrm{PbS}$ quantum dot co-sensitized solar cells. J Alloys Compd 701:131-137

191. Peddapuram A, Cheema H, Adams RE, Schmehl RH, Delcamp JH (2017) A stable panchromatic green dual acceptor, dual donor organic dye for dye-sensitized solar cells. J Phys Chem C 121:8770-8780

192. Pepe G, Cole JM, Waddell PG, McKechine S (2016) Molecular engineering of cyanine dyes to design a panchromatic response in co-sensitized dye-sensitized solar cells. Mol Syst Des Eng 1:86-98

193. Pepe G, Cole JM, Waddell PG, Griffiths JRD (2016) Molecular engineering of fluorescein dyes as complementary absorbers in dye co-sensitized solar cells. Mol Syst Des Eng 1:402-415

194. Prakash K, Sudhakar V, Sankar M, Krishnamoorthy K (2019) Trans- $A_{2} B_{2} Z n(I I)$ porphyrin dyes with various donor groups and their co-sensitization for highly efficient dye-sensitized solar cells. Dyes Pigments 160:386-394

195. Prima EC, Qibtiya MA, Yuliarto B, Suyatman, Dipojono HK (2016) Influence of anthocyanin co-pigment on electron transport and performance in black rice dye-sensitized solar cell. lonics 22:1687-1697

196. Punnoose D, Suh S-M, Kim B-J, Kim S-K, Kumar SSP, Rao SS, Thulasi-Varma CV, Reddy AE, Chung S-H, Kim H-J (2016) The influence of in situ deposition techniques on $\mathrm{PbS}$ seeded CdS/ $\mathrm{CdSe}$ for enhancing the photovoltaic performance of quantum dot sensitized solar cells. J Electroanal Chem 773:27-38

197. Punnoose D, Kumar SSP, Seo HW, Shiratani M, Reddy AE, Rao SS, Thulasi-Varma CV, Kim S-K, Chung S-H, Kim H-J (2016) Reduced recombination with an optimized barrier layer on $\mathrm{TiO}_{2}$ in $\mathrm{PbS} /$ $\mathrm{CdS}$ core shell quantum dot sensitized solar cells. New J Chem 40:3423-3431

198. Qiao W, Zhang D, Zhang L, Kang C (2016) Post-thermal annealing for enhancing photovoltaic performance of $\mathrm{CdS} / \mathrm{CdSe}$ quantum dot co-sensitized $\mathrm{TiO}_{2}$ electrodes. J Alloys Compd 658:697-702

199. Qin C, Numata Y, Zhang S, Islam A, Yang X, Sodeyama K, Tateyama Y, Han L (2013) A near-infrared cis-configured squaraine co-sensitizer for high-efficiency dye-sensitized solar cells. Adv Funct Mater 23(30):3782-3789
200. Raj CJ, Karthick SN, Park S, Hemalatha KV, Kim S-K, Prabakar K, Kim H-J (2014) Improved photovoltaic performance of CdSe/ $\mathrm{CdS} / \mathrm{PbS}$ quantum dot sensitized $\mathrm{ZnO}$ nanorod array solar cell. J Power Sources 248:439-446

201. Ranasinghe CS, Wanninnayake WM, Kumara GR, Rajapakshe RM, Sirimanne PM (2014) An enhancement of efficiency of a solidstate dye-sensitized solar cell due to cocktail effect of N719 and black dye. Opt Int J Light Electron Opt 125(2):813-815

202. Rao GH, Venkateswararao A, Giribabu L, Han L, Bedja I, Gupta RK, Islam A, Singh SP (2016) Near-infrared squaraine co-sensitizer for high-efficiency dye-sensitized solar cells. Phys Chem Chem Phys 18(21):14279-14285

203. Rao HS, Wu WQ, Liu Y, Xu YF, Chen BX, Chen HY, Kuang DB, Su CY (2014) CdS/CdSe co-sensitized vertically aligned anatase $\mathrm{TiO}_{2}$ nanowire arrays for efficient solar cells. Nano Energy 8:1-8

204. Rawal SB, Do Sung S, Moon SY, Shin YJ, Lee WI (2012) Optimization of CdS layer on $\mathrm{ZnO}$ nanorod arrays for efficient $\mathrm{CdS} / \mathrm{CdSe}$ co-sensitized solar cell. Mater Lett 82:240-243

205. Rawal SB, Sung SD, Lee CH, Lee WI (2015) Nanoporous ZnO nanoball for efficient $\mathrm{CdS} / \mathrm{CdSe} \mathrm{Co}$-sensitized quantum dot sensitized solar cells. Bull Mater Sci 36(3):979-983

206. Reddy KSR, Chen Y-C, Wu C-C, Hsu C-W, Chang Y-C, Chen C-M, Yeh C-Y (2018) Cosensitization of structurally simple porphyrin and anthracene-based dye for dye-sensitized solar cells. ACS Appl Mater Interfaces 10:2391-2399

207. Ren X, Yu L, Li Z, Song H, Wang Q (2018) The influence of $\mathrm{CdS}$ intermediate layer on $\mathrm{CdSe} / \mathrm{CdS}$ co-sensitized freestanding $\mathrm{TiO}_{2}$ nanotube solar cells. Superlattices Microstruct 113:696-705

208. Ren Z, Wang J, Pan Z, Zhao K, Zhang H, Li Y, Zhao Y, Mora-Sero I, Bisquert J, Zhong X (2015) Amorphous $\mathrm{TiO}_{2}$ buffer layer boosts efficiency of quantum dot sensitized solar cells to over $9 \%$. Chem Mater 27(24):8398-8405

209. Richhariya G, Kumar A, Tekasakul P, Gupta B (2017) Natural dyes for dye sensitized solar cell: a review. Renew Sustain Energy Rev 69:705-718

210. Risplendi F, Cicero G (2015) Co-adsorbent effect on the sensitization of $\mathrm{TiO}_{2}$ and $\mathrm{ZnO}$ surfaces: a theoretical study. J Phys Chem C 119(49):27348-27353

211. Roda A, Guardigli M, Michelini E, Mirasoli M (2009) Nanobioanalytical luminescence: Förster-type energy transfer methods. Anal Bioanal Chem 393(1):109-123

212. Sahasrabudhe A, Bhattacharyya S (2015) Dual sensitization strategy for high-performance core/shell/quasi-shell quantum dot solar cells. Chem Mater 27(13):4848-4859

213. Salaramoli H, Maleki E, Shariatinia Z, Ranjbar M (2013) CdS/ CdSe quantum dots co-sensitized solar cells with Cu2S counter electrode prepared by SILAR, spray pyrolysis and $\mathrm{Zn}-\mathrm{Cu}$ alloy methods. J Photochem Photobiol A Chem 271:56-64

214. Salvatori P, Amat A, Pastore M, Vitillaro G, Sudhakar K, Giribabu L, Soujanya Y, De Angelis F (2014) Corrole dyes for dye-sensitized solar cells: the crucial role of the dye/semiconductor energy level alignment. Comput Theor Chem 1030:59-66

215. Salvatori P, Agrawal S, Barreddi C, Malapaka C, De Borniol M, De Angelis F (2014) Stability of ruthenium/organic dye cosensitized solar cells: a joint experimental and computational investigation. RSC Adv 4:57620-57628

216. Saxena V, Veerender P, Chauhan AK, Jha P, Aswal DK (2012) Efficiency enhancement in dye sensitized solar cells through co-sensitization of $\mathrm{TiO}_{2}$ nanocrystalline electrodes. Appl Phys Lett 100(13):133303

217. Sayyed SAAR, Beedri NI, Pathan HM (2017) Spinach extract and Eoisin-Y co-sensitized ceria photoanode for dye sensitized solar cell application: effect of dye adsorption time. J Mater Sci Mater Electron 28:5075-5081 
218. Sengupta D, Das P, Mondal B, Mukherjee K (2016) Effects of doping, morphology and film-thickness of photo-anode materials for dye sensitized solar cell application-a review. Renew Sustain Energy Rev 60:356-376

219. Seo KD, Song HM, Lee MJ, Pastore M, Anselmi C, De Angelis F, Nazeeruddin MK, Graetzel M, Kim HK (2011) Coumarin dyes containing low-band-gap chromophores for dye-sensitized solar cells. Dyes Pigments 90:304-310

220. Seo KD, Choi IT, Park YG, Kang S, Lee JY, Kim HK (2012) Novel $\mathrm{D}-\mathrm{A}-\pi-\mathrm{A}$ coumarin dyes containing low band-gap chromophores for dye-sensitized solar cells. Dyes Pigments 94:469-474

221. Seol M, Ramasamy E, Lee J, Yong K (2011) Highly efficient and durable quantum dot sensitized $\mathrm{ZnO}$ nanowire solar cell using noble-metal-free counter electrode. J Phys Chem C 115(44):22018-22024

222. Shalom M, Albero J, Tachan Z, Martínez-Ferrero E, Zaban A, Palomares E (2010) Quantum dot-dye bilayer-sensitized solar cells: breaking the limits imposed by the low absorbance of dye monolayers. J Phys Chem Lett 1(7):1134-1138

223. Shamadpour M (2017) Efficient CdS/CdSe/ZnS quantum dot sensitized solar cells prepared by $\mathrm{ZnS}$ treatment from methanol solvent. Sol Energy 144:63-70

224. Sharma GD, Angaridis PA, Pipou S, Zervaki GE, Nikolaou V, Misra R, Coutsolelos AG (2015) Efficient co-sensitization of dye-sensitized solar cells by novel porphyrin/triazine dye and tertiary aryl-amine organic dye. Org Electron 25:295-307

225. Sharma D, Jha R, Kumar S (2016) Quantum dot sensitized solar cell: recent advances and future perspectives in photoanode. Sol Energy Mater Sol Cells 155:294-322

226. Sharma GD, Zervaki GE, Angaridis PA, Vatikioti A, Gupta KS, Gayathri T, Nagarjuna P, Singh SP, Chandrasekharam M, Banthiya A, Bhanuprakash K (2014) Stepwise co-sensitization as a useful tool for enhancement of power conversion efficiency of dye-sensitized solar cells: the case of an unsymmetrical porphyrin dyad and a metal-free organic dye. Org Electron 15(7):1324-1337

227. Shen H, Lin H, Liu Y, Li J, Oron D (2012) Study of quantum dot/ inorganic layer/dye molecule sandwich structure for electrochemical solar cells. Phys Chem C 116(29):15185-15191

228. Shen YC, Deng H, Fang J, Lu Z (2000) Co-sensitization of microporous $\mathrm{TiO}_{2}$ electrodes with dye molecules and quantum-sized semiconductor particles. Colloids Surf A Physicochem Eng Asp 175(1):135-140

229. Shikoh AS, Ahmad Z, Touati F, Al-Muhtaseb SA (2018) Enhancement of electrical and optical performance of N719 by co-sensitization. Opt Mater 78:201-206

230. Siegers C, Hohl-Ebinger J, Zimmermann B, Würfel U, Mülhaupt R, Hinsch A, Haag R (2007) A dyadic sensitizer for dye solar cells with high energy-transfer efficiency in the device. Chem Phys Chem 8(10):1548-1556

231. Singh M, Kurchania R, Ball RJ, Sharma GD (2016) Efficiency enhancement in dye sensitized solar cells through step wise cosensitization of $\mathrm{TiO}_{2}$ electrode with N719 and metal free dye. Ind J Pure Appl Phys 54:656-664

232. Singh SP, Chandrasekharam M, Gupta KS, Islam A, Han L, Sharma GD (2013) Co-sensitization of amphiphilic ruthenium (II) sensitizer with a metal free organic dye: improved photovoltaic performance of dye sensitized solar cells. Org Electron 14(5):1237-1241

233. Sisman I, Tekir O, Karaca H (2017) Role of ZnO photoanode nanostructures and sensitizer deposition approaches on the photovoltaic properties of $\mathrm{CdS} / \mathrm{CdSe}$ and $\mathrm{CdS}_{1-x} \mathrm{Se}_{x}$ quantum dot-sensitized solar cells. J Power Sources 340:192-200

234. Song BJ, Song HM, Choi IT, Kim SK, Seo KD, Kang MS, Lee MJ, Cho DW, Ju MJ, Kim HK (2011) A desirable hole-conducting coadsorbent for highly efficient dye-sensitized solar cells through an organic redox cascade strategy. Chem A Eur J 17(40):11115-11121

235. Song JG, Song X, Ling T, Du XW, Qiao SZ (2012) Enhancing the conversion efficiency of semiconductor sensitized solar cells via the co-sensitization of dual-sized quantum dots. Ind Eng Chem Res 51(30):10074-10078

236. Song X, Yu X-L, Xie Y, Sun J, Ling T, Du X-W (2010) Improving charge separation of solar cells by the co-sensitization of CdS quantum dots and dye. Semicond Sci Technol 25:095014

237. Su J, Zhu S, Chen R, An Z, Chen X, Chen P (2017) Study on dyeloading mode on $\mathrm{TiO}_{2}$ films and impact of co-sensitizers on highly efficient co-sensitized solar cells. J Mater Sci Mater Electron 28:3962-3969

238. Subramanyam P, Kumar PN, Deepa M, Subrahmanyam Ghosal $P$ (2017) Bismuth sulfide nanocrystals and gold nanocrystals increase the photovoltaic response of a $\mathrm{TiO}_{2} / \mathrm{CdS}$ based solar cells. Sol Energy Mater Sol Cells 159:296-306

239. Sulaeman U, Abdullah AZ (2017) The way forward for the modification of dye-sensitized solar cell towards better power conversion efficiency. Renew Sustain Energy Rev 74:438-452

240. Tetreault N, Gratzel M (2012) Novel nanostructures for next generation dye-sensitized solar cells. Energy Environ Sci 5:8506-8516

241. Tian J, Gao R, Zhang Q, Zhang S, Li Y, Lan J, Qu X, Cao G (2012) Enhanced performance of CdS/CdSe quantum dot co-sensitized solar cells via homogeneous distribution of quantum dots in $\mathrm{TiO}_{2}$ film. J Phys Chem C 116(35):18655-18662

242. Vittal R, Ho K-C (2017) Zinc oxide based dye-sensitized solar cells: a review. Renew Sustain Energy Rev 70:920-935

243. Wang CL, Shiu JW, Hsiao YN, Chao PS, Diau EWG, Lin CY (2014) Co-sensitization of zinc and free-base porphyrins with an organic dye for efficient dye-sensitized solar cells. J Phys Chem C 118(48):27801-27807

244. Wang CL, Hu JY, Wu CH, Kuo HH, Chang YC, Lan ZJ, Wu HP, Diau EWG, Lin CY (2014) Highly efficient porphyrin-sensitized solar cells with enhanced light harvesting ability beyond $800 \mathrm{~nm}$ and exceeding efficiency 10\%. Energy Environ Sci 7:1392-1396

245. Wang J, Mora-Sero I, Pan Z, Zhao K, Zhang H, Feng Y, Yang G, Zhong X, Bisquert J (2013) Core/shell colloidal quantum dot exciplex states for the development of highly efficient quantum-dot-sensitized solar cells. J Am Chem Soc 135(42):15913-15922

246. Wang $Q$, Jin R, Yin C, Wang M, Wang J, Gao S (2017) Photoelectrocatalytic removal of dye and $\mathrm{Cr}(\mathrm{VI})$ pollutants with $\mathrm{Ag}_{2} \mathrm{~S}$ and $\mathrm{Bi}_{2} \mathrm{~S}_{3}$ co-sensitized $\mathrm{TiO}_{2}$ nanotube arrays under solar irradiation. Sep Purif Technol 172:303-309

247. Wang Q, Zheng Q, Jin R, Gao S, Yuan Q, Rong W, Wang R (2017) Photoelectrocatalytic removal of organic dyes and $\mathrm{Cr}(\mathrm{VI})$ ions using $\mathrm{Ag}_{3} \mathrm{PO}_{4}$ nanoparticles sensitized $\mathrm{TiO}_{2}$ nanotube arrays. Mater Chem Phys 199:209-215

248. Wang S, Tian J (2016) Recent advances in counter electrodes of quantum dot-sensitized solar cells. RSC Adv 6:900082-990099

249. Wang YQ, Rui YC, Zhang QH, Li YG, Wang HZ (2013) A facile in situ synthesis route for CulnS $\mathrm{S}_{2}$ quantum dots $/ \mathrm{In}_{2} \mathrm{~S}_{3}$ co-sensitized photoanodes with high photoelectric performance. ACS Appl Mater Int 5(22):11858-11864

250. Wanwong S, Sangkhun W, Wootthikanokkhan J (2018) The effect of co-sensitization methods between N719 and boron dipyrromethene triads on dye-sensitized solar cell performance. RSC Adv 8:9202-9210

251. Weerasinghe HC, Huang F, Cheng Y-B (2013) Fabrication of flexible dye sensitized solar cells on plastic substrates. Nano Energy 2:174-189

252. Wu HP, Ou ZW, Pan TY, Lan CM, Huang WK, Lee HW, Reddy NM, Chen CT, Chao WS, Yeh CY, Diau EW (2012) Molecular 
engineering of cocktail co-sensitization for efficient panchromatic porphyrin-sensitized solar cells. Energy Environ Sci 5(12):9843-9848

253. Wu W, Meng F, Li J, Teng X, Hua J (2009) Co-sensitization with near-IR absorbing cyanine dye to improve photoelectric conversion of dye-sensitized solar cells. Synth Met 159(11):1028-1033

254. Wu W, Xiang $\mathrm{H}$, Fan W, Wang J, Wang $\mathrm{H}$, Hua X, Wang Z, Long Y, Tian H, Zhu W-H (2017) Cosensitized porphyrin system for high-performance solar cells with TOF-SIMS analysis. ACS Appl Mater Interfaces 9(19):16081-16090

255. Xiao J, Huang Q, Xu J, Li C, Chen G, Luo Y, Li D, Meng Q (2014) $\mathrm{CdS} / \mathrm{CdSe}$ co-sensitized solar cells based on a new $\mathrm{SnO}_{2}$ photoanode with a three-dimensionally interconnected ordered porous structure. J Phys Chem C 118(8):4007-4015

256. Xie Y-L, Song P, Zhao S-Q (2016) Preparation of SnS/CdS cosensitized $\mathrm{TiO}_{2}$ photoelectrodes for quantum dots sensitized solar cells. J Electron Mater 45:4952-4957

257. Xie Y, Wu L, Han L, Gao J (2017) Co-sensitization by triarylamine dyes for improved dye-sensitized solar cells. Phys Status Solidi A 214:1600938

258. Xie Y, Tang Y, Wu W, Wang Y, Liu J, Li X, Tian H, Zhu W-H (2015) Porphyrin cosensitization for a photovoltaic efficiency of 11.5\%: a record for non-ruthenium solar cells based on iodine electrolyte. J Am Chem Soc 137:14055-14058

259. Xu SS, Chen WL, Wang YH, Li YG, Liu ZJ, Shan CH, Su ZM, Wang EB (2015) Co-sensitization promoted light harvesting with a new mixed-addenda polyoxometalate $\left[\mathrm{Cu}\left(\mathrm{C}_{12} \mathrm{H}_{8} \mathrm{~N}_{2}\right)_{2}\right]_{2}$ $\left[\mathrm{V}_{2} \mathrm{~W}_{4} \mathrm{O}_{19}\right] \cdot 4 \mathrm{H}_{2} \mathrm{O}$ in dye-sensitized solar cells. Dalton Trans 44(42):18553-18562

260. Xu YF, Wu WQ, Rao HS, Chen HY, Kuang DB, Su CY (2015) CdS/ CdSe co-sensitized $\mathrm{TiO}_{2}$ nanowire-coated hollow spheres exceeding $6 \%$ photovoltaic performance. Nano Energy $11: 621-630$

261. Yadav R, Trivedi M, Kociok-Kohn G, Chauhan R, Kumar A, Gosavi SW (2016) Ferrocenyl dithiocarbamate based $d^{10}$ transitionmetal complexes as potential co-sensitizers in dye-sensitized solar cells. Eur J Chem 7:1013-1021

262. Yadav R, Waghadkar Y, Kociok-Kohn G, Kumar A, Rane SB, Chauhan R (2016) Transition metal ferrocenyl dithiocarbamates functionalized dye-sensitized solar cells with hydroxyl as an anchoring group. Opt Mater 62:176-183

263. Yang CH, Chen PY, Chen WJ, Wang TL, Shieh YT (2013) Spectroscopic evidences of synergistic co-sensitization in dyesensitized solar cells via experimentation of mixture design. Electrochem Acta 107:170-177

264. Yang J, Zhong X (2016) CdTe based quantum dot sensitized solar cells with efficiency exceeding $7 \%$ fabricated from quantum dots prepared in aqueous media. J Mater Chem A 4:16553-16561

265. Yang L, Leung WW, Wang J (2013) Improvement in light harvesting in a dye sensitized solar cell based on cascade charge transfer. Nanoscale 5(16):7493-7498

266. Yang Z, Zhang Q, Xi J, Park K, Xu X, Liang Z, Cao G (2012) CdS/ CdSe Co-sensitized solar cell prepared by jointly using successive ion layer absorption and reaction method and chemical bath deposition process. Sci Adv Mater 4(10):1013-1017

267. Ye M, Gao X, Hong X, Liu Q, He C, Liu X, Lin C (2017) Recent advances in quantum dot-sensitized solar cells: insights into photoanodes, sensitizers, electrolytes and counter electrodes. Sustain Energy Fuels 1:1217-1231

268. Yella A, Mathew S, Aghazada S, Comte P, Gratzel M, Nazeeruddin MK (2017) Dye-sensitized solar cells using cobalt electrolytes: the influence of porosity and pore size to achieve highefficiency. J Mater Chem C 5:2833-2843
269. Yeoh M-E, Chan K-Y (2017) Recent advances in photo-anode for dye-sensitized solar cells: a review. Int J Energy Res 41(15):2446-2467

270. Yin Y, Li J, Wang Y, Wan J, Du X, Hu X, Liu E, Fan J (2017) Constructing $\mathrm{ZnSe}$ and $\mathrm{Au}$ co-sensitized $\mathrm{TiO}_{2}$ nanotube arrays for high-efficiency photoelectrocatalytic activities. Mater Res Bull 88:33-40

271. Yu L, Fan K, Duan T, Chen X, Li R, Peng T (2014) Efficient panchromatic light harvesting with co-sensitization of zinc phthalocyanine and bithiophene-based organic dye for dye-sensitized solar cells. ACS Sustain Chem Eng 2(4):718-725

272. Yu L, Li Z, Liu Y, Cheng F, Sun S (2014) Synthesis of hierarchical $\mathrm{TiO}_{2}$ flower-rod and application in $\mathrm{CdSe} / \mathrm{CdS}$ co-sensitized solar cell. J Power Sources 270:42-52

273. Yu L, Li Z, Liu Y, Cheng F, Sun S (2015) Enhanced photoelectrochemical performance of $\mathrm{CdSe} / \mathrm{CdS} / \mathrm{TiO}_{2}$ nanorod arrays solar cell with a PbS underlayer. J Mater Sci Mater Electron 26(4):2286-2295

274. Yu X, Liu R, Zhang G (2013) Polyoxometalate-CdS quantum dots co-sensitized $\mathrm{TiO}_{2}$ nanorods array: enhanced charge separation and light to electricity conversion efficiency. RSC Adv 3(22):8351-8355

275. Yu X-Y, Lei B-X, Kuang D-B, Su C-Y (2011) Highly efficient $\mathrm{CdTe} / \mathrm{CdS}$ quantum dot sensitized solar cells fabricated by a one-step linker assisted chemical bath deposition. Chem Sci 2:1396-1400

276. Yu XY, Liao JY, Qiu KQ, Kuang DB, Su CY (2011) Dynamic study of highly efficient $\mathrm{CdS} / \mathrm{CdSe}$ quantum dot-sensitized solar cells fabricated by electrodeposition. ACS Nano 5(12):9494-9500

277. Yum JH, Hardin BE, Moon SJ, Baranoff E, Nuesch F, McGehee MD, Gratzel M, Nazeeruddin MK (2009) Panchromatic response in solid-state dye-sensitized solar cells containing phosphorescent energy relay dyes. Angew Chem 48(49):9277-9280

278. Yum JH, Baranoff E, Hardin BE, Hoke ET, McGehee MD, Nüesch F, Grätzel M, Nazeeruddin MK (2010) Phosphorescent energy relay dye for improved light harvesting response in liquid dyesensitized solar cells. Energy Environ Sci 3(4):434-437

279. Yum JH, Hardin BE, Hoke ET, Baranoff E, Zakeeruddin SM, Nazeeruddin MK, Torres T, McGehee MD, Grätzel M (2011) Incorporating multiple energy relay dyes in liquid dye-sensitized solar cells. Chem Phys Chem 12(3):657-661

280. Yun HJ, Jung DY, Lee DK, Jen AKY, Kim JH (2015) Panchromatic quasi-solid-state squaraine dye sensitized solar cells enhanced by Forster resonance energy transfer of DCM-pyran. Dyes Pigments 113:675-681

281. Zani L, Dagar J, Lai S, Centi S, Ratto F, Pini R, Calamante M, Mordini A, Reginato G, Mazzoni M (2017) Studies on the efficiency enhancement of co-sensitized transparent DSSCs by employment of core-shell gold nanorods. Inorg Chem Acta 470:407-415

282. Zeng M, Peng X, Liao J, Wang G, Li Y, Li J, Qin Y, Wilson J, Song A, Lin S (2016) Enhanced photoelectrochemical performance of quantum dot-sensitized $\mathrm{TiO}_{2}$ nanotube arrays with $\mathrm{Al}_{2} \mathrm{O}_{3}$ overcoating by atomic layer deposition. Phys Chem Chem Phys 18:17404-17413

283. Zhang B, Zheng J, Li X, Fang Y, Wang L-W, Lin Y, Pan F (2016) Tuning band alignment by CdS layers using a SILAR method to enhance $\mathrm{TiO}_{2} / \mathrm{CdS} / \mathrm{CdSe}$ quantum-dot solar cell performance. Chem Commun 52:5706-5709

284. Zhang J, Han Z, Fu Z, Wen Y, Zhao F, Cao W (2016) Study of $\mathrm{N}-\mathrm{Ag}-\mathrm{Zn} / \mathrm{TiO}_{2}, \mathrm{~N}-\mathrm{Ag}-\mathrm{Zr} / \mathrm{TiO}{ }_{2}$ with N719 and P3OT co-sensitization effect on the performance of dye-sensitized solar cell. J Sol-Gel Sci Technol 78:207-217

285. Zhang M, Xu Y, Gong Z, Tao J, Sun Z, Lv J, Chen X, Jiang X, He $G$, Wang $P$, Meng F (2015) Enhanced charge collection and 
photocatalysis performance of $\mathrm{CdS}$ and $\mathrm{PbS}$ nanoclusters cosensitized $\mathrm{TiO}_{2}$ porous film. J Alloys Compd 649:190-195

286. Zhang W, Li W, Wu Y, Liu J, Song X, Tian H, Zhu W-H (2016) Novel squaraine cosensitization system for panchromatic light-harvesting with synergistic effect for highly efficient solar cells. ACS Sustain Chem Eng 4(6):3567-3574

287. Zhang $X$, Lin Y, Wu J, Jing J, Fang B (2017) Improved performance of $\mathrm{CdSe} / \mathrm{CdS} / \mathrm{PbS}$ co-sensitized solar cell with doublelayered $\mathrm{TiO}_{2}$ films as photoanode. Opt Commun 395:117-121

288. Zhang X, Lin Y, Wu J, Fang B, Zeng J (2018) Improved performance of $\mathrm{CdSe} / \mathrm{CdS}$ co-sensitized solar cells adopting efficient CuS counter electrode modified by PbS film using SILAR method. Opt Commun 412:186-190

289. Zhang Y, Zhu J, Yu X, Wei J, Hu L, Dai S (2012) The optical and electrochemical properties of $\mathrm{CdS} / \mathrm{CdSe}$ co-sensitized $\mathrm{TiO}_{2}$ solar cells prepared by successive ionic layer adsorption and reaction processes. Sol Energy 86(3):964-971

290. Zhao K, Pan Z, Mora-Sero I, Canovas E, Wang H, Song Y, Gong X, Wang J, Bonn M, Bisquert J, Zhong X (2015) Boosting power conversion efficiencies of quantum-dot-sensitized solar cells beyond $8 \%$ by recombination control. J Am Chem Soc 137(16):5602-5609
291. Zhao Y, Lu F, Zhang J, Dong Y, Zhang B, Feng Y (2017) Stepwise co-sensitization of two metal-based sensitizers: probing their competitive adsorption for improving the photovoltaic performance of dye-sensitized solar cells. RSC Adv 7:10494-10502

292. Zhou N, Chen G, Zhang X, Cheng L, Luo Y, Li D, Meng Q (2012) Highly efficient $\mathrm{PbS} / \mathrm{CdS}$ co-sensitized solar cells based on photoanodes with hierarchical pore distribution. Electrochem Commun 20:97-100

293. Zhou R, Zhang Q, Uchaker E, Lan J, Yin M, Cao G (2014) Mesoporous $\mathrm{TiO}_{2}$ beads for high efficiency CdS/CdSe quantum dot co-sensitized solar cells. J Mater Chem A 2(8):2517-2525

294. Zhu Y, Wang R, Zhang W, Ge H, Li L (2014) CdS and PbS nanoparticles co-sensitized $\mathrm{TiO}_{2}$ nanotube arrays and their enhanced photoelectrochemical property. Appl Surf Sci 315:149-153

295. Zong H, Wang J, Mu X, Xu X, Li J, Wang X, Long F, Wang J, Sun $M$ (2018) Physical mechanism of photoinduced intermolecular charge transfer enhanced by fluorescence resonance energy transfer. Phys Chem Chem Phys 20:13558-13565

296. Zuo P, Li C, Wu YS, Ai XC, Wang XS, Zhang BW, Zhang JP (2006) Mechanism of squarylium cyanine and $\mathrm{Ru}(\mathrm{dcbpy})_{2}(\mathrm{NCS})_{2} \mathrm{CO}-$ sensitization of colloidal $\mathrm{TiO}_{2}$. J Photochem Photobiol A Chem 183(1):138-145

\section{SN Applied Sciences}

